\title{
Metal-organic magnets with large coercivity and ordering temperatures up to $242^{\circ} \mathrm{C}$
}

Perlepe, Panagiota; Oyarzabal, Itziar; Mailman, Aaron; Yquel, Morgane; Platunov, Mikhail; Dovgaliuk, lurii; Rouzières, Mathieu; Négrier, Philippe; Mondieig, Denise; Suturina, Elizaveta A

Total number of authors:

19

Published in:

Science (New York, N.Y.)

Link to article, DOI:

10.1126/science.abb3861

Publication date:

2020

Document Version

Peer reviewed version

Link back to DTU Orbit

Citation (APA):

Perlepe, P., Oyarzabal, I., Mailman, A., Yquel, M., Platunov, M., Dovgaliuk, I., Rouzières, M., Négrier, P., Mondieig, D., Suturina, E. A., Dourges, M-A., Bonhommeau, S., Musgrave, R. A., Pedersen, K. S., Chernyshov, D., Wilhelm, F., Rogalev, A., Mathonière, C., \& Clérac, R. (2020). Metal-organic magnets with large coercivity and ordering temperatures up to $242^{\circ} \mathrm{C}$. Science (New York, N.Y.), 370(6516), 587-592. https://doi.org/10.1126/science.abb3861

\section{General rights}

Copyright and moral rights for the publications made accessible in the public portal are retained by the authors and/or other copyright owners and it is a condition of accessing publications that users recognise and abide by the legal requirements associated with these rights.

- Users may download and print one copy of any publication from the public portal for the purpose of private study or research.

- You may not further distribute the material or use it for any profit-making activity or commercial gain

- You may freely distribute the URL identifying the publication in the public portal 


\title{
This is a self-archived version of an original article. This version may differ from the original in pagination and typographic details.
}

\author{
Author(s): Perlepe, Panagiota; Oyarzabal, Itziar; Mailman, Aaron; Yquel, Morgane; Platunov, \\ Mikhail; Dovgaliuk, lurii; Rouzières, Mathieu; Négrier, Philippe; Mondieig, Denise; \\ Suturina, Elizaveta A.; Dourges, Marie-Anne; Bonhommeau, Sébastien; Musgrave, \\ Rebecca A.; Pedersen, Kasper S.; Chernyshov, Dmitry; Wilhelm, Fabrice; Rogalev, \\ Andrei; Mathonière, Corine; Clérac, Rodolphe
}

Title: Metal-organic magnets with large coercivity and ordering temperatures up to $242^{\circ} \mathrm{C}$

Year: 2020

Version: Accepted version (Final draft)

Copyright: @ 2020 the Authors

Rights: In Copyright

Rights url: http://rightsstatements.org/page/InC/1.0/?language=en

\section{Please cite the original version:}

Perlepe, Panagiota; Oyarzabal, Itziar; Mailman, Aaron; Yquel, Morgane; Platunov, Mikhail; Dovgaliuk, lurii; Rouzières, Mathieu; Négrier, Philippe; Mondieig, Denise; Suturina, Elizaveta A. et al. (2020). Metal-organic magnets with large coercivity and ordering temperatures up to $242^{\circ} \mathrm{C}$. Science, 370 (6516), 587-592. DOI: 10.1126/science.abb3861 


\section{Unlocking the potential of lightweight molecule-based magnets at room temperature}

Panagiota Perlepe ${ }^{1,2}$, Itziar Oyarzabal ${ }^{1,3^{*}}$, Aaron Mailman ${ }^{4}$, Morgane Yquel $^{1,2}$, Mikhail Platunov $^{5, \dagger}$, Iurii Dovgaliuk ${ }^{6 \dagger}$, Mathieu Rouzières ${ }^{1}$, Philippe Negrier ${ }^{7}$, Denise Mondieig $^{7}$, Elizaveta A. Suturina ${ }^{8}$, Marie-Anne Dourges ${ }^{9}$, Sébastien Bonhommeau ${ }^{9}$, Kasper S. Pedersen $^{1,10}$, Dmitry Chernyshov ${ }^{6}$, Fabrice Wilhelm ${ }^{5}$, Andrei Rogalev ${ }^{5}$, Corine Mathonière ${ }^{2}$ and Rodolphe Clérac ${ }^{*}$

${ }^{1}$ Univ. Bordeaux, CNRS, Centre de Recherche Paul Pascal, UMR 5031, F-33600, Pessac, France.

${ }^{2}$ CNRS, Univ. Bordeaux, Bordeaux INP, ICMCB, UMR 5026, F-33600 Pessac, France.

3 Chemistry Faculty, University of the Basque Country, UPV/EHU, 20018, Donostia-San Sebastián, Spain.

${ }^{4}$ Department of Chemistry, University of Jyväskylä, P.O. Box 35, Jyväskylä, Finland.

${ }^{5}$ ESRF-The European Synchrotron, CS 40220, F-38043 Grenoble Cedex 9, France.

${ }^{6}$ Swiss-Norwegian Beamlines at the European Synchrotron Radiation Facility, F-38000 Grenoble, France.

${ }^{7}$ Univ. Bordeaux, CNRS, Laboratoire Ondes et Matière d'Aquitaine, UMR 5798, F-33400 Talence, France.

${ }^{8}$ Department of Chemistry, University of Bath, BA2 7AY, UK.

${ }^{10}$ Department of Chemistry, Technical University of Denmark, DK-2800 Kgs. Lyngby, Denmark.

Present address:

† Institut des Matériaux Poreux de Paris, UMR 8004 CNRS, Ecole Normale Supérieure, Ecole Supérieure de Physique et de Chimie Industrielles de Paris, PSL Université, 75005 Paris, France. $\$$ Kirensky Institute of Physics, Federal Research Center KSC SB RAS, Akademgorodok 50, bld. 38, 660036 Krasnoyarsk, Russia.

*Corresponding author:

Email: itziar.oyarzabal@crpp.cnrs.fr (I.O); clerac@crpp-bordeaux.cnrs.fr (R.C.)

Abstract: 125/125 Words

Magnets derived from inorganic materials (e.g. oxides, rare earth and intermetallic compounds) are key components of modern technological applications. Despite extensive employment and success in a broad range of applications, these inorganic magnets suffer several drawbacks, such as energetically expensive fabrication methods, limited availability of constituent elements, high density, and poor scope for chemical tunability. A promising design strategy for the next generation magnets relies on the versatile coordination chemistry of abundant metal ions and lowcost, simple organic ligands. Following this approach, lightweight molecule-based magnets were synthesized by post-synthetic reduction of known two-dimensional coordination networks composed of chromium metal ions and pyrazine building-blocks. The resulting ferrimagnets feature critical temperatures up to $242^{\circ} \mathrm{C}$ (far exceeding the current record of $115^{\circ} \mathrm{C}$ ), and an unprecedented 7500-Oersted room-temperature coercivity.

\section{One Sentence Summary (37/40 characters): Lightweight molecule-based magnets}




\section{Main Text:}

Magnets that operate at room temperature are usually pure metals, metal oxides or intermetallic compounds, and find applications in numerous aspects of our daily lives. Magnets are, for example, key components for data processing and storage, are commonly employed in electrical motors that power the majority of household appliances, and are essential in renewable energy technologies (1). Despite their extensive use and tremendous success in technological applications, conventional magnets present several drawbacks, such as energetically expensive fabrication methods (e.g. SmCo and AlNiCo) and limited availability of key component elements (e.g. in lanthanide-based magnets, $\mathrm{NdFeB}$ and $\mathrm{SmCo}$ ). Additionally, their purely inorganic nature intrinsically limits their chemical tunability necessary in the design of magnets with optimized properties. Over the last three decades, various approaches have been developed to address these limitations and to access new magnets operating at room temperature. One particular strategy relies on the rational assembly of molecular building-blocks. These molecule-based materials exhibit behaviors similar to traditional magnets, but benefit from the synthetic flexibility of the molecular and coordination chemistries $(2,3,4)$. This synthetic strategy has already led to a vast number of systems with unique magnetic properties, several of which have no counterpart in inorganic materials. Among these molecule-based magnets are discrete high-spin molecules known as Single-Molecule Magnets (SMMs; 5,6), one-dimensional (1-D) magnets (Single-Chain Magnets; 7) and two- and three-dimensional (2-D and 3-D) networks exhibiting magnetically ordered phases (8). By using organic ligands to connect and assemble magnetic metal ions, these molecule-based materials feature low densities (c.a. $1 \mathrm{~g} \mathrm{~cm}^{-3}$ ) compared to pure inorganic materials (generally above $5 \mathrm{~g} \mathrm{~cm}^{-3}$ ). As such, molecule-based materials are promising candidates as lightweight permanent magnets, the applications of which are complementary to those of solid-state magnets often used for their high maximum energy product and thus high magnetic density (9). New lightweight materials will be of great relevance to emergent magnetoelectronic, magnetic sensing and recording technologies. Nonetheless, most of the known molecule-based magnets suffer from low operating temperatures (below the boiling point of $\mathrm{N}_{2}, 77 \mathrm{~K}$ ).

A promising strategy toward high-temperature molecule-based magnets relies on the linking of paramagnetic metal ions by organic radicals to yield 2-D or 3-D coordination networks (8). The direct exchange coupling between the metal and radical spins in the resulting networks can lead to particularly strong magnetic interactions, as controlled by the chemical identity of the ligand and metal ion, and the overlap of their magnetic orbitals $(8,10,11)$. This methodology is well exemplified by the pioneering work of J. S. Miller on a family of magnets incorporating paramagnetic metal ions and the organic tetracyanoethylene (TCNE) ligand (12). In these systems, strong magnetic couplings between the spins localized in the metal $d$ orbitals and those residing on the $[\mathrm{TCNE}]^{-}$radicals result in magnetically ordered phases with critical temperatures $\left(T_{\mathrm{C}}\right)$ as high as $400 \mathrm{~K}\left(\mathrm{~V}[\mathrm{TCNE}]_{x}, x \sim 2\right)$. This remarkably high $T_{\mathrm{C}}$ constitutes the current record value reported for a molecule-based magnet (13). At room temperature, hysteresis effects on the field $(H)$ dependence of the magnetization $(M)$ have also been reported for TCNE-based compounds and derivatives, as well as in several Prussian blue analogues $(2,3,12,14)$ and covalently linked organic radical frameworks $(15,16)$. However, the observed coercivity was systematically found to be small, and of the order of hundred Oersteds in the best case.

These molecule-based materials serve to demonstrate that although challenging, it is indeed possible to synthesize lightweight high- $T_{\mathrm{C}}$ magnets using molecule-based chemistry (17). More recently, a new synthetic strategy was developed, subjecting known coordination networks to post- 
synthetic oxidation or reduction (acting on the ligands or metal ions), to obtain magnetically ordered materials $(18,19,20,21)$. A representative example of this approach involves the ironquinoid metal-organic framework, $\left(\left(\mathrm{CH}_{3}\right)_{2} \mathrm{NH}_{2}\right)_{2}\left[\mathrm{Fe}^{\mathrm{III}} 2\left(\mathrm{~L}^{3-\cdot}\right)_{2} \mathrm{~L}^{2-}\right] \cdot 2 \mathrm{H}_{2} \mathrm{O} \cdot 6 \mathrm{DMF},\left(\mathrm{H}_{2} \mathrm{~L}=2,5-\right.$ dichloro-3,6-dihydroxy-1,4-benzoquinone, $\mathrm{DMF}=\mathrm{N}, \mathrm{N}$-dimethylformamide, 20). The controlled reduction of the third quinoid ligand in this material by cobaltocene $\left(\left(\mathrm{C}_{5} \mathrm{H}_{5}\right)_{2} \mathrm{Co}\right)$ yields $\left(\left(\mathrm{C}_{5} \mathrm{H}_{5}\right)_{2} \mathrm{Co}\right)_{1.43}\left(\left(\mathrm{CH}_{3}\right)_{2} \mathrm{NH}_{2}\right)_{1.57}\left[\mathrm{Fe}_{2} \mathrm{Fe}^{\mathrm{III}} 2\left(\mathrm{~L}^{3-\bullet}\right)_{3}\right] \cdot 4.9 \mathrm{DMF}$, with a concomitant increase of $T_{\mathrm{C}}$ from 80 to $105 \mathrm{~K}$. In the present work, we report on the post-synthetic chemical reduction of two 2-D coordination networks, $\mathrm{CrCl}_{2}$ (pyz) $)_{2}$ and $\mathrm{Cr}\left(\mathrm{OSO}_{2} \mathrm{CH}_{3}\right)_{2}$ (pyz) $)_{2}$ (pyz = pyrazine, 22,23), leading to lightweight ferrimagnets with the highest $T_{\mathrm{C}}$ and room-temperature coercivity reported to date for any molecule-based magnet. While structurally similar, these two materials $\left(\mathrm{CrX}_{2}(\mathrm{pyz})_{2} ; \mathrm{X}^{-}=\right.$ $\left.\mathrm{CH}_{3} \mathrm{SO}_{3}{ }^{-}, \mathrm{Cl}^{-}\right)$exhibit contrasting physical properties. In $\mathrm{Cr}\left(\mathrm{OSO}_{2} \mathrm{CH}_{3}\right)_{2}(\text { pyz) })_{2}$, the octahedral $\mathrm{Cr}^{\mathrm{II}}$ metal ions are bridged by neutral, closed-shell pyrazine ligands $\left(\mathrm{pyz}^{\circ}\right)$, which transmit only weak magnetic interactions between $S=2 \mathrm{Cr}^{\mathrm{II}}$ spins. As a result, this material is an antiferromagnet below $10 \mathrm{~K}$ and an insulator (23). In contrast, $\mathrm{CrCl}_{2}$ (pyz) $)_{2}$ features octahedral $\mathrm{Cr}^{\mathrm{III}}$ metal ions and a mixed valence pair of pyrazine ligands (i.e. $\left.\left[(\mathrm{pyz})_{2}\right]^{--}\right)$. This electronic configuration generates strong magnetic interactions between the $S=3 / 2 \mathrm{Cr}^{\mathrm{III}}$ and delocalized pyrazine spins, leading to a ferrimagnetic ordering below $55 \mathrm{~K}$ and a significant room-temperature electrical conductivity (22). In this report, our strategy involves the post-synthetic reduction of these 2-D coordination networks in order to enhance magnetic interactions and thus to increase the critical temperature of any resulting ferrimagnetic order.

The chemical reduction of the methanesulfonate-paired 2-D material was carried out via the addition of a slight excess of two molar equivalents of lithium 1,2-dihydroacenaphthylenide $\left(\mathrm{Li}\left[\mathrm{C}_{12} \mathrm{H}_{10^{\circ}}\right]\right.$, prepared in situ as a tetrahydrofuran (THF) solution; $E_{1 / 2}=-3.23 \mathrm{~V} v s$. $\left.\left[\left(\mathrm{C}_{5} \mathrm{H}_{5}\right)_{2} \mathrm{Fe}\right]^{+/ 0} ; 19\right)$ into a THF suspension of $\mathrm{Cr}^{\mathrm{II}}\left(\mathrm{OSO}_{2} \mathrm{CH}_{3}\right)_{2}\left(\mathrm{pyz}^{\circ}\right)_{2}$ (Fig. 1A, see supplementary materials for the detailed synthetic procedure; 24). The dark suspension was stirred for 4 days at room temperature and the resulting dark grey microcrystalline powder (compound 1) was collected. The notable color change from light brown of $\mathrm{Cr}\left(\mathrm{OSO}_{2} \mathrm{CH}_{3}\right)_{2}(\mathrm{pyz})_{2}$ to dark grey of $\mathbf{1}$, suggests the occurrence of the expected chemical reduction. The powder X-ray diffraction pattern (PXRD) of the air sensitive solid (1) revealed a highly crystalline phase, with Bragg diffraction peaks corresponding exclusively to $\mathrm{Li}\left[\mathrm{SO}_{3} \mathrm{CH}_{3}\right](25$, Fig. S1, 24). The presence of THF-insoluble $\mathrm{Li}\left[\mathrm{SO}_{3} \mathrm{CH}_{3}\right]$ (a colorless solid) was indeed a promising result, as it implied that the methanesulfonate anions were extracted (either fully or partially) from the 2D precursor upon reduction. Thus, we hypothesized that the targeted reduced phase (featuring two reduced pyrazines; pyz $^{-}$) is either poorly crystalline, nanocrystalline or amorphous and was contaminated with $\mathrm{Li}\left[\mathrm{SO}_{3} \mathrm{CH}_{3}\right]$. The field dependencies of the magnetization were collected for powder 1 at various temperatures (Fig. S2-S4; 24$)$, revealing a broad $M$ vs $H$ hysteresis loops $\left(H_{\text {coer }}=3400\right.$ Oe at $300 \mathrm{~K}$ ) at least up to $400 \mathrm{~K}$ (the temperature limit of the MPMS magnetometer). This remarkable magnetic behavior is in sharp contrast to that reported for any known chromium-based materials (e.g. metal, nanoparticles, oxides...; Fig. 1B, 26,27,28,29,30,31,32). X-ray absorption spectroscopy (XAS) measurements at $\mathrm{Cr} K$-edge were performed for 1, its $\mathrm{Cr}\left(\mathrm{OSO}_{2} \mathrm{CH}_{3}\right)_{2}(\text { pyz) })_{2}$ precursor (in which $\mathrm{Cr}^{\mathrm{II}}$ resides in an octahedral coordination sphere) and a square-planar $\mathrm{Cr}^{\mathrm{II}}$ reference complex $\left[\mathrm{Cr}\left(\mathrm{N}(\mathrm{TMS})_{2}\right)_{2}(\mathrm{py})_{2}\right]$ (noted $\mathbf{C r}(\mathbf{I I})$; TMS $=\mathrm{Si}\left(\mathrm{CH}_{3}\right)_{3}$, py = pyridine; 33). Whereas the X-ray absorption near edge structure (XANES) of $\mathbf{1}$ is markedly different to that of its precursor, as well as Cr oxides and $\mathrm{Cr}$ metal (34), its low energy part and the energy position 45 of the edge are strikingly similar to those of the square-planar $\mathbf{C r}$ (II) reference (Fig. 1C). The near edge structures for both $\mathbf{1}$ and $\mathbf{C r}(\mathbf{I I})$, which are the fingerprint of the Cr oxidation state in a given 
ligand field, show two shoulders at the same energies ( 5991 and $5994 \mathrm{eV})$. These XAS results unequivocally support that the $\mathrm{Cr}$ electronic structure and coordination geometry in $\mathbf{1}$ are essentially the same as in $\mathbf{C r}(\mathbf{I I})$; i.e. a high-spin $S=2 \mathrm{Cr}^{\mathrm{II}}$ metal ion in a square-planar $\left\{\mathrm{Cr}^{\mathrm{II}} \mathrm{N}_{4}\right\}$ environment (33). The structure of $\mathbf{1}$ is thus compatible with a 2-D square coordination network, ' $\mathrm{Cr}^{\mathrm{II}}\left(\mathrm{pyz}^{\circ-}\right)_{2}$ ', reminiscent of the precursor $\mathrm{Cr}^{\mathrm{II}}\left(\mathrm{pyz}^{\circ}\right)_{2}$ layer $(23)$.

A

$$
\begin{aligned}
& \mathrm{Cr}\left(\mathrm{OSO}_{2} \mathrm{CH}_{3}\right)_{2}(\text { pyz })_{2}+2 \mathrm{Li}^{+}\left[\mathrm{C}_{12} \mathrm{H}_{10} 0^{-}\right] \frac{\mathrm{THF}}{-2\left[\mathrm{C}_{12} \mathrm{H}_{10}\right]} 1 \supset\left(\mathrm{Li}_{x}\left(\mathrm{SO}_{3} \mathrm{CH}_{3}\right)_{x}\right)+(2-x) \mathrm{Li}\left[\mathrm{SO}_{3} \mathrm{CH}_{3}\right] \\
& \mathrm{CrCl}_{2}(\text { pyz })_{2}+2 \mathrm{Li}^{+}\left[\mathrm{C}_{12} \mathrm{H}_{10}{ }^{-}\right] \frac{\mathrm{THF}}{-1.3 \mathrm{LiCl}} \mathbf{2} \cdot(\mathrm{THF}) \stackrel{>}{\stackrel{400 \mathrm{~K}}{\longrightarrow}} \mathbf{2} \cdot \mathbf{0 . 2 5} \text { (THF) } \\
& -2\left[\mathrm{C}_{12} \mathrm{H}_{10}\right]
\end{aligned}
$$

\begin{tabular}{|c|c|c|}
\hline Sample (size) & Magnetic behaviour & Ref. \\
\hline Cr bulk & $\mathrm{AF}, T_{\mathrm{N}}=311 \mathrm{~K}$ & 26 \\
\hline Cr powder/strained & $\mathrm{AF}, T_{\mathrm{N}}=450-475 \mathrm{~K}$ & 27,28 \\
\hline $\begin{array}{l}\text { Cr nanoparticles } \\
(2 \mathrm{~nm})\end{array}$ & Curie paramagnetism & 29 \\
\hline $\begin{array}{l}\text { Cr nanoparticles } \\
(13-73 \mathrm{~nm})\end{array}$ & $\begin{array}{l}\text { Their magnetic properties are } \\
\text { extremely sensitive to surface } \\
\text { oxide layers. Paramagnetism } \\
\text { or } A F\left(T_{N} \leq 310 \mathrm{~K}\right) \text { or } F \text { order } \\
\text { can be observed. }\end{array}$ & 30 \\
\hline $\mathrm{Cr}_{2}{ }^{\prime \prime \prime} \mathrm{O}_{3}$ bulk & $\mathrm{AF}, T_{\mathrm{N}}=308 \mathrm{~K}$ & 31 \\
\hline $\mathrm{Cr}^{\mathrm{IV}} \mathrm{O}_{2}$ bulk & $\mathrm{F}, T_{\mathrm{C}}=392(6) \mathrm{K}$ & 32 \\
\hline
\end{tabular}

B

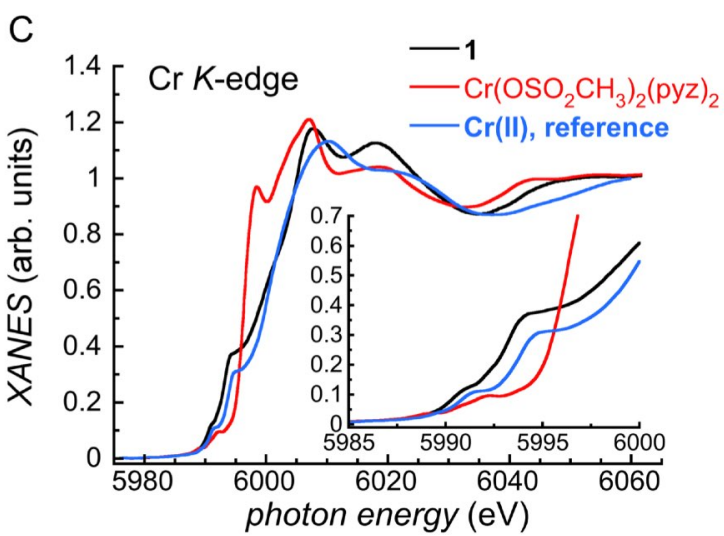

Fig. 1. Chemical reduction of $\mathrm{Cr}\left(\mathrm{OSO}_{2} \mathrm{CH}_{3}\right)_{2}(\mathrm{pyz})_{2}$ and $\mathrm{CrCl}_{2}(\mathrm{pyz})_{2}$. (A) Reaction schemes (the solvents and soluble species are highlighted in blue, while solid materials are noted in black). (B) Summary of the magnetic properties of selected chromium powder, nanoparticles and oxides. $\mathrm{AF}=$ antiferromagnet; $\mathrm{F}=$ ferromagnet. (C) Normalized XANES spectra at the $\mathrm{Cr} K$-edge region of 1 (black trace), $\mathrm{Cr}\left(\mathrm{OSO}_{2} \mathrm{CH}_{3}\right)_{2}(\mathrm{pyz})_{2}$ (red trace) and $\mathbf{C r}(\mathbf{I I})$ reference (blue trace) at $295 \mathrm{~K}$. Inset: zoom in the pre-edge region.

At this stage, we hypothesized that the post-synthetic chemical reduction of $\mathrm{Cr}^{\mathrm{II}}\left(\mathrm{OSO}_{2} \mathrm{CH}_{3}\right)_{2}\left(\mathrm{pyz}^{\circ}\right)_{2}$ was leading to a mixture of crystalline $\mathrm{Li}\left[\mathrm{SO}_{3} \mathrm{CH}_{3}\right]$ and an amorphous ' $\mathrm{Cr}{ }^{\mathrm{II}}\left(\mathrm{pyz}^{-}\right)_{2}$ ' phase, which displayed remarkable hard magnet properties $\left(H_{\mathrm{coer}}=3400\right.$ Oe at 300 $\mathrm{K})$ with a critical temperature above $400 \mathrm{~K}$. Therefore, focus turned to the $\mathrm{CrCl}_{2}$ (pyz) $)_{2}$ system and its post-synthetic reduction, which should lead to the same magnetic material upon reduction of its pyrazine scaffold $\left(\left[(\mathrm{pyz})_{2}\right]^{\circ-} \rightarrow\left(\mathrm{pyz}^{--}\right)_{2}\right)$ and the $\mathrm{Cr}^{\mathrm{III}}$ metal ion $\left(\mathrm{Cr}^{\mathrm{III}} \rightarrow \mathrm{Cr}^{\mathrm{II}}\right)$. LiCl, which is an anticipated product of this reaction (Fig. 1A), is far easier to remove from the Cr-based product than $\mathrm{Li}\left[\mathrm{SO}_{3} \mathrm{CH}_{3}\right]$ due to its higher solubility in organic media (particularly in THF). Using identical experimental conditions to those for the synthesis of $\mathbf{1}$, the $\mathrm{CrCl}_{2}(\mathrm{pyz})_{2}$ precursor was exposed to 2.1 equivalents of $\mathrm{Li}\left[\mathrm{C}_{12} \mathrm{H}_{10}{ }^{\circ}\right]$ (Fig. 1A, 24). Synchrotron PXRD experiments on the resulting dark grey solid ( $90 \%$ isolated yield), revealed several prominent diffraction peaks and notably, the absence of LiCl salt (Fig. S5, 24). The diffractogram was refined in the orthorhombic Pmmm space group with the following cell parameters: $a=6.9239(9), b=6.9524(2)$ and $c=8.478(2) \AA(V=$ 408.1(1) $\AA^{3}$ ). It is worth noting that the $a$ and $b$ lattice parameters obtained for this material (noted $\mathbf{2}$ (THF) in the following) are close to those found in the $\mathrm{CrCl}_{2}(\mathrm{pyz})_{2}$ precursor (Immm space 
group: $a=6.90351(4), b=6.97713(4)$ and $\left.c=10.82548(6) \AA ; V=521.43 \AA^{3} ; \rho=1.803 \mathrm{~g} / \mathrm{cm}^{3}\right)$. This suggests the presence of a 2-D $\mathrm{Cr}$ (pyz) 2 -type network in 2-(THF) (comparable to that in the precursor structure).
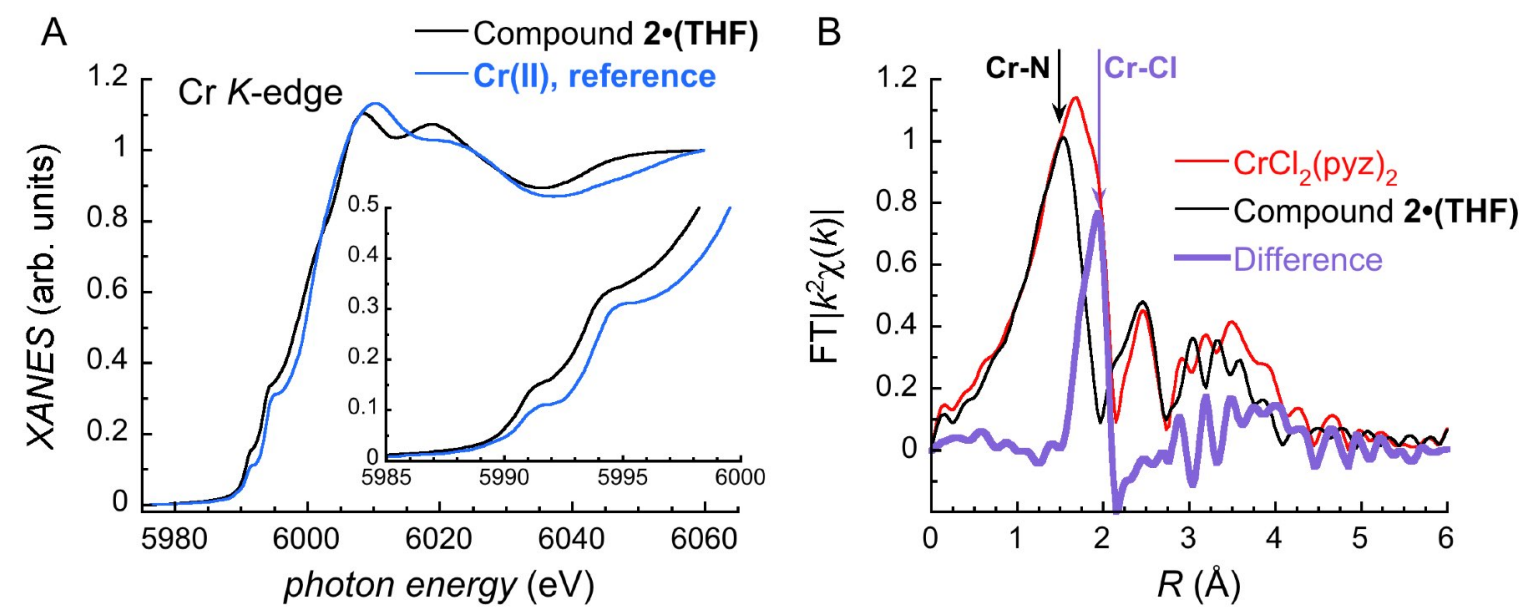

Fig. 2. XANES and EXAFS spectra at the Cr $K$-edge at 295 K. (A) Normalized XANES spectra of $\mathbf{2} \cdot(\mathbf{T H F})$ (black trace) and $\mathbf{C r}$ (II) reference (blue trace). Inset: zoom in the pre-edge region. (B) Fourier-transformed (FT) EXAFS spectra for 2.(THF) (black trace) and $\mathrm{CrCl}_{2}$ (pyz) 2 (red trace; see Figs. S10-S11 for additional EXAFS data, 24). The difference of the two data sets is shown in purple.

The Cr $K$-edge XANES spectra of 2 (THF) is extremely similar to that of both the model squareplanar complex $\mathbf{C r}$ (II) (Fig. 2A) and $\mathbf{1}$ (Fig. 1C), while clearly different to that of the precursor $\mathrm{Cr}^{\mathrm{III}} \mathrm{Cl}_{2}$ (pyz) 2 (Fig. S6, 24). Therefore, we can unambiguously conclude that the reduction of $\mathrm{CrCl}_{2}$ (pyz) $)_{2}$ results in reduction of octahedral high-spin $\mathrm{Cr}^{\mathrm{III}}$ metal ions into square-planar highspin $\mathrm{Cr}^{\mathrm{II}}$ sites, implying the loss of both axial chloride ligands in $\mathbf{2} \cdot(\mathbf{T H F})$. Raman spectroscopy further supports this conclusion, as evidenced by the absence of the characteristic $\mathrm{Cr}-\mathrm{Cl}$ symmetric stretching band (ca. $256 \mathrm{~cm}^{-1}$ ), while the position and narrowness of Raman bands in the pyrazine fingerprint region of the spectrum $\left(600-1700 \mathrm{~cm}^{-1}\right)$ suggest the presence of only reduced pyz ${ }^{\circ}$ ligands (Fig. S7-S8, Tables S2-S4, 24). In order to understand the reduction mechanism and the concomitant chloride decoordination, quantum chemical geometry optimizations were performed on $\left[\mathrm{CrCl}_{x}(\mathrm{pyz})_{4}\right]^{2-x-q}$ molecular fragments (where $x$ is the number of chloride ligand, $x=2,1,0 ; q$ is the number of added electrons, $q=0,1,2,3$ or 4; Fig. S9, Table S5, 24). Upon addition of 4 electrons to the initial $\left[\mathrm{CrCl}_{2} \text { (pyz) }\right]^{0}$ fragment, both chlorides dissociate and the $\mathrm{Cr}^{\mathrm{III}}$ metal ion become $\mathrm{Cr}^{\mathrm{II}}$ while each pyrazine is reduced. The $\left[\mathrm{Cr}(\mathrm{pyz})_{4}\right]^{2-}$ fragment without chlorines and with 4 added electrons was found to adopt a perfect square-planar geometry around the $\mathrm{Cr}^{\mathrm{II}}$ center (24), which makes possible the stabilization of a $2 \mathrm{D} \mathrm{Cr}(\text { pyz })_{2}$-type coordination network where all pyrazines are reduced. Comparison of the extended X-ray absorption fine structure (EXAFS) at the $\mathrm{Cr} K$-edge of $\mathbf{2} \cdot(\mathbf{T H F})$ and its precursor (Figs. S10-S11, 24) provides further experimental evidence for chloride decoordination. As shown in Fig. 2B, the Fourier-transformed EXAFS spectra of $\mathrm{CrCl}_{2}$ (pyz) $)_{2}$ and $\mathbf{2}$ (THF) are similar except at $R \sim 1.9 \AA$ where a significant difference is evident. This corresponds to a major modification in the local environment of the $\mathrm{Cr}^{\mathrm{II}}$ site. In 
the precursor compound, $\mathrm{CrCl}_{2}$ (pyz) 2 , the broad feature at $R=1.67 \AA$ and the shoulder at $1.91 \AA$ can be attributed to the $\mathrm{Cr}-\mathrm{N}(2.003-2.059 \AA)$ and $\mathrm{Cr}-\mathrm{Cl}(2.337 \AA)$ bonds, respectively. However, while the $\mathrm{Cr}-\mathrm{N}$ bond in $\mathbf{2} \cdot(\mathbf{T H F})$ is found at $R=1.53 \AA$, the signature of the $\mathrm{Cr}-\mathrm{Cl}$ bond around $R \sim 1.9 \AA$ is significantly attenuated (see difference in spectra, Fig. 2B), corroborating the loss of axial $\mathrm{Cl}^{-}$ions and the square planar geometry at the $\mathrm{Cr}$ center.

Combustion elemental analysis (EA) and inductively coupled plasma-optical emission spectroscopy (ICP-OES) measurements support the above assumptions and reveal the presence of $0.7(1) \mathrm{Li}$ ion and 0.99(6) THF molecule per $\mathrm{Cr}(\mathrm{pyz})_{2}$ moiety, each assumed to reside between the $\mathrm{Cr}^{\mathrm{II}}\left(\mathrm{pyz}^{-}\right)_{2}$ layers in $\mathbf{2} \cdot($ THF) (Table S1, 24). In addition, XANES measurements at the $\mathrm{Cl} K$-edge for $\mathrm{CrCl}_{2}$ (pyz) $)_{2}$ and $\mathbf{2}$ (THF) provide evidence for remaining chlorine atoms (ca. 0.7 per $\mathrm{Cr}$ ) in the reduced material (Fig. S12, 24). The pre-edge feature, which corresponds in $\mathrm{CrCl}_{2}$ (pyz) 2 or other $\mathrm{Cr} / \mathrm{Cl}$ complexes (22) to a transition from the $\mathrm{Cl} 1 s$ orbital to molecular orbitals formed by hybridized $\mathrm{Cl} 3 p$ and $\mathrm{Cr} 3 d$ states, is much lower in intensity in the spectrum of $\mathbf{2} \cdot(\mathbf{T H F})$. This feature reflects a considerable decrease of the chromium-chloride interaction in $\mathbf{2} \cdot(\mathbf{T H F})$ and an important elongation of the $\mathrm{Cr} \cdots \mathrm{Cl}$ distance (i.e. a decoordination from the $\mathrm{Cr}$ metal ion; 35 ), which corroborates theoretical XANES calculations (Fig. S13, 24), experimental EXAFS data (Figs. 2B, S10-S11, 24) and our structural model discussed below (vide infra). However, the presence of a detectable pre-edge signal indicates that chlorides are still in enough proximity to the $\mathrm{Cr}^{\mathrm{II}}$ ions in order to interact electronically (it is worth noting that LiCl XANES spectra in both 20 solution and solid state do not display any pre-edge features; Fig. S14, 24). Combining the above information, 2-(THF) is a material possessing neutral $\mathrm{Cr}^{\mathrm{II}}\left(\mathrm{pyz}^{--}\right)_{2}$ layers with square planar $\mathrm{Cr}^{\mathrm{II}}$ metal ions and two singly reduced pyrazines separated by one THF molecule and a $0.7(1)$ equivalent amount of $\mathrm{Li}^{+}$and $\mathrm{Cl}^{-}$ions. Therefore, the chemical formula of $\mathbf{2} \cdot(\mathbf{T H F})$ can be summarized as $\mathrm{Li}_{0.7}\left[\mathrm{Cr}(\mathrm{pyz})_{2}\right] \mathrm{Cl}_{0.7} \cdot(\mathrm{THF})$ (with a calculated density of $1.278 \mathrm{~g} / \mathrm{cm}^{3}$ ).

Variable-temperature PXRD measurements between 298 and $500 \mathrm{~K}$ were performed on 2·(THF) and revealed a phase transformation upon heating above $380 \mathrm{~K}$ (Fig. S15, 24). This new phase is stable up to $500 \mathrm{~K}$ and remains the sole phase upon cooling down to room temperature. As demonstrated by thermogravimetric analysis - mass spectrometry measurements (TGA-MS, Figs. S16-S21, 24), this irreversible structural change is due to a loss of the interlayer THF molecules. Fourier-transform infrared spectroscopy (FT-IR, Figs. S22-S25, 24) and EA measurements on samples after prolonged heating ( 18 hours at $400 \mathrm{~K}$ or 10 hours at $500 \mathrm{~K}$ ) show that it is not enough to remove all the interlayer THF. Indeed, EA confirmed the residual presence of about $0.25 \mathrm{THF}$ per formula unit, in good agreement with TGA-MS measurements (Fig. S18, Table S1, 24). XANES measurements were also performed on this partially desolvated material, $\mathbf{2} \cdot \mathbf{0 . 2 5}$ (THF), and the $\mathrm{Cr} K$-edge spectrum showed no significant change in the $\mathrm{Cr}^{\mathrm{II}}$ coordination environment upon THF loss (Fig. S26, 24). However, the $\mathrm{Cl} K$-edge spectrum showed an attenuation in the preedge region vs. 2.(THF) (Fig. S27, 24), indicating less mixing between $\mathrm{Cl} 3 p$ and $\mathrm{Cr} 3 d$ orbitals; i.e. greater localization of $\mathrm{Cl} p$ states. The chloride anions are thus slightly more distant from the $\mathrm{Cr}$ sites after the partial loss of the interlayer THF molecules.

40 The analysis of the PXRD pattern after the complete phase transformation from $\mathbf{2} \cdot(\mathbf{T H F})$ to $\mathbf{2 \cdot 0 . 2 5}$ (THF), reveals a diffractogram for $\mathbf{2 \cdot 0 . 2 5}$ (THF) that is less affected by the anisotropic broadening of the diffraction peaks systematically associated with planes possessing a non-zero $l$ Miller index (Figs. 3A, S15 and S28, 24). This observation implies less crystallographic order along the $c$ direction (and thus in the spacing between the sheets) than within the $a b$ plane of the 2-D network as is expected for layered materials $(36,37)$. The diffractogram of $\mathbf{2 \cdot 0 . 2 5}$ (THF) at 
$290 \mathrm{~K}$ was fully indexed in the tetragonal $P 4 / \mathrm{mmm}$ space group with $a=b=6.9893(1)$ and $c=$ $7.195(3) \AA\left(V=351.5(1) \AA^{3} ; \rho=1.228 \mathrm{~g} / \mathrm{cm}^{3}\right.$; Fig. 3A, Table S6, 24) showing that upon removing the THF molecules, the inter-layer distance diminishes significantly, as evidenced by the decrease of the $c$ parameter from $\sim 8.5$ to $\sim 7.2 \AA$ (for comparison the inter-layer distance in the $\mathrm{CrCl}_{2}(\mathrm{pyz})_{2}$ precursor is $5.41 \AA$ ).
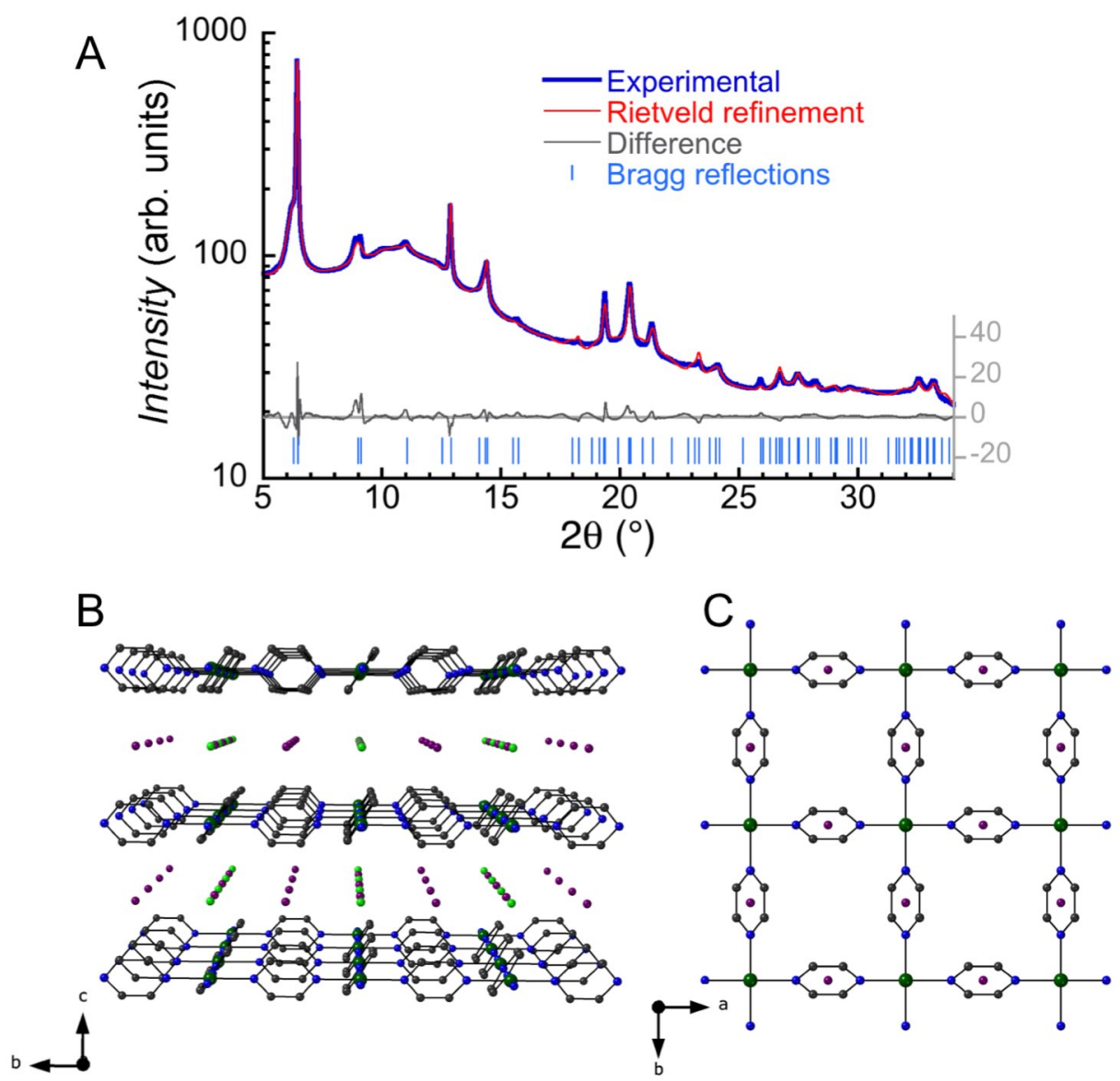

Fig. 3. Structural model of $\mathrm{Li}_{0.7}\left[\mathrm{Cr}\left(\mathrm{pyz}_{2}\right] \mathrm{Cl}_{0.7} \cdot \mathbf{0 . 2 5}\right.$ (THF) $(2 \cdot 0.25(\mathrm{THF}))$. (A) The best Rietveld refinement (red trace; change $R_{\mathrm{I}}=4.23 \%$ ) of the synchrotron PXRD pattern of 2.0.25(THF) at $290 \mathrm{~K}$ (after cooling from $500 \mathrm{~K}$ in a sealed capillary; blue trace) is shown together with the experimental/model difference (grey trace) and calculated diffraction positions (blue bars). (B) Perspective view (along the $a$ direction) of $\mathbf{2 \cdot 0 . 2 5}$ (THF) showing the alternation of $\left\{\mathrm{Li}_{0.7} \mathrm{Cl}_{0.7}\right\}$ and neutral $\mathrm{Cr}^{\mathrm{II}}\left(\mathrm{pyz}^{*-}\right)_{2}$ layers stacking along the $c$ direction. (C) Eclipsed layered structure viewed along the $c$ direction. $\mathrm{Cr}$ : dark green, N: blue, $\mathrm{C}$ : black. The disordered positions of the $\mathrm{Cl}$ (light green) and $\mathrm{Li}$ (purple) are all shown while they are occupied at a fixed percentage of $70 \%$. Hydrogen atoms have been omitted for clarity.

Considering all the above information, an appropriate structural model was used to refine the experimental PXRD pattern obtained for 2·0.25(THF) (Fig. 3, Table S6, 24). Unambiguously, the $\mathrm{Cr}$ sites in $\mathbf{2 \cdot 0 . 2 5}$ (THF) are bridged by pyrazine ligands forming a 2-D square $\mathrm{Cr}(\mathrm{pyz})_{2}$ network in the crystallographic $a b$ plane. In contrast to $\mathrm{CrCl}_{2}(\mathrm{pyz})_{2}$ and $\mathrm{Cr}\left(\mathrm{OSO}_{2} \mathrm{CH}_{3}\right)_{2}(\mathrm{pyz})_{2}(22,23)$, these 
$\mathrm{Cr}(\mathrm{pyz})_{2}$ layers are eclipsed along the $c$ direction (Fig. 3C). The square-planar coordination sphere of $\mathrm{Cr}$ is occupied by four nitrogen atoms from four pyz ligands, with a $\mathrm{Cr}-\mathrm{N}$ distance of $2.044 \AA$. As evidence by other techniques on $2 \cdot$ THF and $\mathbf{2} \cdot \mathbf{0 . 2 5}$ (THF) (vide supra), the $\mathrm{Cl}^{-}$anions are not coordinated to the $\mathrm{Cr}$ metal ions, but are located in between $\mathrm{Cr}$ sites of two adjacent layers with a $\mathrm{Cr} \cdots \mathrm{Cl}$ distance of $3.598 \AA$. Within this structural model, it was not possible to localize THF molecules, but the Li cations are most likely positioned over two disordered positions in between pyrazines for electrostatic reasons and slightly better refinement of the PXRD data.

The magnetic properties of $\mathbf{2} \cdot$ (THF) were studied and compared with those collected for $\mathbf{1}$ (Figs. S2-S4; 24). Zero-field cooled (ZFC)/field-cooled (FC) magnetization data were collected under a $d c$ field of 50 Oe for $\mathbf{2} \cdot$ (THF) (and thus for $\mathbf{2 \cdot 0 . 2 5}$ (THF) after the loss of THF above $400 \mathrm{~K}$ ) on a Microsense Vibrating Sample Magnetometer (VSM) capable of achieving temperatures up to 600 $\mathrm{K}$. The magnetization bifurcation point of the $\mathrm{ZFC} / \mathrm{FC}$ data, which corresponds to the temperature at which the coercive field vanishes, is found at $\sim 510 \mathrm{~K}$ (Fig. 4A). This temperature agrees well with the $M$ vs $H$ curves which show a crossover between $S$-shape and linear (typical of a paramagnetic state) variations between 510 and $520 \mathrm{~K}$ (Fig. 4B-C). As also confirmed by the vanishing of the remnant magnetization (Fig. 4D), the critical temperature is thus $\sim 510 \mathrm{~K}$, exceeding the current record ordering temperature for any molecule-based magnet by $110 \mathrm{~K}\left(T_{\mathrm{C}}=\right.$ $400 \mathrm{~K}$ for $\left.\mathrm{V}[\mathrm{TCNE}]_{x}, 13\right)$. It is worth emphasizing that the linear dependence of the magnetization at higher temperatures after the disappearance of the $M$ vs $H$ hysteresis loops rules out the presence of any superparamagnetic chromium and/or chromium oxide nanoparticles. Upon cooling from $520 \mathrm{~K}$ to room temperature, the $M v s H$ hystereses are recovered as expected for a paramagneticferri- or ferromagnetic phase transition. Nevertheless, the absolute values of the magnetization are slightly lower than in the heating process (Figs. S29-S30, 24), which suggests that the critical temperature of $\mathbf{2 \cdot 0 . 2 5}$ (THF) is in close proximity to its decomposition temperature under the experimental conditions of the magnetic measurements (i.e. in a sealed quartz tube of $\mathrm{Ar}$ or $\mathrm{N}_{2}$ ). Similar to the amorphous powder 1 (Fig. S2-S4, 24), 2-(THF) is a crystalline hard magnet with a remarkably large coercive field of $5300 \mathrm{Oe}$ at room temperature $(13500 \mathrm{Oe}$ at $1.85 \mathrm{~K}$; Figs. 4B-C and S31,24), a value which sets a new record for room-temperature molecule-based magnets, and competes well with commonly used inorganic magnets (Table S7, 24). It is interesting to note that the coercive field reproducibly displays an anomalous increase at ca. $350 \mathrm{~K}$ on the initial heating of 2.(THF) (Fig. S31, 24) and $\mathbf{1}$ (Fig. S4, 24) samples, while no such feature is observed in the remnant magnetization, shown in Figs. 4D, S30 and S3 (24). This anomaly of the coercive field, which is absent in measurements on pre-annealed 2-0.25(THF) (Figs. S31-S36, 24), is thus likely linked to the partial loss of interlayer THF around 300-400 K (vide supra) and the associated irreversible structural rearrangement (Fig. S15, 24). Indeed, the magnetic properties of 2.(THF) and pre-annealed $\mathbf{2 \cdot 0 . 2 5}$ (THF) samples are similar, with only slight variation in $T_{\mathrm{C}}(510 \mathrm{~K} v \mathrm{~s} .515$ $\mathrm{K}$ respectively), but a noticeable $50 \%$ difference in the coercivity at $300 \mathrm{~K}(5300 \mathrm{Oe} v s .7500 \mathrm{Oe}$ respectively; Figs. 4C and S33, 24). These results show that the pre-annealing of the sample to remove most of the THF molecules, significantly improves the $T_{\mathrm{C}}$ and $H_{\text {coer }}$ characteristics of the resulting magnet.

Using Cr $K$-edge X-ray magnetic circular dichroism (XMCD), it is possible to measure the local chromium magnetization, as the spin-orbit interactions of the ligand atoms are negligibly small and consequently cannot introduce a significant orbital moment at the $\mathrm{Cr}$ centers (22). The XMCD spectra for $\mathbf{2}$ (THF) and $\mathbf{2 \cdot 0 . 2 5}$ (THF) (at $295 \mathrm{~K}$; Fig. S37, 24) are essentially identical in shape and intensity (including Coster-Kronig multielectron excitations at 6040-6045 eV), unambiguous- 
ly demonstrating the indistinguishable electronic and magnetic characteristics of $\mathrm{Cr}$ in the two materials. As expected, the field dependence of the local $\mathrm{Cr}$ magnetization (obtained by monitoring the intensity of XMCD signal at $6000.7 \mathrm{eV}$ at $295 \mathrm{~K}$ ) are perfectly superimposed on the bulk $M$ vs. $H$ hysteresis loops (Fig. S38, 24), evidencing the dominant role of the $\mathrm{Cr}^{\mathrm{II}}$ ions in the magnetic behavior of $\mathbf{2} \cdot(\mathrm{THF})$ and $\mathbf{2} \cdot \mathbf{0 . 2 5}(\mathrm{THF})$.
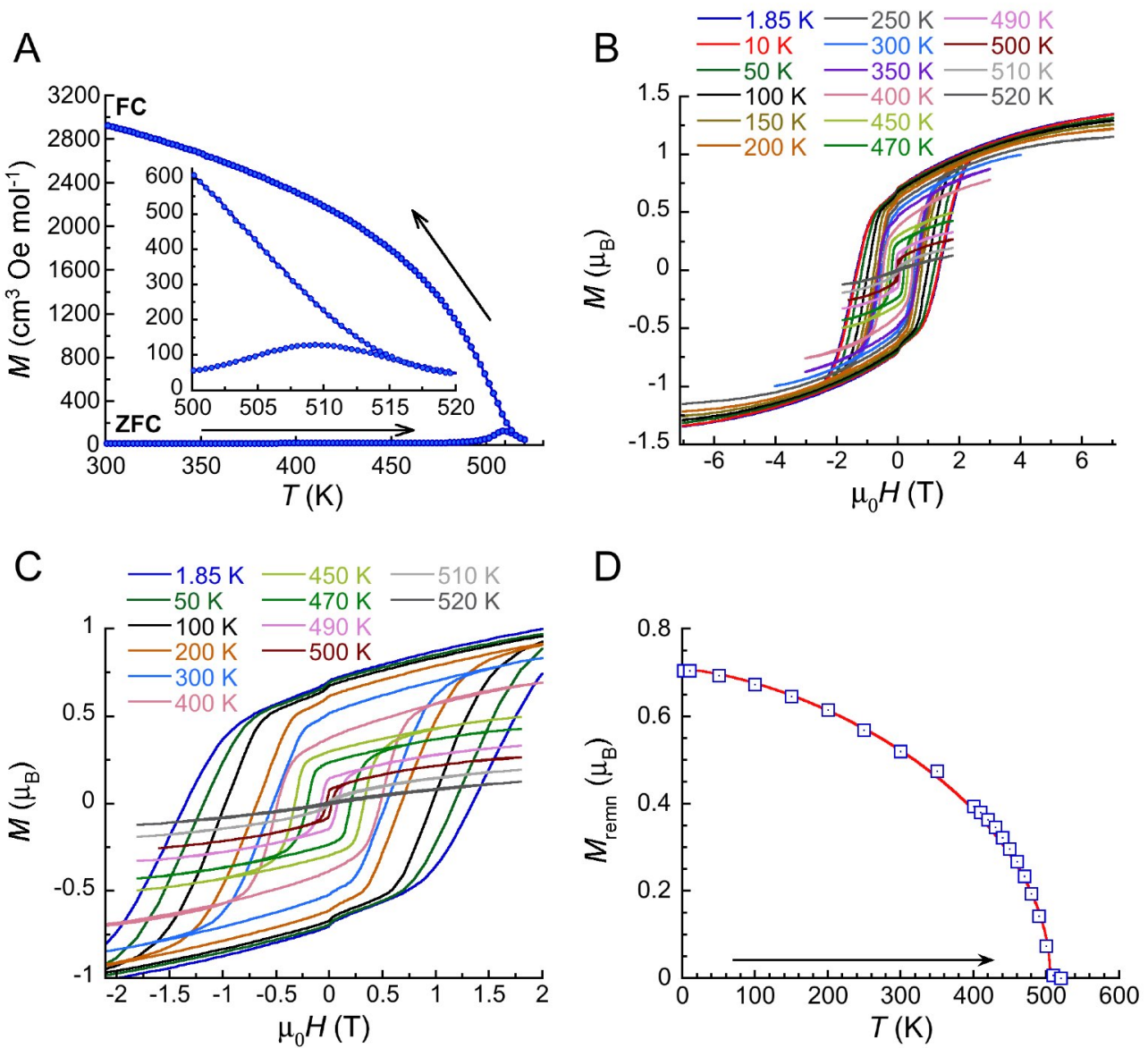

Fig. 4. Magnetic properties of $2 \cdot(\mathrm{THF}$ ) and $2 \cdot 0.25$ (THF) (after the loss of THF above $400 \mathrm{~K}$ ). (A) Zero field-cooled (ZFC)/field-cooled (FC) magnetization data obtained under an applied $d c$ magnetic field of $50 \mathrm{Oe}$ at $5 \mathrm{~K} / \mathrm{min}$. Inset: zoom of the main plot in the $500-520 \mathrm{~K}$ temperature range. The solid lines are a guide for the eye. (B) Magnetization versus applied $d c$ magnetic field data (at 5 to $12 \mathrm{Oe} / \mathrm{s}$ ) in the -7 to $7 \mathrm{~T}$ field range, from $1.85 \mathrm{~K}$ to $520 \mathrm{~K}$. (C) Zoom of selected data from Fig. $4 \mathrm{~B}$ in the -2 to $2 \mathrm{~T}$ field range. (D) Temperature dependence of the remnant magnetization, $M_{\text {remn }}$, determined from the $M v s$. $H$ data from $1.85 \mathrm{~K}$ to $520 \mathrm{~K}$ (Figs. 4B-4C). The solid red line is the best fit to the mean-field (MF) Bloch law: $M_{\text {remn }} \propto\left(1-\left(T / T_{\mathrm{C}-\mathrm{MF}}\right)^{3 / 2}\right)^{1 / 2}$ with $T_{\mathrm{C}}$ $=506 \mathrm{~K},(38)$.

At $1.85 \mathrm{~K}$, the magnetization of both $\mathbf{2} \cdot(\mathbf{T H F})$ and $\mathbf{2 \cdot 0 . 2 5}(\mathbf{T H F})$ does not saturate at $7 \mathrm{~T}$, but reproducibly reaches a maximum value of $1.34 \mu_{\mathrm{B}}$ (Figs. 4B and S32, 24). This value is significantly lower than that of $2 \mu_{\mathrm{B}}$ predicted for an ordered ferrimagnetic state with 
antiferromagnetically coupled spins (one $S=2 \mathrm{Cr}^{\mathrm{II}}$ center and two $S=1 / 2$ pyrazine radicals; assuming $g$-factors of 2). Analogously to $\mathrm{CrCl}_{2}(\mathrm{pyz})_{2}$ (22), the low magnetization may originate from the high degree of conjugation between the $\mathrm{Cr} d$ orbitals and pyrazine $\pi$ states, which leads to a partial delocalization of the $\mathrm{Cr}$ spin density over the organic scaffold, and strong $\mathrm{Cr}$-radical antiferromagnetic interactions. As evidence by broken-symmetry calculations performed on the $\left[\mathrm{Cr}(\mathrm{pyz})_{4}\right]^{2-}$ fragment from the structural model of $\mathbf{2 \cdot 0 . 2 5}$ (THF), the Cr-radical exchange coupling is strongly antiferromagnetic and ranges from -336 to $-429 \mathrm{~cm}^{-1}(-483$ to $-617 \mathrm{~K}$ with the $-2 \mathrm{~J}$ convention) depending on the tilting of the radical pyrazines (Tables S8-S9, Figs. S39, 24). These strong antiferromagnetic interactions are in perfect agreement with the ferrimagnetic order experimentally observed at high temperature for these materials.

This work demonstrates the unprecedented efficiency of the post-synthetic chemical reduction of coordination networks to synthesize lightweight magnets with high critical temperature and large room-temperature coercivity, which compete well with the characteristics of the traditional inorganic magnets (Table S7, 24). This general and simple chemical approach offers exciting perspectives for the preparation of a completely new generation of lightweight magnets, with yet unrealized application in emergent technologies. Finally, it should be highlighted that the reduced materials reported in this study are, as expected due to the absence of mixed-valency, electrically insulating $\left(\sigma_{\mathrm{RT}}=\sim 10^{-10} \mathrm{~S} \mathrm{~cm} \mathrm{~cm}^{-1}\right)$, while the mixed valence $\left[\mathrm{Cr}^{\mathrm{III}} \mathrm{Cl}_{2}\left(\mathrm{pyz}_{2}\right)^{\cdot-}\right]$ precursor shows a significant room-temperature conductivity of $32 \mathrm{mS} \mathrm{cm}^{-1}(22)$. Therefore, exciting potential exists in fine-tuning the extent of post-synthetic chemical reduction in these $2 \mathrm{D}$ coordination materials, leading to the further development of new high- $T_{\mathrm{C}}$ conducting lightweight magnets.

\section{References and Notes:}

1. O. Gutfleisch, M. A. Willard, E. Brück, C. H. Chen, S. G. Sankar, J. P. Liu, Magnetic materials and devices for the 21st century: stronger, lighter, and more energy efficient. Adv. Mater. 23, 821-842 (2011).

2. J. S. Miller, Organic- and molecule-based magnets. Mater. Today 17, 224-235 (2014).

3. J. S. Miller, Magnetically ordered molecule-based materials. Chem. Soc. Rev., 40, 3266-3296 (2011).

4. O. Kahn, Molecular Magnetism, VCH, Weinheim (1993).

5. D. Gatteschi, R. Sessoli, J. Villain, Molecular Nanomagnets, Oxford University Press. (2006).

6. S. Demir, I.-R. Jeon, J. R. Long, T. D. Harris, Radical ligand-containing single-molecule magnets. Coord. Chem. Rev. 289-290, 149-176 (2015).

7. C. Coulon, V. Pianet, M. Urdampilleta, R. Clérac, Single-Chain Magnets and Related Systems. Molecular Nanomagnets and Related Phenomena. Structure and Bonding, vol 164, S. Gao Eds. (Springer, Berlin, Heidelberg, 2014), pp. 143-184.

8. A. E. Thorarinsdottir, T. David Harris, Metal-organic framework magnets. Chem. Rev., (2020) DOI: 10.1021/acs.chemrev.9b00666

9. J. M. D. Coey, Magnetism and Magnetic Materials, Cambridge University Press, Cambridge (2010).

10. X N. Motokawa, H. Miyasaka, M. Yamashita, K. R. Dunbar, An electron-transfer ferromagnet with $T_{\mathrm{C}}=107 \mathrm{~K}$ based on a three-dimensional [ $\left.\mathrm{Ru}_{2}\right]_{2} / \mathrm{TCNQ}$ system. Angew. Chem. Int. Ed. 47, 7760-7763 (2008). 
11. X. Ma, E. A. Suturina, S. De, P. Négrier, M. Rouzières, R. Clérac, P. Dechambenoit, A redoxactive bridging ligand to promote spin delocalization, high-spin complexes, and magnetic multi-switchability. Angew. Chem. Int. Ed. 57, 7841-7845 (2018).

12. J. S. Miller, S.-I. Ohkoshi, High- $T_{\mathrm{C}}$ Ordered Molecular Magnets. Molecular Magnetic Materials: Concepts and Applications, B. Sieklucka, D. Pinkowicz, Eds. (Wiley-VCH, 2017), chap. 7.

13. J. M. Manriquez, G. T. Yee, R. S. Mclean, A. J. Epstein, J. S. Miller, A room-temperature molecular/organic-based magnet. Science 252, 1415-1417 (1991).

14. S. Ferlay, T. Mallah, R. Ouahès, P. Veillet, M. Verdaguer, A room-temperature organometallic magnet based on Prussian blue, Nature 378, $701-703$ (1995).

15. J. Mahmood, J. Park, D. Shin, H.-J. Choi, J.-M. Seo, J.-W. Yoo, J.-B. Baek, Organic ferromagnetism: trapping spins in the glassy state of an organic network structure. Chem 4, 2357-2369 (2018).

16. H. Phan, T. S. Herng, D. Wang, X. Li, W. Zeng, J. Ding, K. P. Loh, A. T. S. Wee, J. Wu, Room-temperature magnets based on 1,3,5-triazine-linked porous organic radical frameworks. Chem 5, 1223-1234 (2019).

17. J. S. Miller, Oliver Kahn lecture: composition and structure of the V[TCNE $]_{x}$ $(\mathrm{TCNE}=$ tetracyanoethylene) room-temperature, organic-based magnet - a personal perspective. Polyhedron 28, 1596-1605 (2009).

18. K. Taniguchi, J. Chen, Y. Sekine, H. Miyasaka, Magnetic phase switching in a tetraoxolenebridged honeycomb ferrimagnet using a lithium ion battery system. Chem. Mater. 29, 1005310059 (2017).

19. L. Liu, J. A. DeGayner, L. Sun, D. Z. Zee, T. D. Harris, Reversible redox switching of magnetic order and electrical conductivity in a 2D manganese benzoquinoid framework. Chem. Sci. 10, 4652-4661 (2019).

20. J. A. DeGayner, I.-R. Jeon, L. Sun, M. Dincă, T. D. Harris, 2D conductive iron-quinoid magnets ordering up to $T=105 \mathrm{~K}$ via heterogenous redox chemistry. J. Am. Chem. Soc. 139, 4175-4184 (2017).

21. L. E. Darago, M. L. Aubrey, C. J. Yu, M. I. Gonzalez, J. R. Long, Electronic conductivity, ferrimagnetic ordering, and reductive insertion mediated by organic mixed-valence in a ferric semiquinoid metal-organic framework. J. Am. Chem. Soc. 137, 15703-15711 (2015).

22. K. S. Pedersen, P. Perlepe, M. L. Aubrey, D. N. Woodruff, S. E. Reyes-Lillo, A. Reinholdt, L. Voigt, Z. Li, K. Borup, M. Rouzières, D. Samohvalov, F. Wilhelm, A. Rogalev, J. B. Neaton, J. R. Long, R. Clérac, Formation of the layered conductive magnet $\mathrm{CrCl}_{2}$ (pyrazine) 2 through redox-active coordination chemistry. Nat. Chem. 10, 1056-1061 (2018).

23. P. Perlepe, I. Oyarzabal, K. S. Pedersen, P. Negrier, D. Mondieig, M. Rouzières, E. A. Hillard, F. Wilhelm, A. Rogalev, E. A. Suturina, C. Mathonière, R. Clérac, $\mathrm{Cr}(\text { pyrazine })_{2}\left(\mathrm{OSO}_{2} \mathrm{CH}_{3}\right)_{2}$ : a two-dimensional coordination polymer with an antiferromagnetic ground state. Polyhedron 153, 248-253 (2018).

$40 \quad 24$. See supplementary materials.

25. T. Trella, W. Frank, poster presented at the 17. Conference of the GDCh Division of Solid State Chemistry and Materials Research, Dresden, DE, 15-17 September 2014.

26. E. Fawcett, Spin-density-wave antiferromagnetism in chromium. Rev. Mod. Phys. 60, 209-283 (1988).

27. C. G. Shuli, M. K. Wilkinson, Neutron diffraction studies of various transition elements. Rev. Mod. Phys. 25, 100-107 (1953). 
28. G. E. Bacon, N. Cowlam, Magnetic studies of annealed and alloyed chromium by neutron diffraction. J. Phys. C: Solid State Phys. 2, 238-251 (1969).

29. T. Furubayashi, I. Nakatani, Curie paramagnetism of chromium ultrafine particles. J. Appl. Phys. 73, 6412-6413 (1993).

30. W. Abdul-Razzaq, M. S. Seehra, Observation of oxidation and mechanical strain in $\mathrm{Cr}$ nanoparticles produced by ball-milling. Phys. Stat. Sol. 193, 94-102 (2002).

31. S. Foner, High-field antiferromagnetic resonance in $\mathrm{Cr}_{2} \mathrm{O}_{3}$. Phys. Rev. 130, 183-197 (1963).

32. J. M. D. Coey, M. Venkatesan, Half-metallic ferromagnetism: example of $\mathrm{CrO}_{2}$. J. Appl. Phys. 91, 8345-8350 (2002).

33. Y.-F. Deng, T. Han, Z. Wang, Z. Ouyang, B. Yin, Z. Zheng, J. Krzystek, Y.-Z-Zheng, Uniaxial magnetic anisotropy of square-planar chromium(II) complexes revealed by magnetic and HFEPR studies. Chem. Commun. 51, 17688-17691 (2015).

34. S. Cuello, J. Entwisle, J. Benning, C. Liu, S. Coburn, K. G. McAdam, J. Braybrook, H. Goenaga-Infante, Complementary HPLC-ICP-MS and synchrotron X-ray absorption spectroscopy for speciation analysis of chromium in tobacco samples. J. Anal. At. Spectrom. 31, 1818-1829 (2016).

35. S. DeBeer George, P. Brant, E. I. Solomon, Metal and ligand K-edge XAS of organotitanium complexes: metal $4 \mathrm{p}$ and $3 \mathrm{~d}$ contributions to pre-edge intensity and their contributions to bonding. J. Am. Chem. Soc. 127, 667-674 (2005).

36. A. B. Cairns, A. L. Goodwin, Structural disorder in molecular framework materials. Chem. Soc. Rev. 42, $4881-4893$ (2013).

37. T. N. Ramesh, R. S. Jayashree, P. V. Kamath, Disorder in layered hydroxides: DIFFaX simulation of the X-ray powder diffraction patterns of nickel hydroxide. Clays Clay Miner. 51, 570-576 (2003).

38. A. Zhukov, Novel Functional Magnetic Materials in Springer Series in Materials Science 231 Eds. (Springer, 2016), chap. 9.

Acknowledgments: The authors thank the GdR MCM-2 (Magnétisme et Commutation Moléculaires) and the MOLSPIN COST action CA15128. A. Väisänen (JYU, Jyväskylä, Finland), E. Hautakangas (JYU, Jyväskylä, Finland), G. Le Bourdon (ISM, Talence, France), L. Vellutini (ISM, Talence, France), L. Voigt (DTU, Lyngby, Denmark), Y.-G. Li (Northeast Normal University, Changchun, China; thanks a lot for the fantastic hydrothermal reactors made in China), X. Ma (CRPP, Pessac, France), R. Musgrave (CRPP, Pessac, France) and S. De (CRPP, Pessac, France) are thanked for helpful discussions, comments and experimental assistance. Funding: This work was supported by the University of Bordeaux, the Région Nouvelle Aquitaine and the Centre National de la Recherche Scientifique (CNRS). I.O. and R.C. are grateful to the Basque Government for I.O.'s postdoctoral grant. K.S.P. thanks the VILLUM FONDEN for a Villum Young Investigator grant (15374). Author contributions: R.C. conceived the original idea and formulated the research aims. P.P. executed the syntheses. A.R., F.W., M.P., P.P., I.O., M.Y., R.C. and C.M. performed the X-ray absorption spectroscopy experiments and analyzed the results. Crystallographic work was carried out by I.D., D.C., P.N. and D.M. Raman and infrared spectra were collected by S.B., A.M., I.O. and M.Y. Elemental analysis and inductively coupled plasma measurements were carried out by A.M., K.S.P. and P.P. Thermogravimetric analysis-mass spectrometry data were collected and analyzed by M.-A.D., P.P. and I.O. Magnetic measurements were conducted by P.P., M.R., R.C. and C.M. E.A.S. performed the DFT studies. After a first complete draft of manuscript written by I.O., P.P., C.M. and R.C., all the authors were involved in 
finalizing manuscript and gave their consent to its publication; Competing interests: the authors declare no competing interests; Data and materials availability: Crystallographic data of $\mathrm{Li}_{0.7}\left[\mathrm{Cr}(\text { pyrazine })_{2}\right] \mathrm{Cl}_{0.7} \bullet 0.25$ (THF) $(\mathbf{2} \bullet \mathbf{0 . 2 5}$ (THF)) at 290 and $500 \mathrm{~K}$ are available free of charge from the Cambridge Crystallographic Data Centre under reference numbers 1983877 and 2007863, respectively. All other data is available in the main text or the supplementary materials.

\section{Supplementary Materials:}

Materials and Methods

Figures S1-S40

$10 \quad$ Tables S1-S9

References (39-63) 


\section{Science MIAAAS}

\section{Supplementary Materials for \\ Unlocking the potential of lightweight molecule-based magnets at room temperature}

Panagiota Perlepe, Itziar Oyarzabal*, Aaron Mailman, Morgane Yquel, Mikhail Platunov, Iurii

Dovgaliuk, Mathieu Rouzières, Philippe Negrier, Denise Mondieig, Elizaveta A. Suturina, Marie-Anne Dourges, Sebastien Bonhommeau, Kasper S. Pedersen, Dmitry Chernyshov, Fabrice Wilhelm, Andrei Rogalev, Corine Mathonière and Rodolphe Clérac*

*Correspondence to: itziar.oyarzabal@crpp.cnrs.fr (I. O.); clerac@crpp-bordeaux.cnrs.fr (R.C.)

\section{This PDF file includes:}

Materials and Methods

Figs. S1 to S40

Tables S1 to S9

References 


\section{Materials and Methods}

All chemicals (lithium, 1,2-dihydroacenaphtylene 99\% - CAS: 83-32-9, $\mathrm{CrCl}_{2}$ 99.99\%, pyrazine $\geq 99 \%$ ) were purchased from commercial sources and used without further purification. $\mathrm{CrCl}_{2}$ (pyz) $)_{2}$ and $\mathrm{Cr}\left(\mathrm{OSO}_{2} \mathrm{CH}_{3}\right)_{2}$ (pyz) $)_{2}$ were synthesized as previously described $(22,23)$. All manipulations were carried out in an Innovative Technology PureLab HE or an Mbraun Unilab glovebox under a dinitrogen or argon atmosphere and/or by standard Schlenk techniques. Tetrahydrofuran (THF) was dried with an Innovative Technology solvent-purification system and subsequently stored over $4 \AA$ molecular sieves $\left(\mathrm{H}_{2} \mathrm{O}\right.$ content $<2$ ppm, measured by a Metrohm 899 coulometer entry-level titrator). All reactions were carried out by using Pyrex glass-coated magnetic stirring bars and the resulting solid was manipulated with polypropylene or pyrex spatulas to avoid the presence of any magnetic impurity. Due to the extreme air and moisture sensitivity of the reduced compounds, all manipulations were performed under dinitrogen or argon atmosphere. To avoid the loss of intercalated THF molecules over time, the samples were stored inside the glovebox freezer at $T=248 \mathrm{~K}$ when not in use.

Synthesis of compound 1: chemical reduction of $\mathrm{Cr}\left(\mathrm{OSO}_{2} \mathrm{CH}_{3}\right)_{2}(\text { pyz })_{2}$

$$
\mathrm{Cr}\left(\mathrm{OSO}_{2} \mathrm{CH}_{3}\right)_{2}\left(\mathrm{pyz}_{2}+2 \mathrm{Li}^{+}\left[\mathrm{C}_{12} \mathrm{H}_{10}{ }^{-}\right] \frac{\mathrm{THF}}{-2\left[\mathrm{C}_{12} \mathrm{H}_{10}\right]} 1 \supset\left(\mathrm{Li}_{x}\left(\mathrm{SO}_{3} \mathrm{CH}_{3}\right)_{x}\right)+(2-x) \mathrm{Li}^{2}\left[\mathrm{SO}_{3} \mathrm{CH}_{3}\right]\right.
$$

Lithium 1,2-dihydroacenaphtylenide was prepared by stirring $231.3 \mathrm{mg}$ (1.5 mmol) of 1,2dihydroacenaphtylene over a 10-fold excess of lithium metal (104 mg) in $8 \mathrm{~mL}$ of THF for 3 hours. The resulting dark olive (dark yellow-green) colored solution was filtered using a $0.2 \mu \mathrm{m}$ PTFE membrane syringe filter and added dropwise to a stirred suspension of $\mathrm{Cr}\left(\mathrm{OSO}_{2} \mathrm{CH}_{3}\right)_{2}(\mathrm{pyz})_{2}$ (286 mg, $0.71 \mathrm{mmol}$ ) in $5 \mathrm{~mL}$ of THF. The mixture was stirred for 4 days at room temperature and the resulting dark grey fine microcrystalline powder was separated by centrifugation, washed with THF, and allowed to stand in a nitrogen atmosphere for 10 minutes. Collected: $344 \mathrm{mg}$ of solid.

Synthesis of $\mathrm{Li}_{0.7}\left[\mathrm{Cr}\left(\mathrm{pyz}_{2}\right] \mathrm{Cl}_{0.7} \cdot(\mathrm{THF})(\mathbf{2} \cdot(\mathbf{T H F}))\right.$

$$
\begin{gathered}
\mathrm{CrCl}_{2}(\mathrm{pyz})_{2}+2 \mathrm{Li}^{+}\left[\mathrm{C}_{12} \mathrm{H}_{10}{ }^{\circ-}\right] \underset{\mathrm{THF}}{\frac{\mathrm{TH}}{-1.3 \mathrm{LiCl}}} \\
-2\left[\mathrm{C}_{12} \mathrm{H}_{10}\right]
\end{gathered}
$$

Chemical reduction of $\mathrm{CrCl}_{2}$ (pyz) $)_{2}$ was accomplished following the same procedure as given for 1, using $\mathrm{CrCl}_{2}$ (pyz) 2 (200 mg, $\left.0.71 \mathrm{mmol}\right)$ as precursor instead of $\mathrm{Cr}\left(\mathrm{OSO}_{2} \mathrm{CH}_{3}\right)_{2}(\mathrm{pyz})_{2}$. The compound was filtered on a fine sintered glass Buchner funnel, washed with $2 \times 15 \mathrm{~mL}$ of dry THF and dried for a few minutes under static vacuum $\left(10^{-1} \mathrm{bar}\right)$ at room temperature to afford a dark brown solid. Yield: $\sim 200 \mathrm{mg}, \sim 90 \%$ yield based on $\mathrm{CrCl}_{2}(\mathrm{pyz})_{2}$. 
Comments on the synthesis:

a) The duration of the reaction (4 days) is crucial for the isolation of the phase-pure compound. The use of fewer than two equivalents of the reducing agent $\left(\mathrm{Li}\left[\mathrm{C}_{12} \mathrm{H}_{10}\right]\right)$ or shorter reaction times lead to a mixture of $\mathbf{2} \cdot(\mathbf{T H F})$ and $\mathrm{CrCl}_{2}(\text { pyz })_{2}$ phases, as determined by magnetic measurements. b) The amount of THF in the final material decreases over time when $\mathbf{2} \cdot$ (THF) is allowed to stand at room temperature and/or upon grinding, as demonstrated by FT-IR measurements (Fig. S23). Thus, the samples were habitually stored in a freezer $(248 \mathrm{~K})$ inside the glovebox to avoid the loss of intercalated solvent molecules.

c) ICP measurements (vide infra) showed that under the employed synthetic conditions (amount of solvent and reaction time), the Cr:Li ratio in the final compound was of 1:0.7(1) (based on nine different batches). The $\mathrm{Cr}$ : $\mathrm{Cl}$ ratio of ca. 1:0.7 was independently estimated from the XANES data at the $\mathrm{Cl} K$-edge (Fig. S12). The $\mathrm{Cr}$ :Li and $\mathrm{Cr}$ :Cl ratios were further confirmed by EA (Table S1) and gravimetric analysis of the $\mathrm{LiCl}$ that remained in solution after the reaction. For such purpose, the THF fractions were combined and the volatiles flash distilled to afford a beige solid. The organic residues were extracted with toluene and the insoluble solid, assumed to be $\mathrm{LiCl}$, was collected on a pre-weighted, fine sintered glass funnel. The mass of the solid obtained by difference, $0.0374 \mathrm{~g}$, was consistent with the presence of $1.3 \mathrm{LiCl}$ equivalents (expected value: $0.0391 \mathrm{~g})$ in the filtrate.

d) The "drying" of 2.(THF) was performed by heating the solvate in a capped but only partially sealed screw cap-vial at $400 \mathrm{~K}$ for 18 hours or at $500 \mathrm{~K}$ for 10 hours under dinitrogen or argon atmosphere. However, $\sim 25 \%$ of the THF remained in the final material, leading to the general formulation $\mathrm{Li}_{0.7}\left[\mathrm{Cr}(\mathrm{pyz})_{2}\right] \mathrm{Cl}_{0.7} \cdot 0.25$ (THF), $\mathbf{2 \cdot 0 . 2 5}$ (THF) (Table $\mathrm{S} 1$ ). Further drying of the material under dynamic vacuum $\left(>10^{-2}\right.$ bar) was unsuccessful as $\mathbf{2 \cdot 0 . 2 5}$ (THF) readily decomposed, as verified by both the FTIR (Fig. S25) and EA measurements.

\section{Elemental analyses}

Samples for C, H, N were prepared in pre-weighed $6 \times 6 \times 10 \mathrm{~mm}$ Sn foil pans, typically using 3$5 \mathrm{mg}$ of solid sample. The pans were transferred to the analyzer sealed in $0.5 \mathrm{~mL}$ Eppendorf Flextube ${ }^{\circledR}$ microcentrifuge tube and placed inside a separate vial under Argon. The pre-calibrated Vario EL III element analyzer was used to determine the C, H, N weight percentage from sample masses (obtained by weighing by difference the pre-weighted centrifuge tube and Sn foil pan before quickly transferring them to the sampling chamber). The error on the $\mathrm{C}, \mathrm{H}$ and $\mathrm{N}$ values is estimated between $0.5 \%$ and $0.1 \%(0.1 \%$ corresponds to the error in the ideal standard conditions given by Vario). The results are summarized in Table S1.

Inductively coupled plasma (ICP) - optical emission spectroscopy (OES)

ICP-OES measurements were performed on two different spectrometers, which required different sample preparations: 
(a) Samples were prepared by refluxing approximately $10 \mathrm{mg}$ of solid in a mixture of $1 \mathrm{~mL}$ of $\mathrm{HNO}_{3}(65 \%)$ and $1 \mathrm{~mL}$ of $\mathrm{HCl}(37 \%)$ under argon atmosphere and diluting to $100 \mathrm{~mL}$ with MilliQ water. Samples were analyzed by ICP-OES on a Varian ICP/OES 720 ES spectrometer.

(b) Samples were prepared by digesting approximately $20 \mathrm{mg}$ of solid in $10 \mathrm{~mL}$ of hot concentrated $\mathrm{HNO}_{3}(65 \%)$ in a sealed pressure vessel under argon and diluting to $20 \mathrm{~mL}$ with Milli-Q water. Samples were analyzed by ICP-OES on a Perkin-Elmer Optima 4300 DV ICP optical emission spectrometer for simultaneous multi-element detection.

Measurements carried out on nine independently prepared samples gave an average Cr:Li ratio of 1:0.7 with an estimated standard deviation of 0.1 (the experimental values are $1: 0.65,0.67,0.52$, $0.77,0.64,0.85,0.73,0.69,0.71)$.

\section{Fourier-transform infrared spectroscopy}

FT-IR spectra of neat, solid samples were recorded on a Bruker Alpha Platinum single reflection diamond ATR module using 24 scans at $4 \mathrm{~cm}^{-1}$ resolution in an argon filled glovebox.

\section{$\underline{\text { Raman spectroscopy }}$}

Raman scattering measurements were carried out in backscattering geometry using a commercial (XploRA, Horiba scientific) confocal Raman spectrometer equipped with a motorized $x y$ stage, a 1200 grooves $/ \mathrm{mm}$ grating, and a long working distance $\times 50$ Olympus objective with 0.45 numerical aperture. The samples were loaded into quartz capillaries of $0.5 \mathrm{~mm}$ diameter and irradiated at $785 \mathrm{~nm}$ with an $0.37 \mathrm{~mW}$ laser power. The integration time was 3 minutes and two accumulations were performed.

\section{Computational details}

Molecular model calculations on the X-ray structure fragments were done with ORCA 4.1 $(39,40)$ package. The positions of the hydrogen atoms were added and optimized using the B3LYP $(41,42,43,44)$ method and def2-TZVP (45) basis set. The exchange interactions were calculated at the same level of theory using the broken-symmetry approach (Ising Hamiltonian) assuming that the exchange coupling between the $\mathrm{Cr}$ spin and each pyrazine radical spin is the same. The spinHamiltonian of the $\left[\mathrm{Cr}(\mathrm{pyz})_{4}\right]^{4-}$ model complex can be written using an Ising model considering Cr-radical interactions $\left(J_{C r-R}\right)$ and interactions between two radicals in trans-positions $\left(J_{R R}\right)$ and in cis-positions $\left(U_{R^{\prime} R}\right)$ :

$$
H=-2 J_{C r-R} \sum_{i=1-4} S_{z}^{C r} S_{z, i}^{R}-2 J_{R R} \sum_{\substack{i=1,2 \\ j=3,4}} S_{z, i}^{R} S_{z, j}^{R}-2 J_{R^{\prime} R} \sum_{i=1,3} S_{z, i}^{R} S_{z, i+1}^{R}
$$

The exchange parameters can be estimated using the energies of the broken-symmetry solutions (see Table S8):

$$
J_{C r-R}=-\frac{E_{a a a a A}-E_{b b b b A}}{16}
$$




$$
\begin{gathered}
J_{R R}=-\frac{E_{a a a a A}+E_{b b b b A}-2 E_{a b a b A}}{8} \\
J_{R^{\prime} R}=-\frac{E_{a a a a A}+E_{b b b b A}+2 E_{a b a b A}-4 E_{a b b a A}}{8}
\end{gathered}
$$

Geometry optimization and frequency calculations together with Raman intensities were calculated using Gaussian16 (46) for neutral and reduced pyrazine ligands and molecular fragments of the $\mathrm{Cr}$ complex using different methods and basis sets detailed below.

X-ray absorption spectra of $\mathrm{Cl} K$-edge were simulated using orbital energies (47) calculated with the pure functional BP86 $(48,49)$ and scalar relativistic approximation ZORA with relativistic version of def2-TZVP basis set $(50)$, while spin-orbit coupling $(51,52)$ was accounted as a perturbation. The spectra were plotted using $0.7 \mathrm{eV}$ line width and accounting for quadrupole contributions to the intensities (Fig. S13).

Thermogravimetric analysis - mass spectrometry (TGA-MS)

TGA-MS for compound 2.(THF) was performed on a NETZSCH STA 409C/CD (Erich NETZSCH GmbH \& Co. Holding KG, Selb, Germany) thermogravimetric analyzer with a heating rate of $5 \mathrm{~K} \mathrm{~min}^{-1}$. Due to the extreme air sensitivity of the compound, the pre-weighed sample $(8.6 \mathrm{mg})$ was covered with anhydrous cyclohexane $(14.13 \mathrm{mg})$ inside a $\mathrm{N}_{2}$-filled glovebox. The pan containing the suspension was kept inside a closed vial and it was quickly transferred to the TGA-MS instrument after removing the vial from the glovebox.

\section{Powder X-ray diffraction (PXRD)}

Microcrystalline powder samples were loaded into $0.5 \mathrm{~mm}$ borosilicate glass capillaries inside a glovebox under a dinitrogen atmosphere, and the capillaries were sealed with wax. High-resolution powder X-ray diffraction data were subsequently collected at beamline BM01 (part of the SwissNorwegian Beamlines, SNBL) at the European Synchrotron Radiation Facility (ESRF) in Grenoble, France. Diffraction patterns were collected with a wavelength of 0.6673 and $0.7829 \AA$ for compounds 1 and 2-(THF), respectively. For the variable-temperature PXRD studies, the sample was heated under a dinitrogen stream using a Cryostream $700+$ with a $6 \mathrm{~K} \mathrm{~min}^{-1}$ ramping rate.

The indexing of the powder X-ray diffraction patterns, Pawley refinements, structure solution, and the final Rietveld refinement were performed with the Fullprof (53) and Materials Studio (54) programs. The refinement of the crystal structure of $\mathbf{2 \cdot 0 . 2 5}$ (THF) (Table S6) was performed on a powder pattern collected at $500 \mathrm{~K}$ (Fig. S28) and at $290 \mathrm{~K}$ after cooling from $500 \mathrm{~K}$ (Fig. 3). The refinement was done considering the size-strain anisotropic peak broadening of the powder patterns and preferred orientation along [100] direction (Modified March's function). Using $\mathrm{CrCl}_{2}(\mathrm{pyz})_{2}(\mathrm{CCDC} 1563526)$ as a structure model, the following atomic restrains for the pyrazine 
rings were used: $d_{(\mathrm{N}-\mathrm{N})}=2.90 \AA, d_{(\mathrm{N}-\mathrm{C})}=1.35 \AA, d_{(\mathrm{C}-\mathrm{C}) \text { short }}=1.33 \AA, d_{(\mathrm{C}-\mathrm{C}) \text { long }}=2.56 \AA$ with $\sigma=$ $0.001 \AA$ and $d_{(\mathrm{C}-\mathrm{C})}=1.62 \AA$ between disordered pyrazine rings with $\sigma=0.01 \AA$. Atomic displacement parameters were refined isotropically at first: independently for $\mathrm{Cr}$, with the same $B_{\text {iso }}$ for $\mathrm{C}, \mathrm{N}$ and $\mathrm{Cl}$, and with a $1.5 B_{\text {iso }}$ of $\mathrm{C}, \mathrm{N}$ and $\mathrm{Cl}$ for Li. Finally, they were fixed and the $B$ (overall) was refined together with atomic coordinates. The $\mathrm{Li} / \mathrm{Cl}$ content was fixed at 0.7 according to the ICP, EA, gravimetric (vide supra) and XANES data (Fig. S12). It is worth mentioning that THF molecules were not found and thus were not included in the final structural model.

X-ray absorption spectroscopy (XAS):

X-ray absorption experiments have been performed at the ID12 beamline (55) of the European Synchrotron Radiation Facility (ESRF). For the $\mathrm{Cr} K$-edge experiments, the X-ray source was the first harmonic of APPLE-II type helical undulator (HU-38), whereas for the $\mathrm{Cl} K$-edge ones, it was the first harmonic of HELIOS-II-type helical undulator (HU-52) in pure helical mode. The advantage of using helical mode is that the content of the higher order harmonics is strongly reduced, since only the fundamental harmonic is emitted on the undulator axis. The X-ray beam was monochromatized using a fixed-exit double-crystal monochromator equipped with a pair of $\mathrm{Si}(111)$ crystals. Powdered samples were pressed into pellets and mounted inside He filled glovebox into vacuum tight sample holders covered with $13-\mu \mathrm{m}$ thick kapton foil. X-ray absorption near edge structure (XANES) spectra were recorded using total fluorescence yield detection mode. The $\mathrm{X}$-ray fluorescence signal from the samples were collected in the back-scattering geometry, through the kapton window, using Si photodiodes. The $\mathrm{Cr} K$-edge extended X-ray absorption fine structure (EXAFS) spectra were measured in transmission mode using an optimized "gap-scanning technique" (56). The processing of experimental EXAFS spectra was done using the Viper software (57). No corrections for the phase and amplitude of backscattering atoms were applied. Local magnetic properties of the $\mathrm{Cr}$ site at $295 \mathrm{~K}$ were studied using X-ray magnetic circular dichroism (XMCD) method at the Cr K-edge. The XMCD spectra were obtained as the difference between two consecutive XANES spectra recorded with opposite photon helicities of the incoming photons under external magnetic field produced by a superconducting solenoid. Measurements were performed for both directions of applied magnetic field parallel and antiparallel to the incoming X-ray wavevector in order to ensure the absence of experimental artifacts. The elementselective magnetization curve was recorded by monitoring the maximum of XMCD signal as a function of an applied magnetic field.

\section{Magnetic measurements}

The characterization of the magnetic properties was performed on a Quantum Design SQUID magnetometer MPMS-XL operating between 1.8 and $400 \mathrm{~K}$ for applied $d c$ fields ranging from -7 to $7 \mathrm{~T}$. The measurements were performed on microcrystalline samples $(\sim 10 \mathrm{mg})$ sealed in polyethylene bag (size $\sim 3 \times 0.5 \times 0.02 \mathrm{~cm}$ ), which was subsequently sealed into a polypropylene bag to allow measurements up to $400 \mathrm{~K}$. The additional polypropylene bag was also used to protect 
the samples, which are extremely sensitive to air and moisture. The magnetic data were corrected for the in-situ sample decomposition above $300 \mathrm{~K}$, the intrinsic diamagnetic contributions of the sample and sample holder. The magnetic data for 1 (Figs. S2-S4) were calculated based on the molecular weight of the $\mathrm{Cr}\left(\mathrm{OSO}_{2} \mathrm{CH}_{3}\right)_{2}$ (pyz) precursor $\left(402.39 \mathrm{~g} \mathrm{~mol}^{-1}\right)$.

The high-temperature magnetic characterization (up to $540 \mathrm{~K}$ ) was performed on a Microsense Vibrating Sample Magnetometer (VSM) for applied $d c$ fields ranging from -1.8 to $1.8 \mathrm{~T}$. The microcrystalline powder $(\sim 10 \mathrm{mg})$ was loaded into a quartz tube of $\sim 4 \mathrm{~mm}$ internal diameter and sealed with epoxy glue to second quartz tube of $\sim 4 \mathrm{~mm}$ external diameter. The preparation of the sample was carried in a glovebox under inert atmosphere. The zero field-cooled (ZFC)/fieldcooled (FC) magnetization data were collected on samples of $\mathbf{2} \cdot($ THF) (Fig. 4) and 2・0.25(THF) (Fig. S36) introduced first in the magnetometer at $300 \mathrm{~K}$ under zero field. Magnetization data were obtained while warming in the presence of a magnetic field of 50 Oe (ZFC) and subsequently cooling (FC) to room temperature under the same magnetic field. The high-temperature VSM $M$ vs $H$ data $(400-520 \mathrm{~K})$ were scaled to the results obtained at 300 and $400 \mathrm{~K}$ from the SQUID MPMS magnetometer.

\section{Electrical conductivity}

Resistivity measurements on $\mathbf{1}, \mathbf{2} \cdot($ THF) and $2 \cdot 0.25$ (THF) were carried out using a home-made 4-point probe installed inside a Quantum Design PPMS-9 system working between 1.8 and 400 K. Acquisitions were performed with the use of an external device (Keithley 2401 source-meter). These measurements were performed on pellets of polycrystalline samples (typically $7 \mathrm{~mm}$ diameter and $1 \mathrm{~mm}$ thickness; about 50-60 mg) prepared under dinitrogen atmosphere with a manual press. The pellets were loaded in the homemade resistivity cell allowing the four aligned needle probes (mounted on springs) to be in contact with the pellet. 


\section{Table S1.}

Elemental analysis results for $2 \cdot($ THF) and $2 \cdot 0.25($ THF).

\begin{tabular}{|c|c|c|c|}
\hline & $\mathrm{C}(\%)$ & $\mathrm{H}(\%)$ & $\mathrm{N}(\%)$ \\
\hline 2.(THF) Sample 1 - 1 st measurement & 46.53 & 5.127 & 18.01 \\
\hline 2.(THF) Sample 1 - 2nd measurement & 44.47 & 5.137 & 17.82 \\
\hline 2.(THF) Sample 1 - 3rd measurement & 45.61 & 5.164 & 18.19 \\
\hline 2.(THF) Sample 2 & 44.79 & 4.683 & 17.34 \\
\hline 2.(THF) Sample 3 - 1 st measurement & 46.65 & 5.195 & 17.56 \\
\hline 2.(THF) Sample 3 - 2nd measurement & 45.55 & 5.023 & 17.88 \\
\hline Average (ESD) for $2 \cdot(\mathrm{THF})$ & $45.60(88)$ & $5.05(19)$ & $17.80(31)$ \\
\hline Calc. for $\mathrm{Li}_{0.7}\left[\mathrm{Cr}(\mathrm{pyz})_{2}\right] \mathrm{Cl}_{0.7} \cdot(\mathrm{THF})$ & 45.91 & 5.14 & 17.84 \\
\hline $\begin{array}{l}\text { After heating at } 400 \mathrm{~K} \text { the compound } \\
\mathbf{2} \cdot(\mathrm{THF}) \text { (average on } 6 \text { measurements with } \\
\text { ESD) }\end{array}$ & $41.71(53)$ & $3.84(37)$ & $21.81(121)$ \\
\hline $\begin{array}{l}\text { After heating at } 480-500 \mathrm{~K} \text { the compound } \\
\mathbf{2} \cdot(\mathbf{T H F}) \text { (average on } 6 \text { measurements with } \\
\text { ESD) }\end{array}$ & $41.13(96)$ & $3.66(19)$ & $21.82(106)$ \\
\hline Calc. for $\mathrm{Li}_{0.7}\left[\mathrm{Cr}(\mathrm{pyz})_{2}\right] \mathrm{Cl}_{0.7} \cdot 0.25(\mathrm{THF})$ & 41.60 & 3.88 & 21.56 \\
\hline
\end{tabular}

The $\mathrm{CHN}$-analysis were performed without the addition of a $\mathrm{V}_{2} \mathrm{O}_{5}$ additive (to avoid additional weighing errors) and the variation of the $C$ percentages could be caused by the formation of metal carbide during the combustion cycle. 


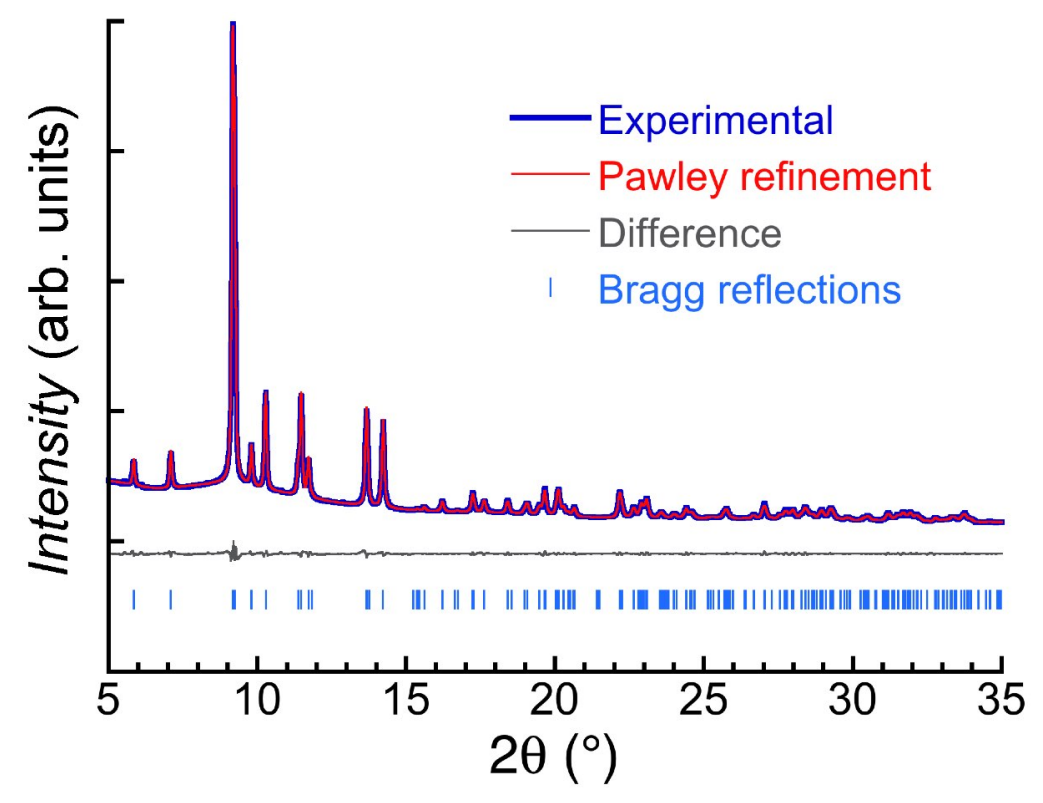

\section{Fig. S1.}

Synchrotron X-ray powder diffraction pattern of 1 (solid blue line), collected at room-temperature $(298 \mathrm{~K})$ with a wavelength of $0.6673 \AA$ and its Pawley refinement (solid red line). The Pawley refinement led to $C 2 / m$ space group with $a=7.8081(5) \AA, b=7.4473(5) \AA, c=6.5356(4) \AA$ and $\beta=90.561(3)^{\circ}$, similar to what found for $\mathrm{Li}\left[\mathrm{CH}_{3} \mathrm{SO}_{3}\right](a=7.8586(16) \AA, b=7.4889(15) \AA, c=$ $6.5454(13) \AA$ and $\left.\beta=90.234(15)^{\circ}, 25\right)$. The difference (solid gray line) between the best Pawley fit (solid red line) and the experimental data (solid blue line), and calculated line positions (blue bars) are also shown in the figure. Considering that the Bragg diffraction peaks correspond exclusively to the salt $\mathrm{Li}\left[\mathrm{CH}_{3} \mathrm{SO}_{3}\right]$, these data suggest that the $\mathrm{Cr}$-based magnet present in $\mathbf{1}$, is poorly crystalline, nanocrystalline or amorphous. 


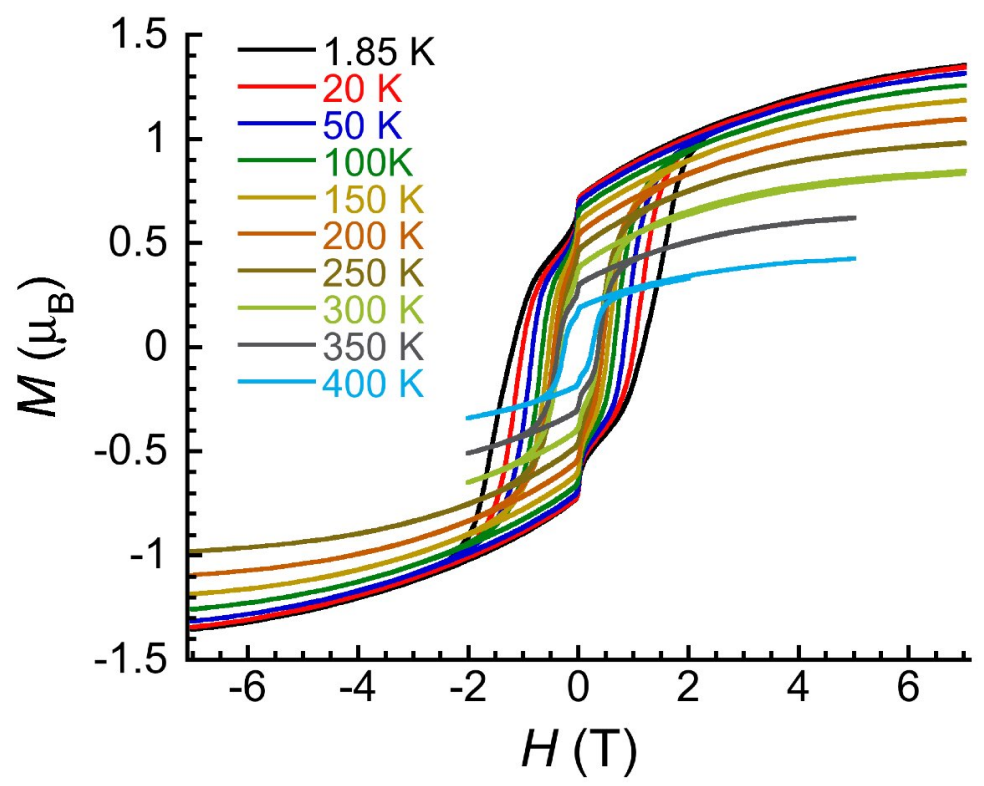

Fig. S2.

Magnetization versus applied $d c$ magnetic field data (at 7 to $8 \mathrm{Oe} / \mathrm{s}$ ) in the -7 to $7 \mathrm{~T}$ field range for 1 at selected temperatures from $1.85 \mathrm{~K}$ and increasing the temperature up to $400 \mathrm{~K}$. As the exact composition of $\mathbf{1}$ is unknown, the magnetization data were normalized using the molecular weight of the $\mathrm{Cr}\left(\mathrm{OSO}_{2} \mathrm{CH}_{3}\right)_{2}$ (pyz) $)_{2}$ parent compound. 


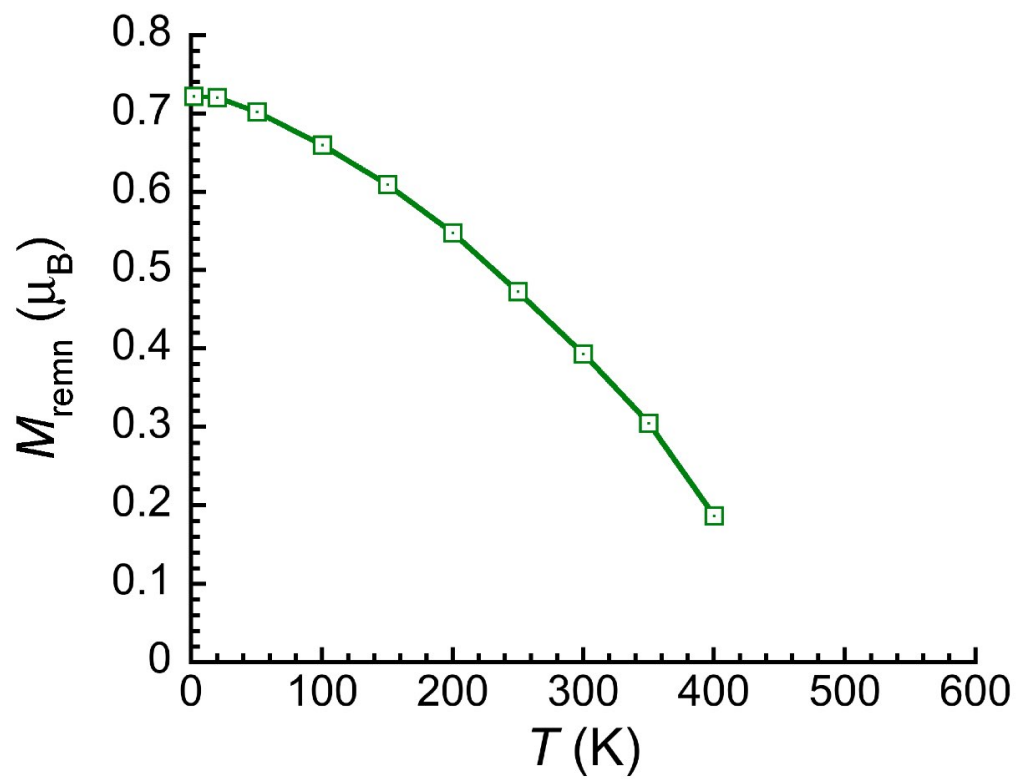

\section{Fig. S3.}

Temperature dependence of the remnant magnetization, $M_{\text {remn }}$, determined from the $M v s . H$ data (Fig. S2) at each temperature for $\mathbf{1}$. As the exact composition of $\mathbf{1}$ is unknown, the magnetization data were normalized using the molecular weight of the $\mathrm{Cr}\left(\mathrm{OSO}_{2} \mathrm{CH}_{3}\right)_{2}(\text { pyz })_{2}$ parent compound. The green line is a guide for the eye. 


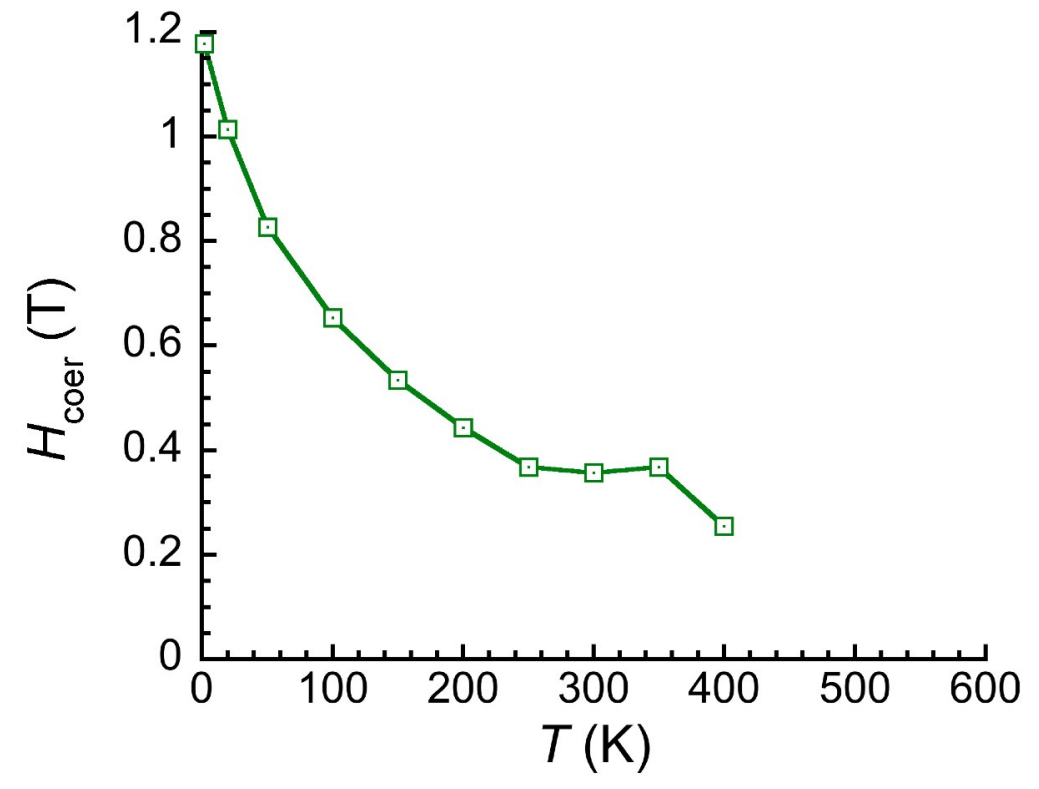

\section{Fig. S4.}

Temperature dependence of the coercive field, $H_{\text {coer, }}$ determined from the $M v s$. $H$ data (Fig. S2) at each temperature for $\mathbf{1}$. The green line is a guide for the eye. 


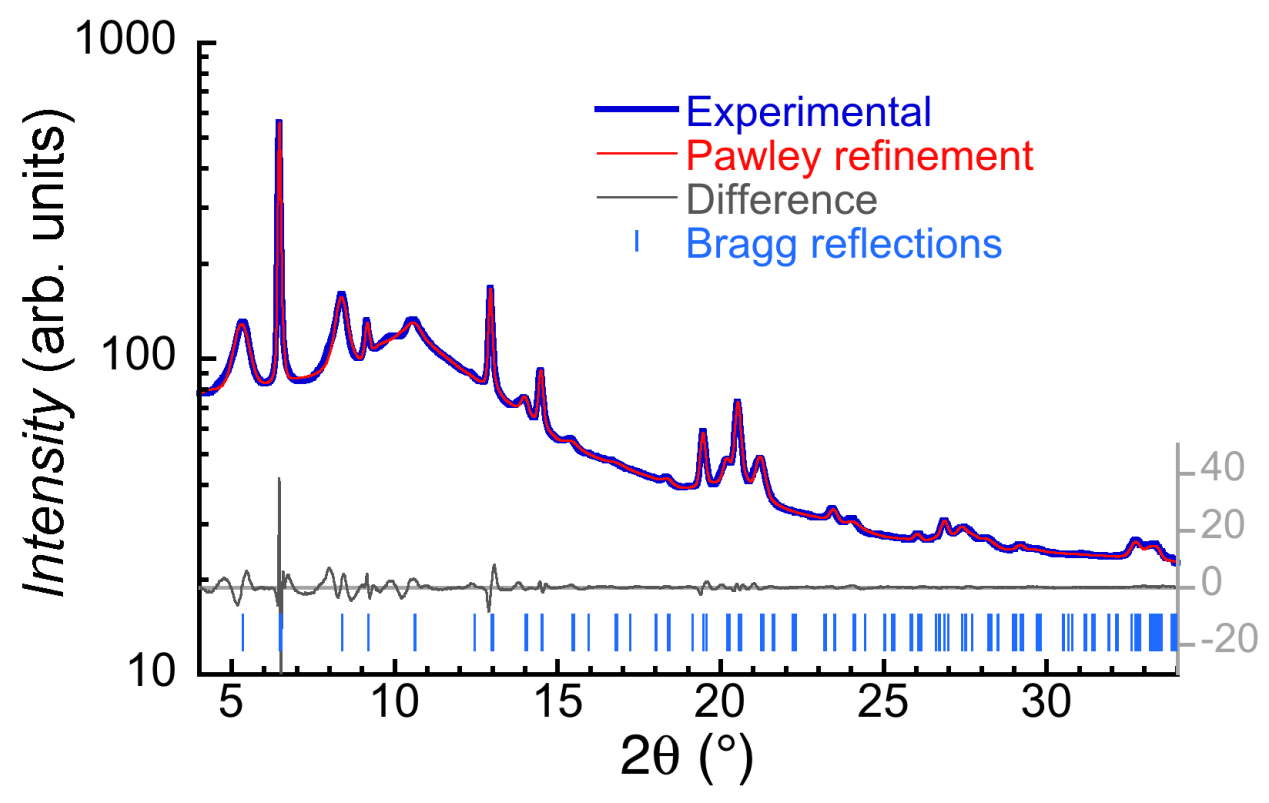

\section{Fig. S5.}

Synchrotron X-ray powder diffraction pattern of 2 (THF) (solid blue line), collected at roomtemperature $(298 \mathrm{~K})$ with a wavelength of $0.7829 \AA$ and its Pawley refinement (solid red line; $R_{\mathrm{p}}$ $=1.33 \%$ and $R_{\mathrm{wp}}=1.75 \%$ ). The Pawley refinement led to an orthorhombic Pmmm space group with the following cell parameters: $a=6.9239(9) \AA, b=6.9524(2) \AA$ and $c=8.478(2) \AA$. The difference (solid gray line) between the best Pawley fit (solid red line) and the experimental data (solid blue line), and calculated line positions (blue bars) are also shown in the figure. 


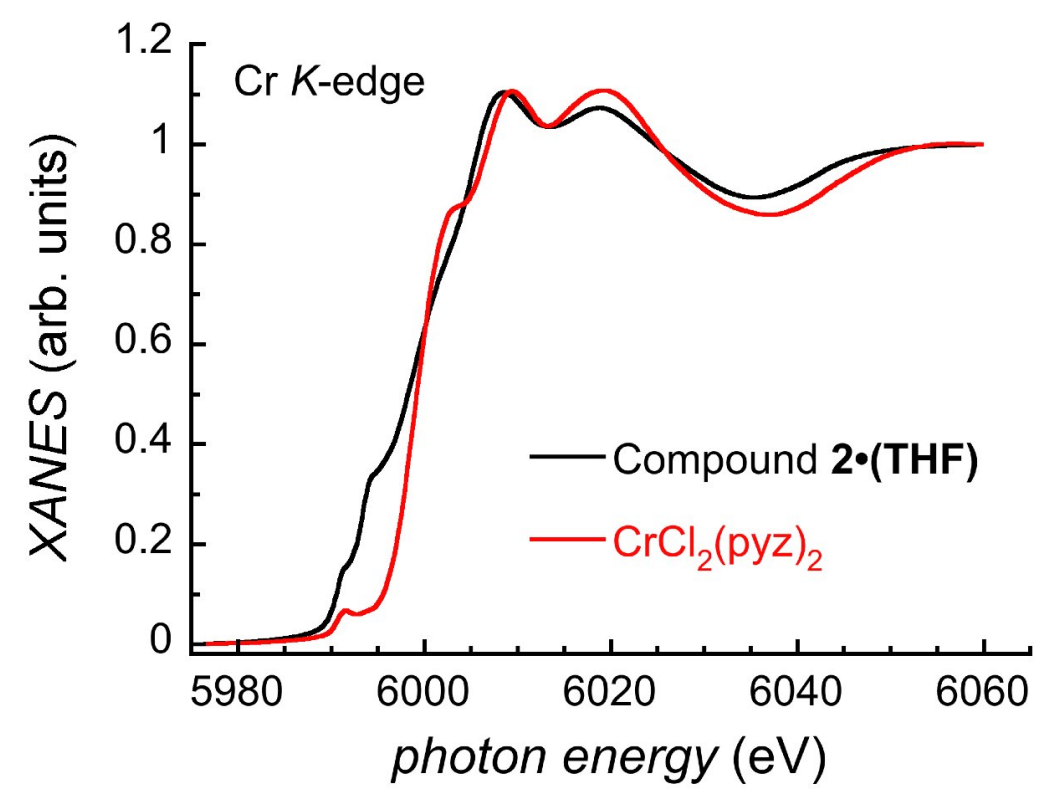

Fig. S6.

Normalized XANES spectra at the $\mathrm{Cr} K$-edge of 2·(THF) (black line) and $\mathrm{CrCl}_{2}$ (pyz) 2 (red line) recorded at $295 \mathrm{~K}$. 


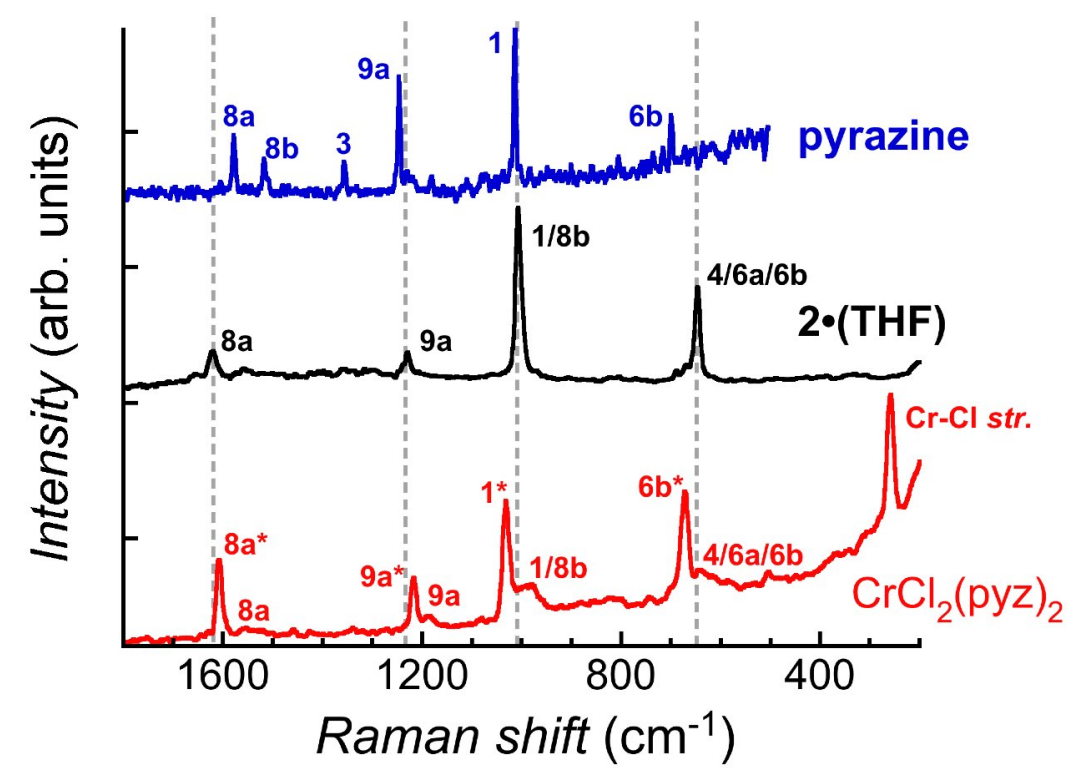

\section{Fig. S7.}

Normalized Raman spectrum $(\lambda=785 \mathrm{~nm}$ ) of neutral pyrazine (pyz; blue trace), $\mathbf{2} \cdot($ THF) (black trace) and $\mathrm{Cr}^{\mathrm{III}} \mathrm{Cl}_{2}$ (pyz) 2 (red trace) between 1800 and $200 \mathrm{~cm}^{-1}$ recorded at room temperature. The labelling denotes the Wilson nomenclature (58). Peak assignment of pyrazine ${ }^{\dagger}: 1578 \mathrm{~cm}^{-1}-\mathbf{8 a}$; $1518 \mathrm{~cm}^{-1}-\mathbf{8 b} ; 1356 \mathrm{~cm}^{-1}-\mathbf{3} ; 1246 \mathrm{~cm}^{-1}-\mathbf{9 a} ; 1013 \mathrm{~cm}^{-1}-\mathbf{1} ; 700 \mathrm{~cm}^{-1}-\mathbf{6 b}$. Tentative peak assignment of $\mathbf{2} \cdot \mathbf{( T H F})^{\dagger, t}: 1620 \mathrm{~cm}^{-1}-\mathbf{8 a} ; 1229 \mathrm{~cm}^{-1}-\mathbf{9 a} ; 1007 \mathrm{~cm}^{-1}-\mathbf{1}$ and/or $\mathbf{8 b} ; 646 \mathrm{~cm}^{-1}{ }_{-}$ 4, $6 \mathbf{a}$ or $6 \mathbf{b}$. The spectra of $\mathbf{2}$ (THF) does not show any bands corresponding to THF, which could be due to partial evaporation of THF before (grinding of the samples to load them into quartz capillaries) and/or during the measurements (heat generated during the irradiation of the sample). Tentative peak assignment of $\mathrm{Cr}^{\mathrm{III}} \mathrm{Cl}_{2}(\mathrm{pyz})_{2}$ (* denotes neutral pyrazine ligands) ${ }^{\dagger, \downarrow}, \S: 1607 \mathrm{~cm}^{-1}{ }_{-}$ 8a*; $1556 \mathrm{~cm}^{-1}-\mathbf{8 a} ; 1218 \mathrm{~cm}^{-1}-\mathbf{9 a *} ; 1187 \mathrm{~cm}^{-1}-\mathbf{9 a} ; 1031 \mathrm{~cm}^{-1}-\mathbf{1} * ; \sim 979 \mathrm{~cm}^{-1}-\mathbf{1}$ and/or $\mathbf{8 b} ; 673 \mathrm{~cm}^{-1}-\mathbf{6 b} * ; 638 \mathrm{~cm}^{-1}-\mathbf{4}, \mathbf{6 a}$ or $\mathbf{6 b} ; 260 \mathrm{~cm}^{-1}-$ sym $\mathrm{Cr}-\mathrm{Cl}$ stretching.

†a: sym. $\mathrm{C}=\mathrm{C}$ stretching; 8b: asym. $\mathrm{C}-\mathrm{N}$ stretching; 3: $\mathrm{C}-\mathrm{H}$ in-plane rocking; 9a: sym. C-H scissoring; 1: sym. C-H scissoring, in-plane ring-breathing; 6b: asym. in-plane ring-deformation; 4: C-H twisting, asym. out-of-plane ring-deformation; 6a: sym. in-plane ring-deformation.

$\$$ Detailed computational analysis of optimized geometries, vibrational frequencies and Raman activities of neutral and reduced pyrazine are shown in Table S2. The chosen method, PBE0/def2QZVP level, reproduces the experimental structure of neutral pyrazine with $0.01 \AA$ accuracy (Table S3) and the harmonic frequencies together with the Raman activities, which agree with previous theoretical studies (59). There is little information available for the Raman spectra of reduced pyrazine, however, Raman surface scattering at silver electrodes indicated that the reduction of pyrazine leads to low energy shift of all observed bands (60). Thus, in the experimental spectra of the parent compound, $\mathrm{Cr}^{\mathrm{III}} \mathrm{Cl}_{2}(\mathrm{pyz})_{2}$, the most intense peaks are assigned to neutral pyrazine (denoted with *), while the shoulders can tentatively be assigned to the reduced 
pyrazine in this mixed valence compound. In contrast, the well-defined peaks in $\mathbf{2 \cdot ( T H F ) ~ s t r o n g l y ~}$ suggest the presence of only reduced pyrazine, as expected for complete reduction of all pyrazine ligands.

The calculated vibrational frequency analysis given in Table S2 shows that the highest intensity peak at $1059 \mathrm{~cm}^{-1}(\mathbf{1}$, according to Wilson notation) is associated with the $5 y m$. C-H scissoring and ring breathing mode and predicted to shift to lower frequency by $54 \mathrm{~cm}^{-1}$ upon reduction. However, the band $\mathbf{8 b}$ that corresponds to asym. C-N stretching and in-plane ring deformation shifts by $600 \mathrm{~cm}^{-1}$ and almost overlaps with 1 when pyrazine is reduced. Moreover, 4 shifts by $\sim 100 \mathrm{~cm}^{-1}$ and gains significant intensity upon reduction. This computational analysis reflects the difficulty in assigning the experimental spectra of reduced pyrazine, which has been attributed to both the shift in the fundamental frequencies and to the changes in Raman activities of certain bands (60). $\S$ The band at $260 \mathrm{~cm}^{-1}$ in the $\mathrm{Cr}^{\mathrm{III}} \mathrm{Cl}_{2}(\mathrm{pyz})_{2}$ parent compound can be assigned to the symmetric $\mathrm{Cr}-\mathrm{Cl}$ stretching, as supported by harmonic frequency calculations of the gas phase optimized structure of $\left[\mathrm{CrCl}_{2}\left(\mathrm{pyz}_{4}\right]^{\circ}\left(\mathrm{B} 3 \mathrm{LYP} / \mathrm{def} 2-\mathrm{SVP}\right.\right.$, calculated value $\left.=263 \mathrm{~cm}^{-1}\right)$. 


\section{Table S2.}

Normal mode analysis and Raman activities computed for neutral and reduced pyrazine at PBE0/def2-QZVP level. The most active Raman bands observed in our experimental window (Fig. S7) are highlighted by a blue background.

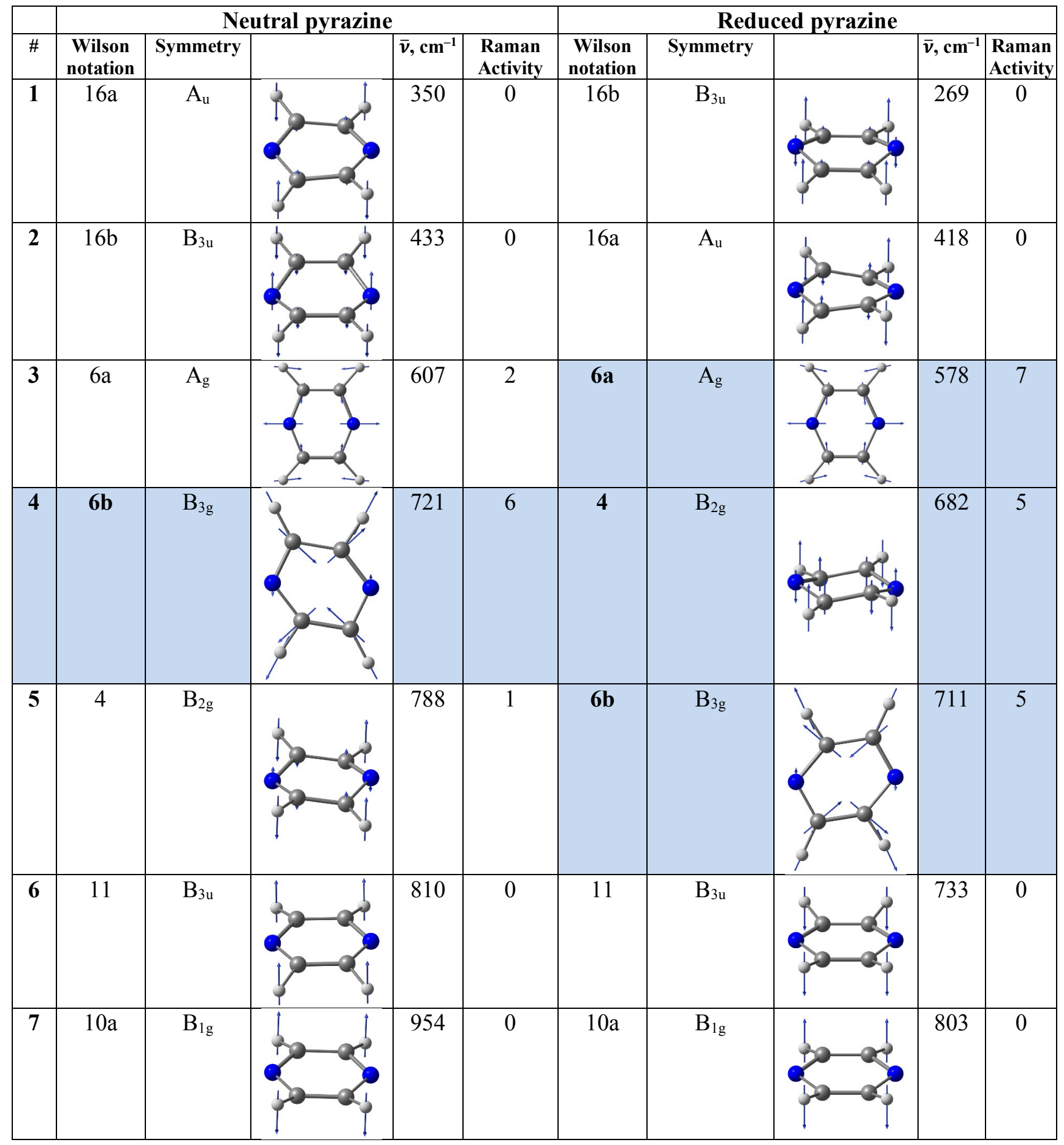




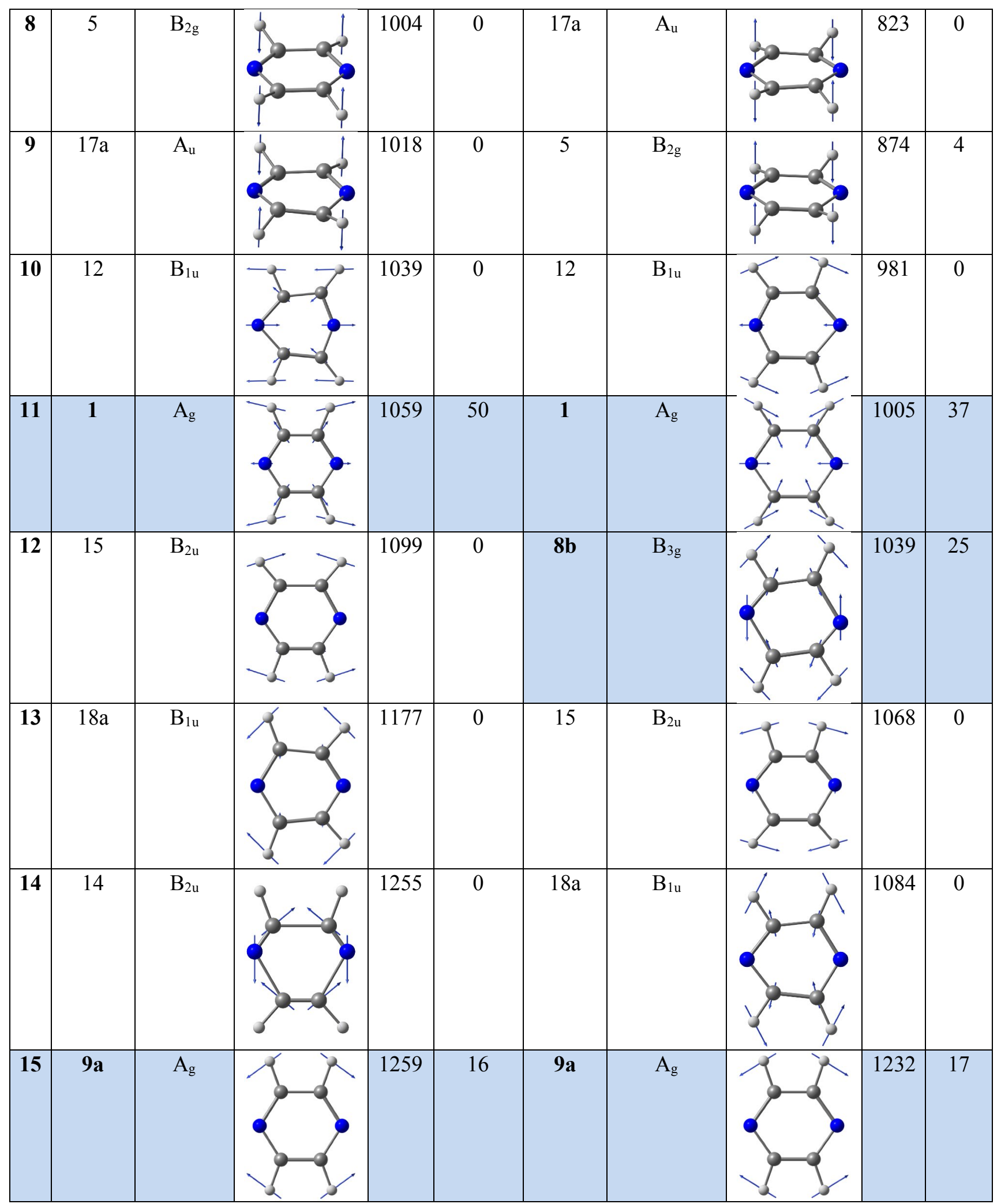




\begin{tabular}{|c|c|c|c|c|c|c|c|c|}
\hline 16 & 3 & $B_{3 g}$ & 1375 & 1 & $19 b$ & $\mathrm{~B}_{2 \mathrm{u}}$ & 1302 & 0 \\
\hline 17 & $19 b$ & $\mathrm{~B}_{2 \mathrm{u}}$ & 1451 & 0 & 3 & $\mathrm{~B}_{3 \mathrm{~g}}$ & 1365 & 7 \\
\hline 18 & $19 a$ & $\mathrm{~B}_{1 \mathrm{u}}$ & 1528 & 0 & $19 a$ & $\mathrm{~B}_{1 \mathrm{u}}$ & 1453 & 0 \\
\hline 19 & $8 b$ & $B_{3 g}$ & 1617 & 6 & 14 & $\mathrm{~B}_{2 \mathrm{u}}$ & 1475 & 0 \\
\hline 20 & $8 \mathbf{a}$ & $\mathrm{A}_{\mathrm{g}}$ & 1643 & 21 & $\mathbf{8 a}$ & $\widehat{A_{g}}$ & 1637 & 117 \\
\hline 21 & $7 b$ & $B_{3 g}$ & 3166 & 134 & $7 b$ & $B_{3 g}$ & 3080 & 202 \\
\hline 22 & 13 & $\mathrm{~B}_{1 \mathrm{u}}$ & 3167 & 0 & 13 & $\mathrm{~B}_{1 \mathrm{u}}$ & 3082 & 0 \\
\hline
\end{tabular}




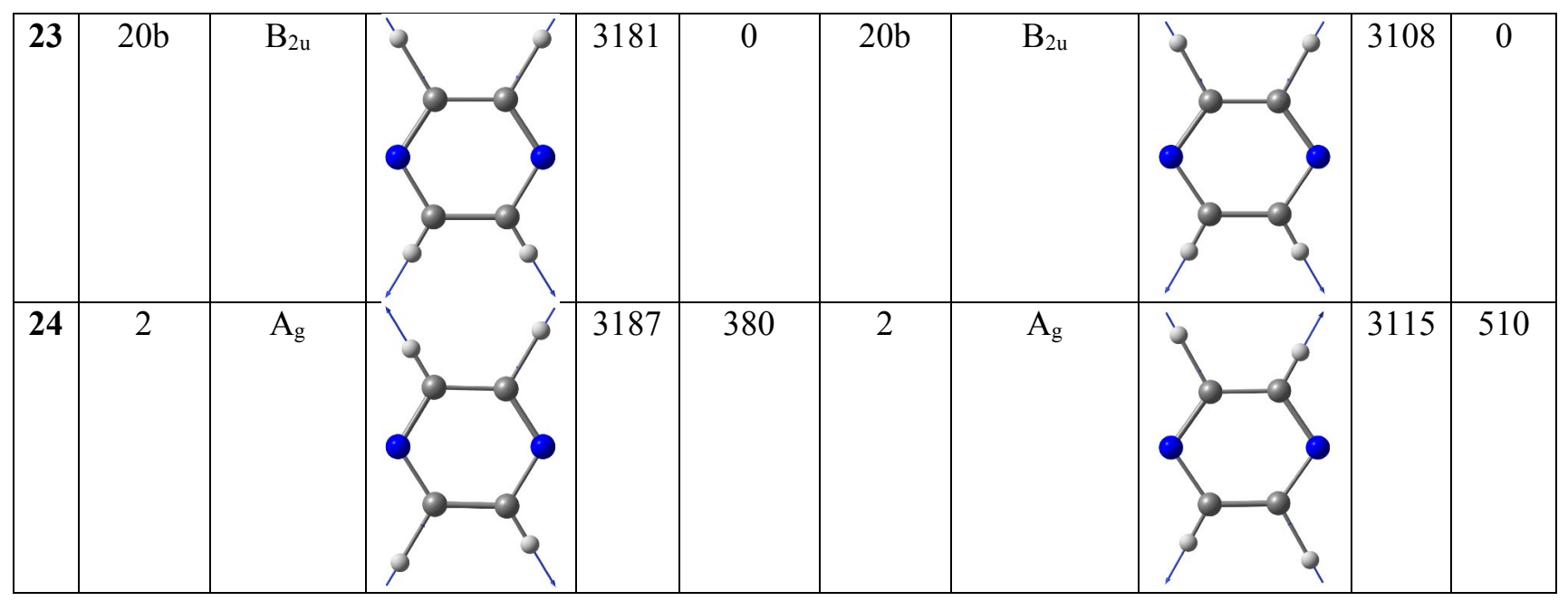




\section{Table S3.}

Computed harmonic frequencies $\left(\overline{\boldsymbol{v}}\right.$, in $\left.\mathrm{cm}^{-1}\right)$ and Raman activities of neutral and reduced pyrazine using PBE0 with different basis sets. It is worth noting that the relative intensities of Raman spectra are strongly basis set dependent. Nevertheless, Def2-QZVP is the largest basis set that should thus be considered as the best choice to describe experimental results. The red boxes without background indicated the regions of the experimental Raman spectra where bands are observed in Fig. S7.

\begin{tabular}{|c|c|c|c|c|c|c|c|c|c|c|c|c|c|c|c|c|c|c|c|}
\hline \multicolumn{4}{|c|}{ def2-QZVP } & \multicolumn{4}{|c|}{ def2-TZVP } & \multicolumn{4}{|c|}{ def2-SVP } & \multicolumn{4}{|c|}{ aug-cc-pVDZ } & \multicolumn{4}{|c|}{$6-31++G * *$} \\
\hline \multicolumn{2}{|c|}{ neutral } & \multicolumn{2}{|c|}{ reduced } & \multicolumn{2}{|c|}{ neutral } & \multicolumn{2}{|c|}{ reduced } & \multicolumn{2}{|c|}{ neutral } & \multicolumn{2}{|c|}{ reduced } & \multicolumn{2}{|c|}{ neutral } & \multicolumn{2}{|c|}{ reduced } & \multicolumn{2}{|c|}{ neutral } & \multicolumn{2}{|c|}{ reduced } \\
\hline $\bar{v}$ & Activity & $\overline{\boldsymbol{v}}$ & Activity & $\bar{v}$ & Activity & $\bar{v}$ & Activity & $\overline{\boldsymbol{v}}$ & Activity & $\overline{\boldsymbol{v}}$ & Activity & $\overline{\boldsymbol{v}}$ & Activity & $\bar{v}$ & Activity & $\bar{v}$ & Activity & $\overline{\boldsymbol{v}}$ & Activity \\
\hline 350 & 0 & 269 & 0 & 350 & 0 & 280 & 0 & 351 & 0 & 296 & 0 & 349 & 0 & 226 & 1 & 348 & 0 & 230 & 0 \\
\hline 433 & 0 & 418 & 0 & 433 & 0 & 421 & 0 & 441 & 0 & 419 & 0 & 430 & 0 & 423 & 0 & 431 & 0 & 407 & 0 \\
\hline 607 & 2 & 578 & 7 & 607 & 3 & 578 & 4 & 603 & 3 & 577 & 4 & 604 & 2 & 574 & 1122 & 605 & 3 & 575 & 425 \\
\hline 721 & 6 & 682 & 5 & 721 & 6 & 678 & 2 & 727 & 7 & 672 & 3 & 717 & 5 & 675 & 1 & 721 & 7 & 664 & 0 \\
\hline 788 & 1 & 711 & 5 & 788 & 0 & 711 & 6 & 791 & 1 & 720 & 6 & 779 & 0 & 706 & 9 & 775 & 1 & 711 & 10 \\
\hline 810 & 0 & 733 & 0 & 809 & 0 & 731 & 0 & 810 & 0 & 746 & 0 & 805 & 0 & 729 & 0 & 807 & 0 & 732 & 0 \\
\hline 954 & 0 & 803 & 0 & 955 & 0 & 813 & 1 & 953 & 2 & 832 & 10 & 947 & 0 & 819 & 40 & 949 & 0 & 819 & 109 \\
\hline 1004 & 0 & 823 & 0 & 1000 & 0 & 857 & 0 & 1006 & 0 & 908 & 0 & 983 & 0 & 890 & 0 & 988 & 0 & 884 & 0 \\
\hline 1018 & 0 & 874 & 4 & 1015 & 0 & 871 & 0 & 1017 & 0 & 918 & 0 & 1004 & 0 & 910 & 0 & 999 & 0 & 889 & 9 \\
\hline 1039 & 0 & 981 & 0 & 1039 & 0 & 979 & 0 & 1036 & 0 & 983 & 12 & 1034 & 0 & 985 & 0 & 1036 & 0 & 986 & 0 \\
\hline 1059 & 50 & 1005 & 37 & 1060 & 47 & 1006 & 40 & 1067 & 37 & 986 & 0 & 1057 & 56 & 1003 & 3554 & 1059 & 50 & 1004 & 1135 \\
\hline 1099 & 0 & 1039 & 25 & 1099 & 0 & 1026 & 12 & 1101 & 0 & 1018 & 34 & 1097 & 0 & 1066 & 157 & 1102 & 0 & 1050 & 187 \\
\hline 1177 & 0 & 1068 & 0 & 1178 & 0 & 1067 & 0 & 1178 & 0 & 1076 & 0 & 1172 & 0 & 1069 & 0 & 1179 & 0 & 1074 & 0 \\
\hline 1255 & 0 & 1084 & 0 & 1259 & 16 & 1085 & 0 & 1253 & 21 & 1085 & 0 & 1253 & 17 & 1078 & 0 & 1264 & 17 & 1083 & 0 \\
\hline 1259 & 16 & 1232 & 17 & 1259 & 0 & 1234 & 21 & 1305 & 0 & 1231 & 31 & 1279 & 0 & 1225 & 3044 & 1281 & 0 & 1238 & 1036 \\
\hline 1375 & 1 & 1302 & 0 & 1374 & 1 & 1303 & 0 & 1363 & 1 & 1327 & 0 & 1362 & 1 & 1307 & 0 & 1375 & 2 & 1319 & 0 \\
\hline 1451 & 0 & 1365 & 7 & 1451 & 0 & 1365 & 6 & 1456 & 0 & 1355 & 6 & 1444 & 0 & 1356 & 19 & 1454 & 0 & 1369 & 23 \\
\hline 1528 & 0 & 1453 & 0 & 1527 & 0 & 1454 & 0 & 1528 & 0 & 1450 & 0 & 1518 & 0 & 1444 & 0 & 1529 & 0 & 1457 & 0 \\
\hline 1617 & 6 & 1475 & 0 & 1618 & 6 & 1482 & 0 & 1649 & 7 & 1513 & 0 & 1623 & 7 & 1475 & 0 & 1628 & 7 & 1481 & 0 \\
\hline 1643 & 21 & 1637 & 117 & 1645 & 19 & 1646 & 44 & 1663 & 18 & 1674 & 28 & 1651 & 23 & 1630 & 19450 & 1653 & 23 & 1633 & 8025 \\
\hline 3166 & 134 & 3080 & 202 & 3168 & 137 & 3077 & 207 & 3180 & 149 & 3068 & 227 & 3183 & 135 & 3102 & 167 & 3197 & 142 & 3109 & 172 \\
\hline 3167 & 0 & 3082 & 0 & 3169 & 0 & 3079 & 0 & 3181 & 0 & 3071 & 1 & 3184 & 0 & 3103 & 0 & 3198 & 0 & 3111 & 0 \\
\hline 3181 & 0 & 3108 & 0 & 3184 & 0 & 3106 & 0 & 3194 & 0 & 3096 & 0 & 3199 & 0 & 3129 & 0 & 3212 & 0 & 3137 & 0 \\
\hline 3187 & 380 & 3115 & 510 & 3190 & 371 & 3113 & 523 & 3201 & 383 & 3107 & 537 & 3204 & 389 & 3135 & 2296 & 3217 & 391 & 3143 & 1250 \\
\hline
\end{tabular}




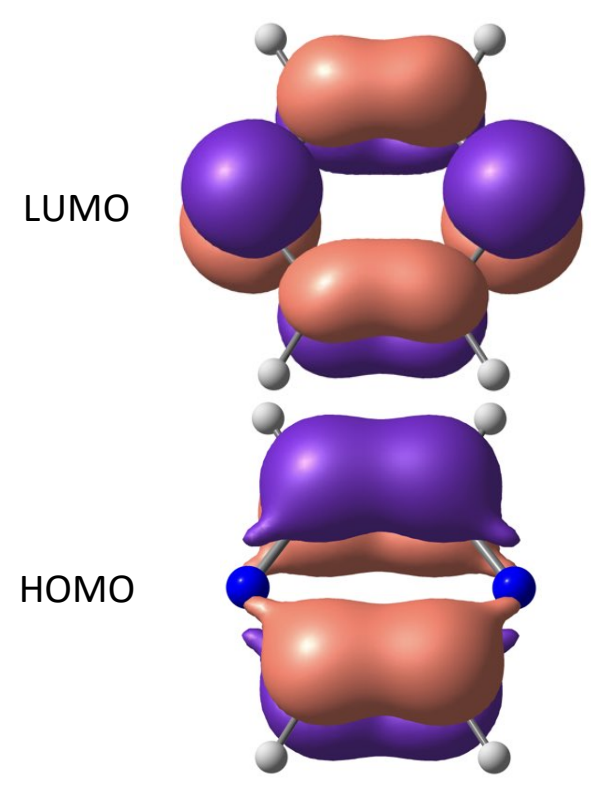

Fig. S8.

Highest occupied molecular orbital (HOMO) and lowest unoccupied molecular orbital (LUMO) of a neutral pyrazine molecule. The LUMO orbital features bonding $\mathrm{C}-\mathrm{C}$ and antibonding $\mathrm{C}-\mathrm{N}$ interactions, leading to shortening of the former and lengthening of the latter upon reduction (Table S4). 


\section{Table S4.}

Bonds lengths $(\AA)$ for DFT-optimized structures of neutral and reduced pyrazines.

\begin{tabular}{|l|l|l|l|l|l|l|l|l|l|l|l|l|}
\cline { 2 - 12 } \multicolumn{1}{c|}{} & Experiment & \multicolumn{2}{c|}{ PBE0/def2-QZVP } & \multicolumn{2}{c|}{ PBE0/def2-TZVP } & \multicolumn{2}{c|}{ PBE0/def2-SVP } & \multicolumn{3}{c|}{ PBE0/aug-cc-pVDZ } & \multicolumn{2}{|c|}{ PBE0/6-31++G** } \\
\cline { 2 - 14 } \multicolumn{1}{c|}{} & neutral (59) & neutral & reduced & neutral & reduced & neutral & reduced & neutral & reduced & neutral & reduced \\
\hline N-C & $1.3376(13)$ & 1.326 & 1.369 & 1.327 & 1.370 & 1.329 & 1.372 & 1.333 & 1.373 & 1.333 & 1.373 \\
\hline C-C & $1.3968(37)$ & 1.388 & 1.368 & 1.389 & 1.368 & 1.397 & 1.376 & 1.396 & 1.378 & 1.395 & 1.377 \\
\hline C-H & $1.0831(37)$ & 1.085 & 1.090 & 1.086 & 1.092 & 1.096 & 1.103 & 1.092 & 1.097 & 1.088 & 1.093 \\
\hline
\end{tabular}




\section{Table S5.}

Gas phase optimized (B3LYP/def2-TZVP) molecular fragments of $\left[\mathrm{CrCl}_{2}(\mathrm{pyz})_{4}\right]^{-q}$, $\left[\mathrm{CrCl}(\mathrm{pyz})_{4}\right]^{1-q},\left[\mathrm{Cr}(\mathrm{pyz})_{4}\right]^{2-q}$ where $q=0,1,2,3$ and 4 . The highest point group symmetry (with $R<0.01$ ) and Mulliken spin population on the $\mathrm{Cr}$ site (in parentheses) are shown above each structure (Mulliken spin population values close to 3 and 4 correspond to $\mathrm{Cr}^{\mathrm{III}}$ and $\mathrm{Cr}^{\mathrm{III}}$, respectively). The bond lengths in the first coordination sphere are shown in $\AA$.

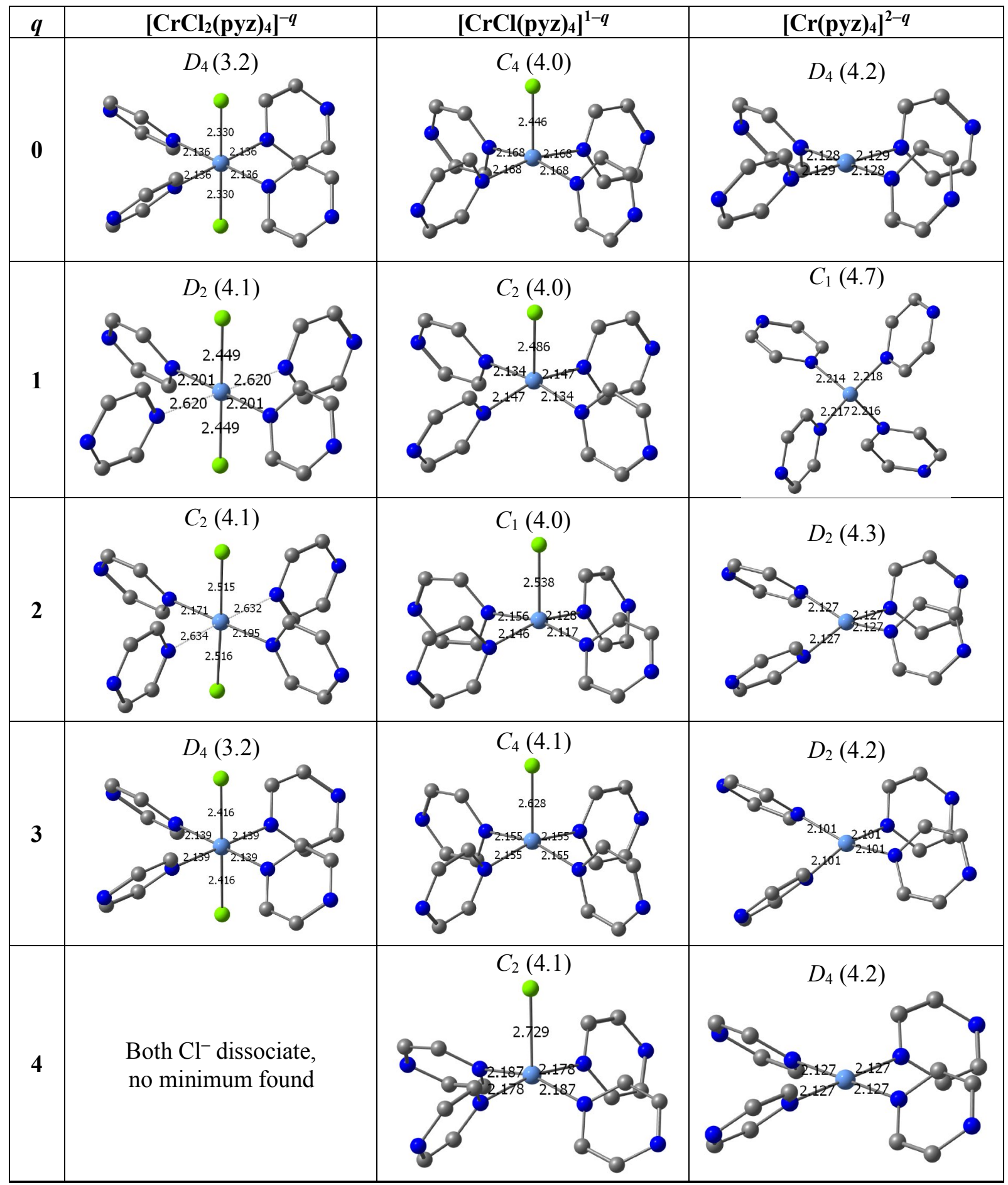




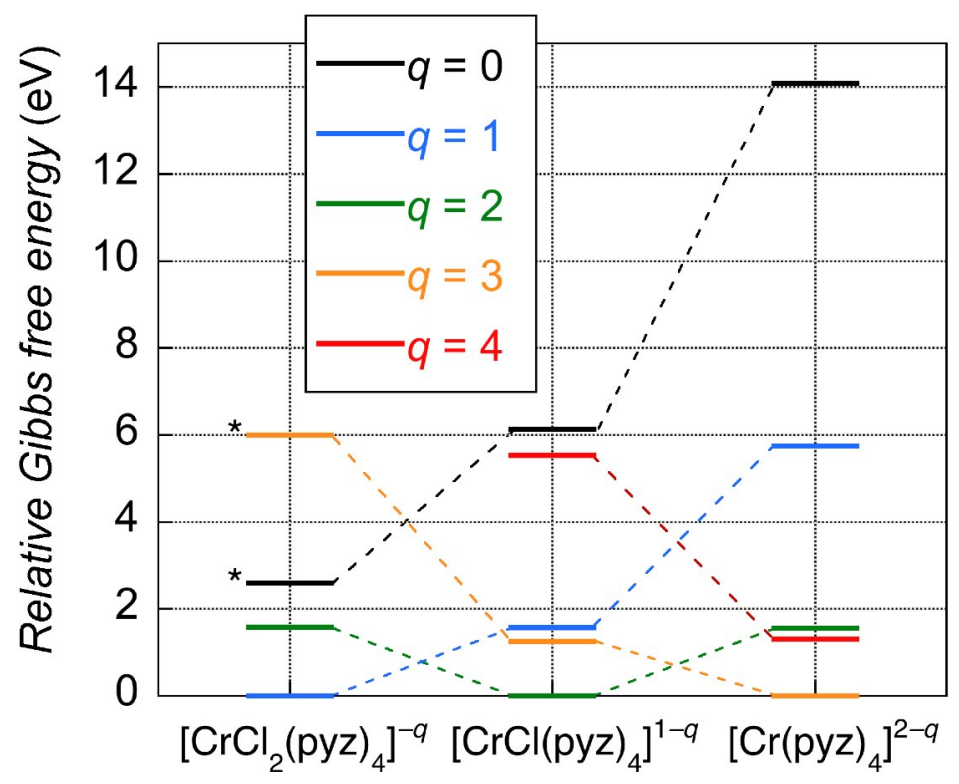

\section{Fig. S9.}

Calculated gas phase (B3LYP/def2-TZVP) relative Gibbs free energy (in eV) of molecular fragments of $\left[\mathrm{CrCl}_{2}(\mathrm{pyz})_{4}\right]^{-q},\left[\mathrm{CrCl}(\mathrm{pyz})_{4}\right]^{1-q}$ and $\left[\mathrm{Cr}(\mathrm{pyz})_{4}\right]^{2-q}$ where $q=0,1,2,3$ and 4 is the number of added electrons. The ${ }^{*}$ symbols indicate the states with a $\mathrm{Cr}^{\mathrm{III}}$ metal ion, while others possess a $\mathrm{Cr}^{\mathrm{II}}$ center as illustrated by the fragment structures given in Table S5. These calculations establish that reduction of the pyrazine ligands is more favorable and facilitated by the complete dissociation of the chloride ligands, as indicated by the relative stability of $\left[\mathrm{Cr}(\mathrm{pyz})_{4}\right]^{2-q}$ where $q$ $=3$ or 4 , compared to $\left[\mathrm{CrCl}(\mathrm{pyz})_{4}\right]^{1-q}$ and $\left[\mathrm{CrCl}_{2}(\mathrm{pyz})_{4}\right]^{-q}$ derivatives. 


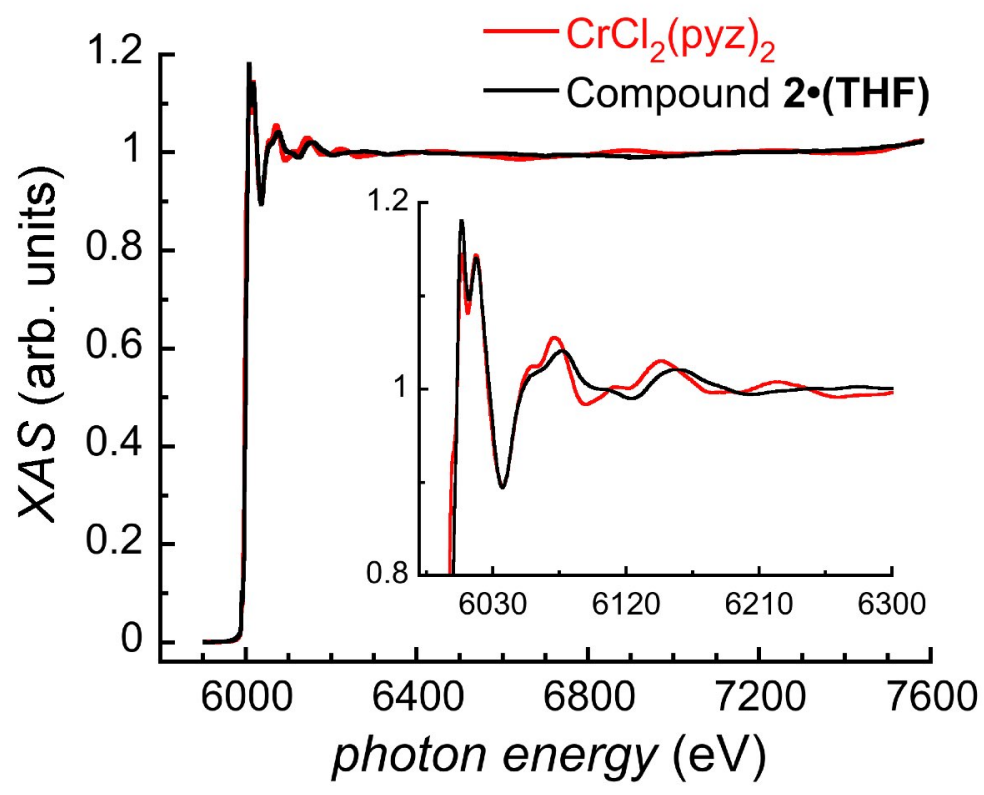

Fig. S10.

Normalized XAS spectra at the $\mathrm{Cr} K$-edge for $\mathbf{2}$ (THF) (black line) and $\mathrm{CrCl}_{2}$ (pyz) 2 (red line), at $295 \mathrm{~K}$. Inset: zoom in the EXAFS region of the spectra. 


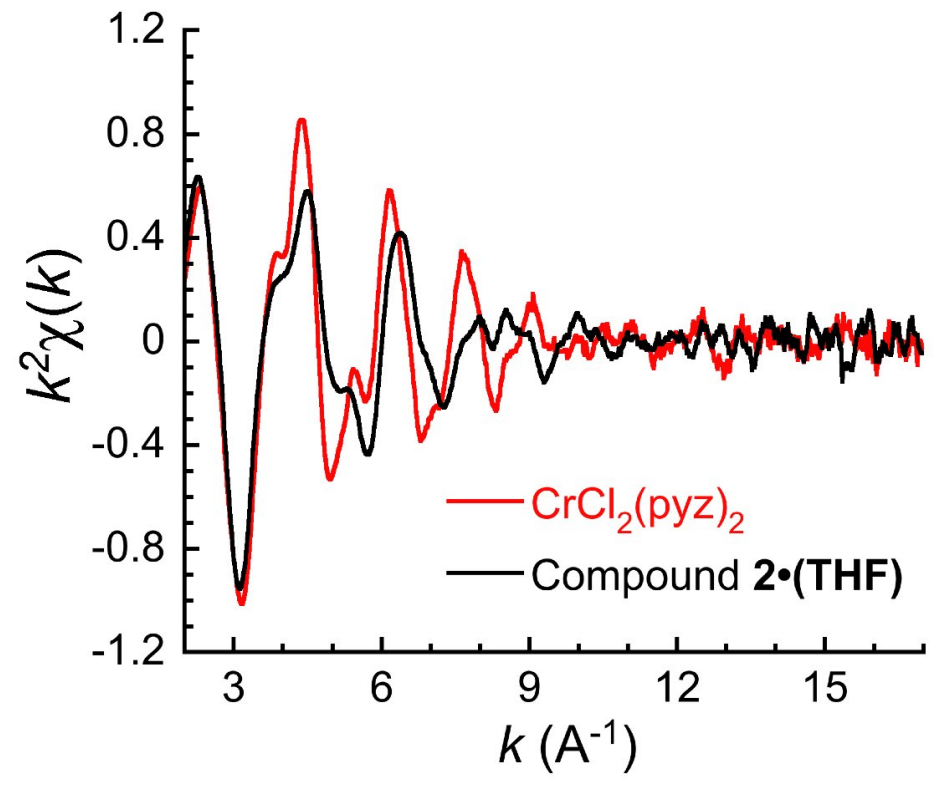

Fig. S11.

$k^{2}$-weighted EXAFS spectra at the $\mathrm{Cr} K$-edge for compound $\mathbf{2} \cdot(\mathbf{T H F})$ (black line) and $\mathrm{CrCl}_{2}(\mathrm{pyz})_{2}$ (red line) at $295 \mathrm{~K}$. 


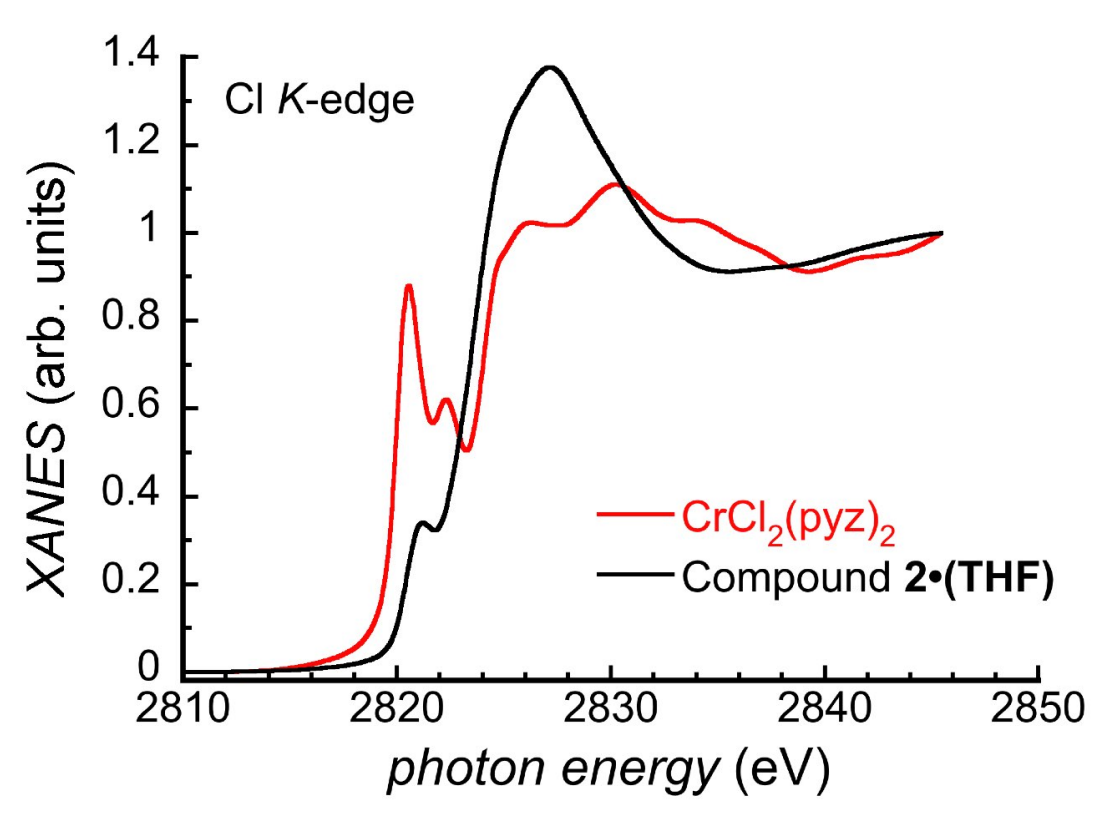

Fig. S12.

Normalized XANES spectra at the $\mathrm{Cl} K$-edge of $\mathbf{2} \cdot(\mathbf{T H F})^{\dagger}$ (black line) and $\mathrm{CrCl}_{2}$ (pyz) 2 (red line) recorded at $295 \mathrm{~K}$.

${ }^{\dagger}$ Considering the raw XANES spectra at the $\mathrm{Cl} K$-edge of $\mathbf{2} \cdot(\mathbf{T H F})$ and $\mathrm{CrCl}_{2}(\text { pyz) })_{2}$ measured in the exact same experimental conditions (including the same sample holder) with only a few minutes of intervals, it is possible to evaluate at about 0.74 , the respective amount of chloride per chromium in $\mathbf{2}$ (THF) knowing that two chlorides are present in $\mathrm{CrCl}_{2}$ (pyz) 2 (see below the calculations for two sets of measurements on two different $\mathbf{2}$ (THF) samples).

First set of measurements:

\begin{tabular}{|c|c|c|c|c|c|}
\hline Compounds & $\begin{array}{c}\text { Intensity at } \\
2810.7 \mathrm{eV}\end{array}$ & $\begin{array}{c}\text { Intensity at } \\
2845.8 \mathrm{eV}\end{array}$ & Difference & Average & $\mathrm{Cl}$ amount in $2 \cdot(\mathrm{THF})$ \\
\hline $\mathrm{CrCl}_{2}(\mathrm{pyz})_{2}$ & 0.3614 & 2.6256 & 2.2642 & \multirow{2}{*}{2.2664} & \multirow{4}{*}{0.75 per $\mathrm{Cr}$} \\
\hline $\mathrm{CrCl}_{2}(\mathrm{pyz})_{2}$ & 0.3507 & 2.6194 & 2.2687 & & \\
\hline $\begin{array}{l}2 \cdot(\mathrm{THF}) \\
\text { sample } 1 \\
\end{array}$ & 0.4191 & 1.2427 & 0.8236 & \multirow{2}{*}{0.8482} & \\
\hline $\begin{array}{l}2 \cdot(\mathrm{THF}) \\
\text { sample } 1 \\
\end{array}$ & 0.3666 & 1.2394 & 0.8728 & & \\
\hline
\end{tabular}

Second set of measurements:

\begin{tabular}{|c|c|c|c|c|c|}
\hline Compounds & $\begin{array}{c}\text { Intensity at } \\
2810.7 \mathrm{eV}\end{array}$ & $\begin{array}{c}\text { Intensity at } \\
2845.8 \mathrm{eV}\end{array}$ & Difference & Average & Cl amount in $2 \cdot($ THF $)$ \\
\hline $\mathrm{CrCl}_{2}(\mathrm{pyz})_{2}$ & 0.2181 & 1.9202 & 1.7021 & \multirow{2}{*}{1.7036} & \multirow{4}{*}{0.73 per $\mathrm{Cr}$} \\
\hline $\mathrm{CrCl}_{2}(\mathrm{pyz})_{2}$ & 0.2169 & 1.9220 & 1.7051 & & \\
\hline $\begin{array}{l}\cdot(\text { THF }) \\
\text { sample } 2\end{array}$ & 0.2450 & 0.8698 & 0.6248 & \multirow{2}{*}{0.6245} & \\
\hline $\begin{array}{l}2 \cdot(\text { THF }) \\
\text { sample } 2\end{array}$ & 0.2447 & 0.8689 & 0.6242 & & \\
\hline
\end{tabular}




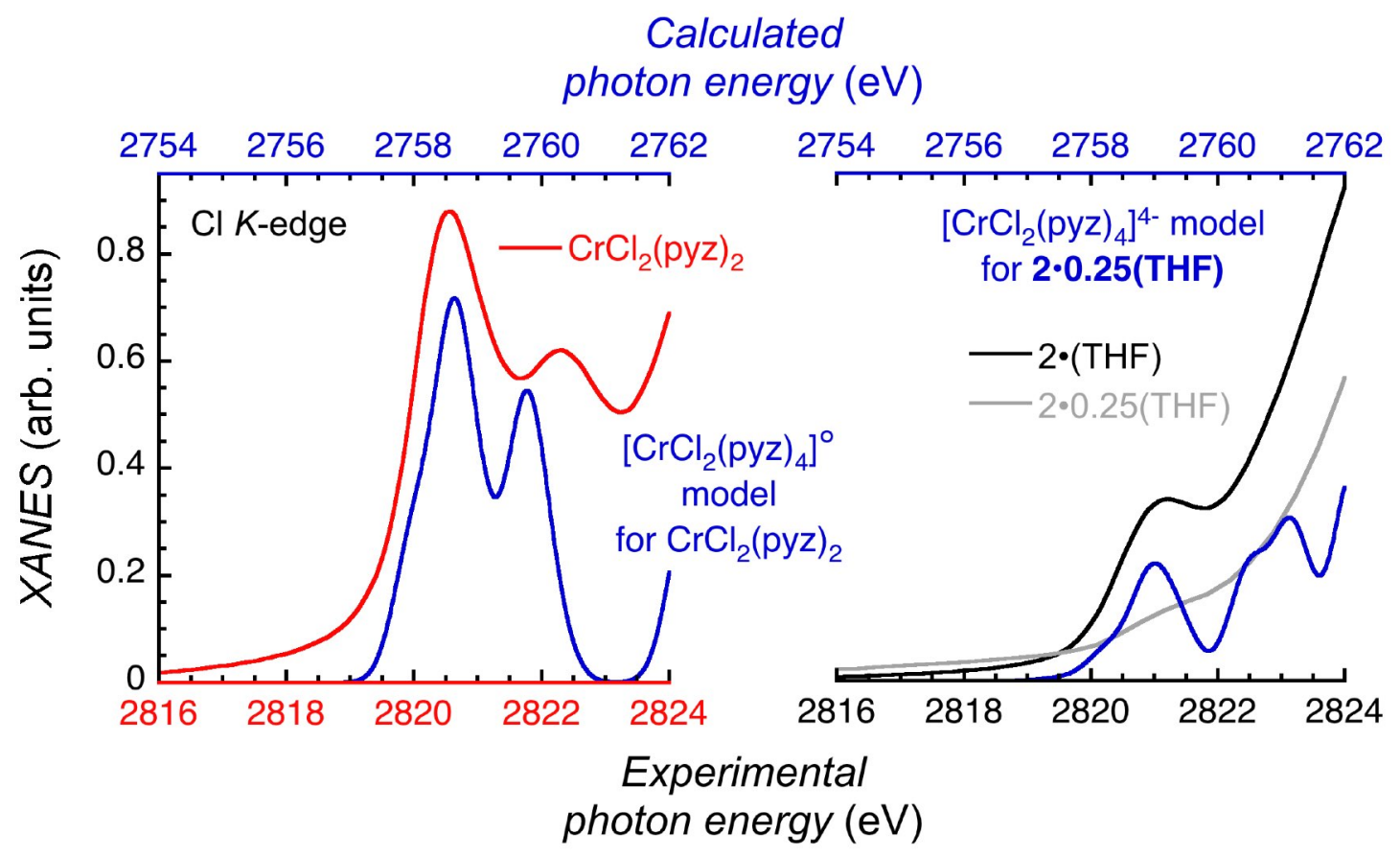

\section{Fig. S13.}

Calculated (BP86/def2-TZVP/ZORA, linewidth of $0.7 \mathrm{eV}$ ) XANES spectra at the $\mathrm{Cl} K$-edge (excitations from $\mathrm{Cl} 1 \mathrm{~s}$ orbital) of the molecular fragments (i) $\left[\mathrm{CrCl}_{2}(\mathrm{pyz})_{4}\right]^{4-}$ taken from structural model of $\mathbf{2} \cdot \mathbf{0 . 2 5}$ (THF) (Fig. $3 ; d_{\mathrm{Cr} \cdots \mathrm{Cl}}=3.598 \AA$, blue trace on the right plot) and (ii) $\left[\mathrm{CrCl}_{2}(\mathrm{pyz})_{4}\right]^{\circ}$ taken from X-ray structure of $\mathrm{CrCl}_{2}(\mathrm{pyz})_{2}\left(d_{\mathrm{Cr}-\mathrm{Cl}}=2.337 \AA\right.$, blue trace on the left plot, 22). For comparison, the pre- and rising $\mathrm{Cl} K$-edge regions of the normalized experimental XANES spectra for 2.(THF) (black trace), for $\mathbf{2 \cdot 0 . 2 5}$ (THF) (grey trace) and $\mathrm{CrCl}_{2}(\text { pyz) })_{2}$ (red trace) are shown at $295 \mathrm{~K}$. The calculated spectra (top $x$-axis; blue traces) are shifted by $61.9 \mathrm{eV}$ from the experimental ones, but the energy shift and loss of intensity associated with $\mathrm{Cl}$ dissociation and change of $\mathrm{Cr}$ oxidation state are well reproduced. The energy difference between two peaks in $\mathrm{CrCl}_{2}(\mathrm{pyz})_{2}$ XANES $(1.8 \mathrm{eV})$ agrees well with the calculated ligand field splitting of $t_{2} g$ and $e_{g}$ orbitals (Fig. $\mathrm{S} 40,2 \mathrm{eV}$ ). Due to $\mathrm{Cl}$ decoordination in $\mathbf{2} \cdot \mathbf{0 . 2 5}$ (THF), the calculated gap between barycenter of $t_{2} g$ and $e g$ orbitals is reduced to $1.4 \mathrm{eV}$ (Fig. S40), which is smaller than the experimental linewidth of the near edge spectra of $\mathbf{2} \cdot \mathbf{0 . 2 5}$ (THF) and $\mathbf{2} \cdot$ (THF). 


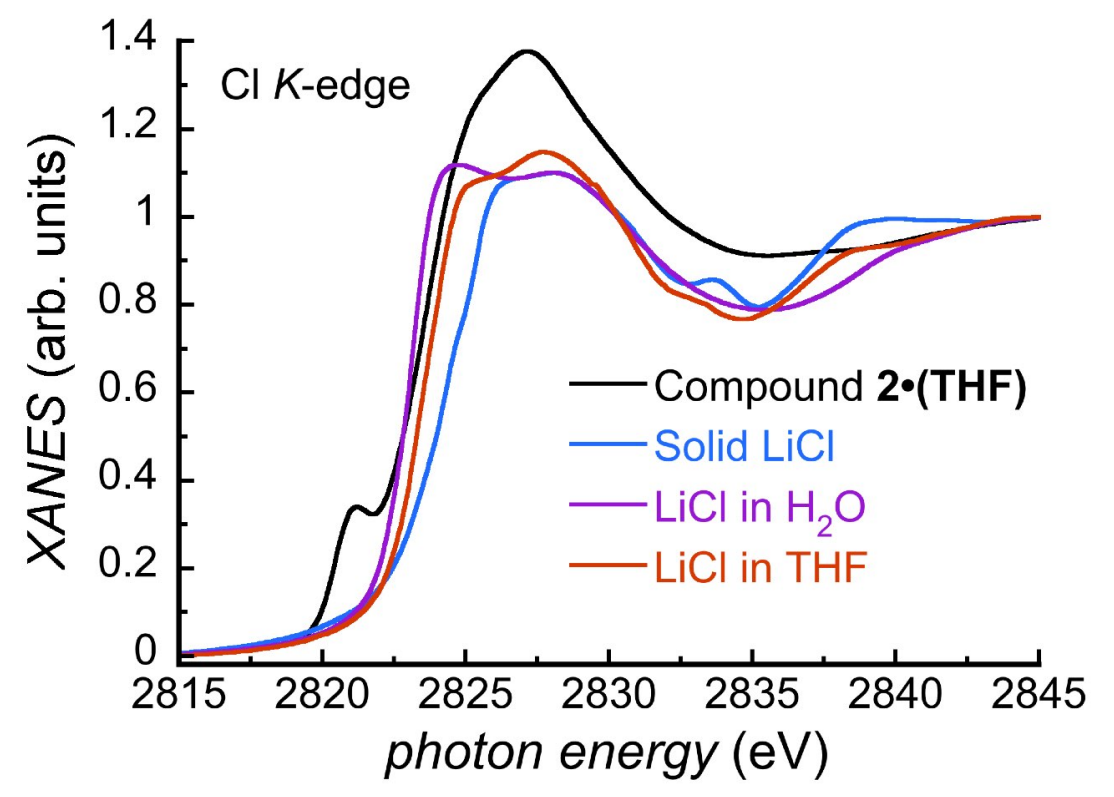

Fig. S14.

Normalized XANES spectra at the $\mathrm{Cl} K$-edge of $\mathbf{2}$ (THF) (black line) and $\mathrm{LiCl}$ in its solid form (blue line) and in aqueous (purple line) and THF (red line) solutions recorded at $295 \mathrm{~K}$. 


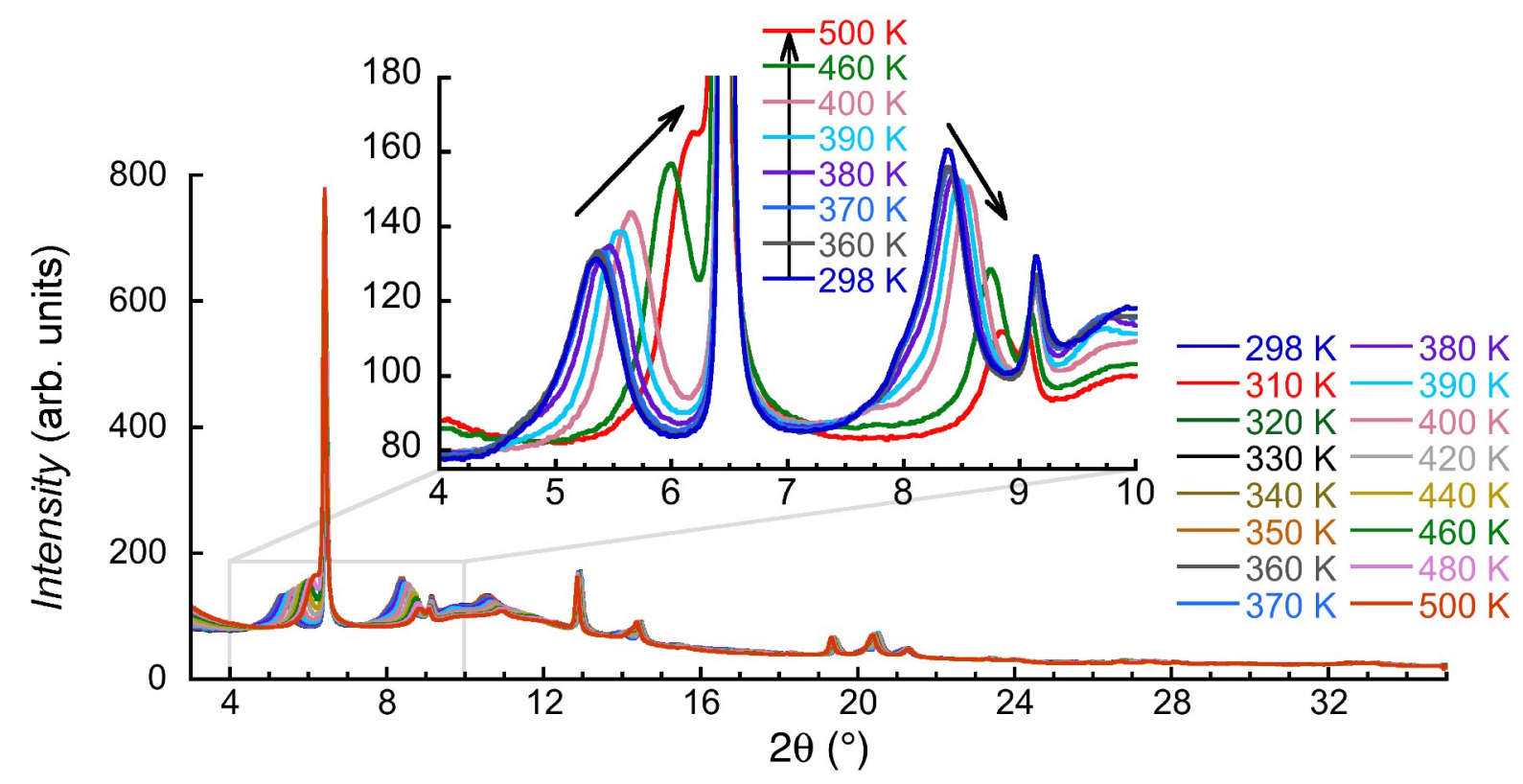

Fig. S15.

Temperature dependence of the synchrotron powder X-ray diffraction patterns of $\mathbf{2} \cdot(\mathbf{T H F})$, collected between 298 and $500 \mathrm{~K}$ with a heating rate of $6 \mathrm{~K} \mathrm{~min}^{-1}(\lambda=0.7829 \AA)$ Inset: Zoom of the low-angle region $\left(4-10^{\circ}\right)$ for selected temperatures highlighting the diffraction shifts at the structural change above $380 \mathrm{~K}$ linked to the THF loss (see main text). 


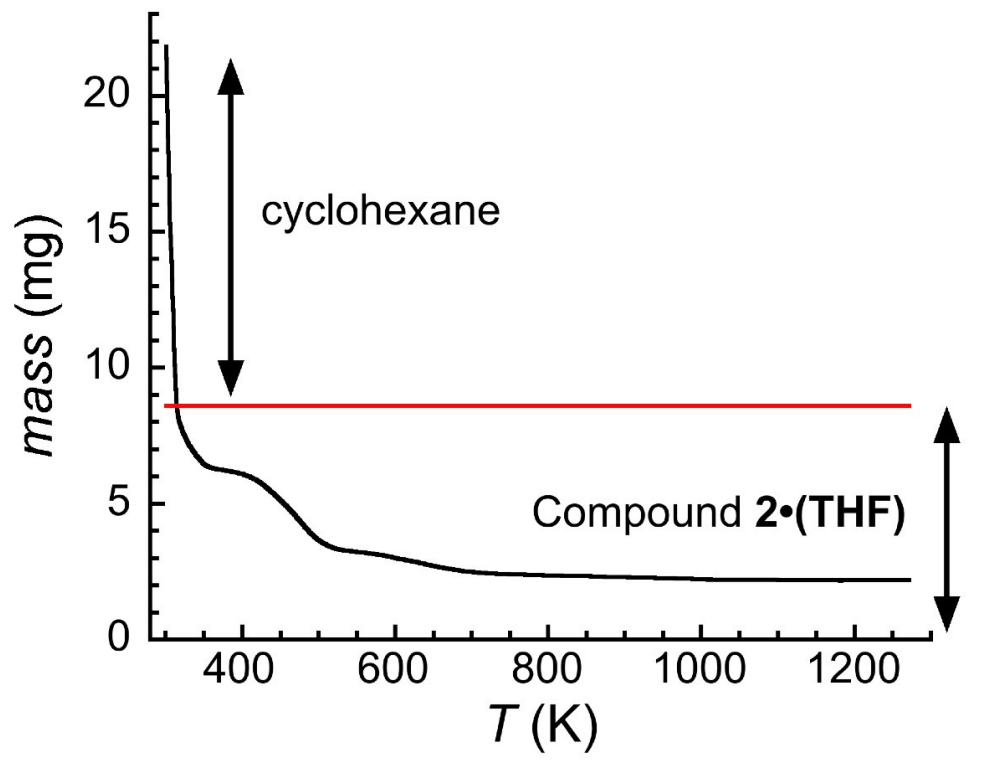

\section{Fig. S16.}

Thermogravimetric analysis (TGA) of 2.(THF) under a flow of argon at a 5-K $\mathrm{min}^{-1}$ heating rate. The initial mass drop corresponds to cyclohexane $(14.13 \mathrm{mg})$ that was used to protect the sample $(8.6 \mathrm{mg})$. Note that even though the initial mass was of $22.73 \mathrm{mg}, 0.946 \mathrm{mg}$ of cyclohexane evaporated during the furnace closing and temperature stabilization. Therefore, the initial mass in the TGA spectra is of $21.784 \mathrm{mg}$, which was obtained at $301.15 \mathrm{~K}$. 


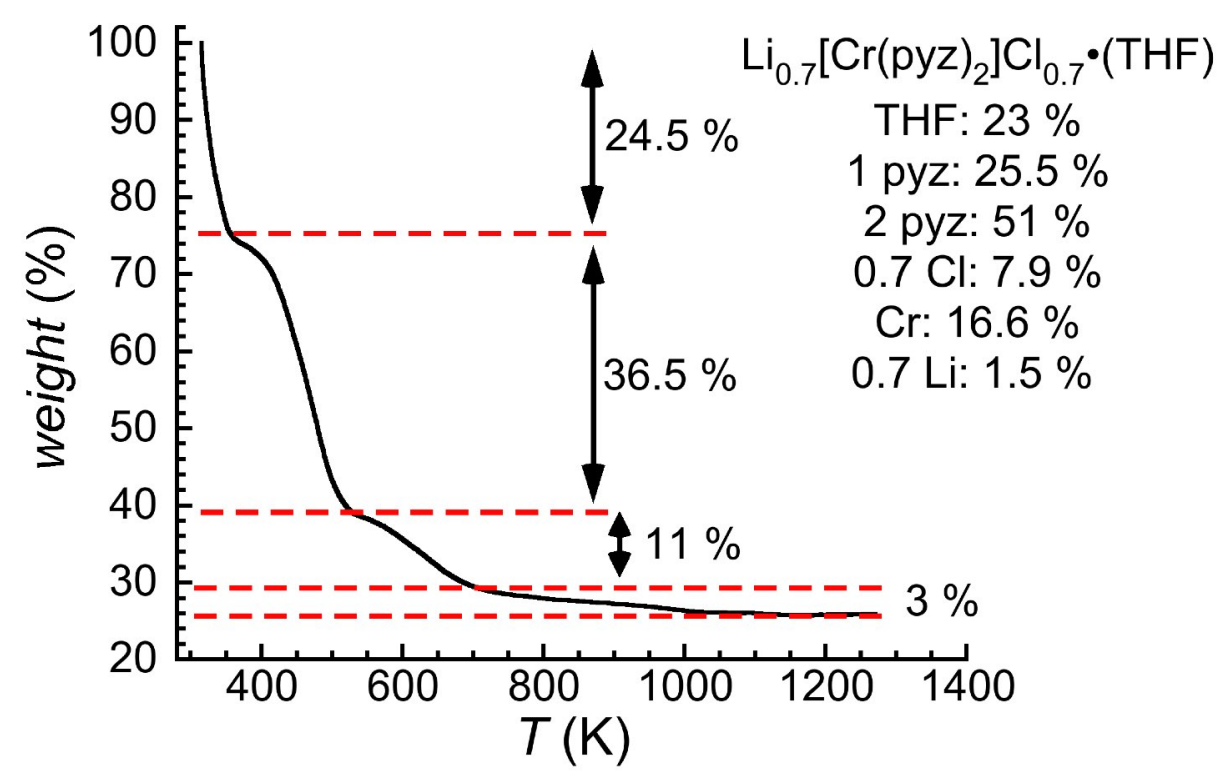

\section{Fig. S17.}

Thermogravimetric analysis (TGA) of $\mathbf{2}$ (THF) derived from Fig. S16 after removing the mass corresponding to cyclohexane (at $5 \mathrm{~K} \mathrm{~min}^{-1}$ ). Expected weight percentages for $\mathrm{Li}_{0.7}\left[\mathrm{Cr}(\text { pyz) })_{2}\right] \mathrm{Cl}_{0.7} \cdot$ (THF): 1 THF, $23.0 \%$; 1 pyz, $25.5 \%$; 2 pyz, $51 \%$; 0.7 Cl, $7.9 \%$; Cr, $16.6 \%$; $0.7 \mathrm{Li}, 1.5 \%$. Thermogravimetric analysis - mass spectrometry (TGA-MS) measurements (Fig. S18-S21) indicate that (a) the $1^{\text {st }}$ step between $300-355 \mathrm{~K}(24.5 \%)$ corresponds to the loss of almost one THF, (b) the $2^{\text {nd }}(355-520 \mathrm{~K}, 36.5 \%)$ and the $3^{\text {rd }}(520-700 \mathrm{~K}, 11 \%)$ steps originate the loss of pyrazine ligands and/or decomposition products of pyrazine, in addition to some residual THF that was not evaporated in the $1^{\text {st }}$ step, (c) the $4^{\text {th }}$ (above $\sim 700 \mathrm{~K}, 3 \%$ ) step is due to a partial loss of chloride. The residual weight percentage (25\%) agrees with the sum expected for lithium, chromium, and the remaining chloride amount $(23 \%)$. The premature decomposition of the compound below $520 \mathrm{~K}$ can be ascribed to the way of preparing and heating the sample in the TGA experiment, as the material is clearly stable at least up to $520 \mathrm{~K}$ when heated in closed containers (under argon or dinitrogen), as confirmed by powder X-ray diffraction (Fig. S15) and magnetic (Fig. 4) measurements. 


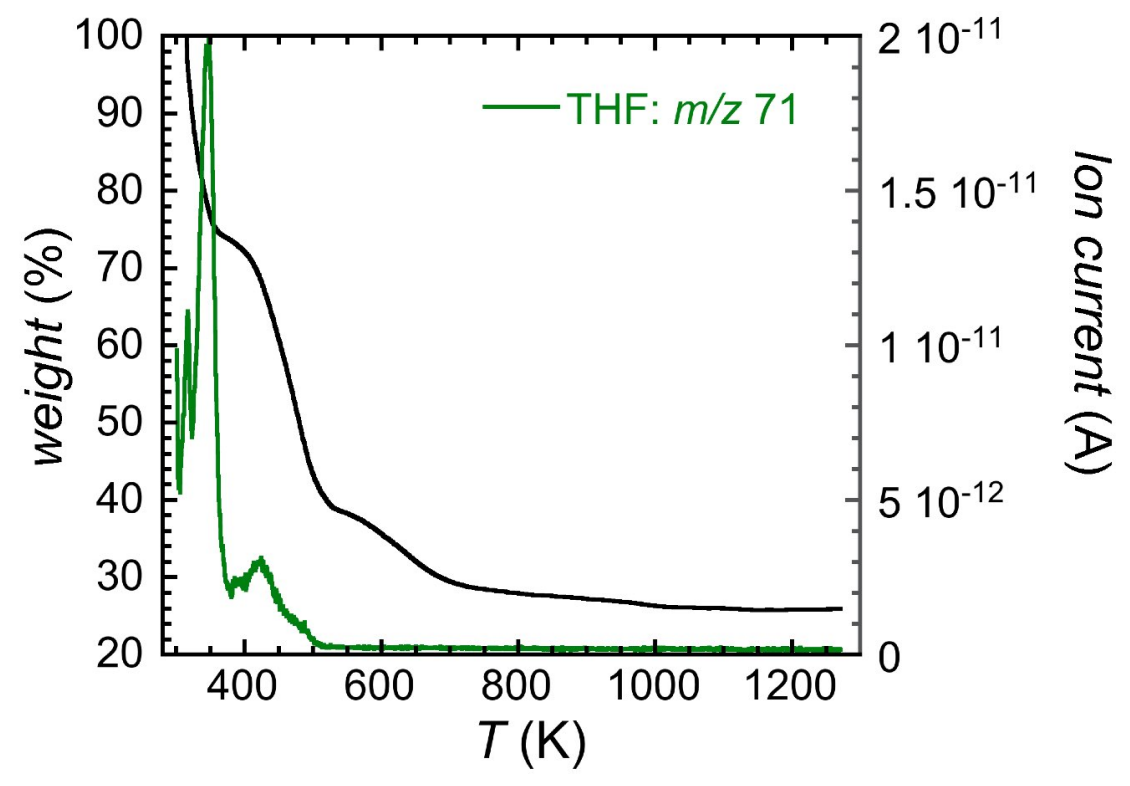

Fig. S18.

TGA-MS thermogram showing the weight loss in $\mathbf{2} \cdot$ (THF) (black line; at $5 \mathrm{~K} \mathrm{~min}^{-1}$ ) highlighting the THF loss and the corresponding ion current at $m / z=71\left(\mathrm{C}_{4} \mathrm{H}_{7} \mathrm{O}^{+}\right.$fragment, green line). 


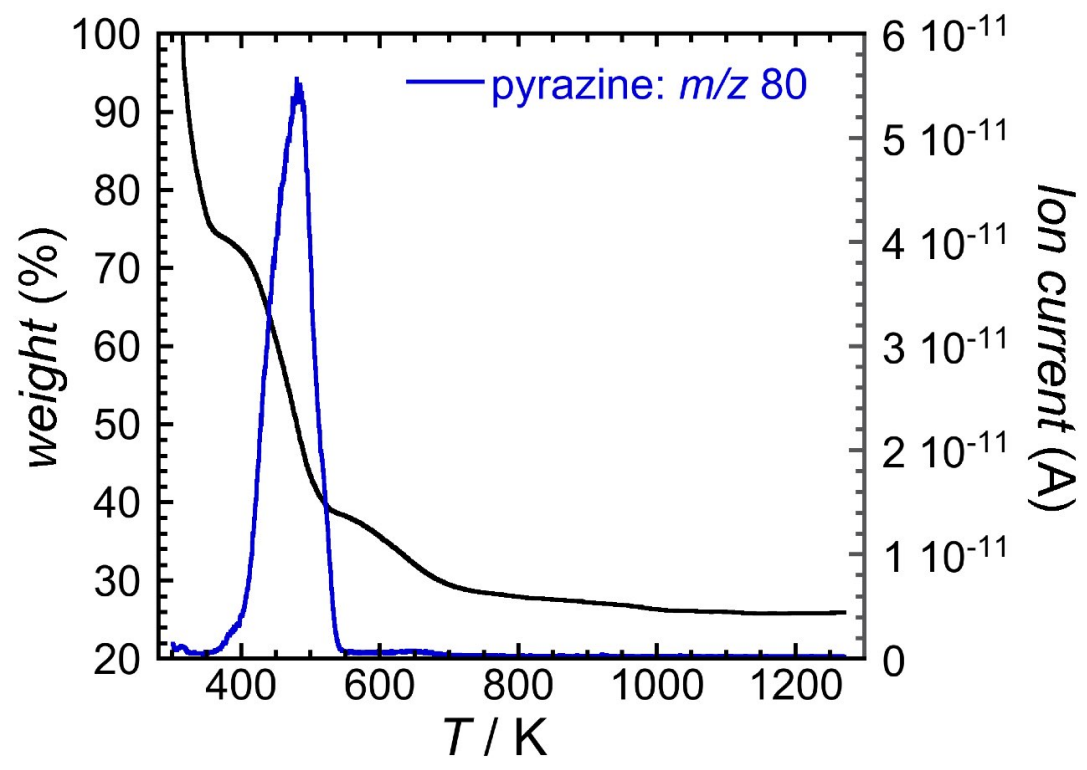

Fig. S19.

TGA-MS thermogram showing the weight loss in $\mathbf{2} \cdot$ (THF) (black line; at $5 \mathrm{~K} \mathrm{~min}^{-1}$ ) highlighting the pyrazine loss and the corresponding ion current at $\mathrm{m} / \mathrm{z}=80$ (blue line). 


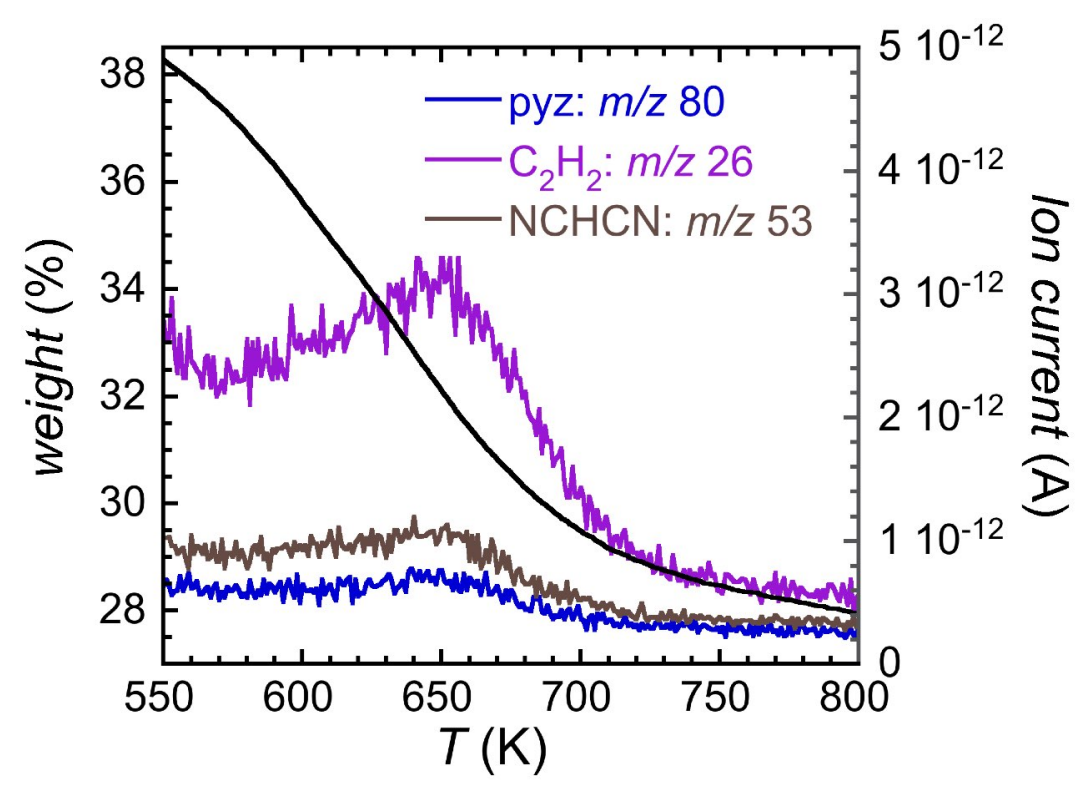

Fig. S20.

Zoom of TGA-MS thermogram showing the weight loss in $\mathbf{2} \cdot$ (THF) (black line; at $5 \mathrm{~K} \mathrm{~min}^{-1}$ ) highlighting the loss of pyrazine (ion current at $m / z=80$, blue line) and decomposition products of pyrazine (ion current at $m / z=26, \mathrm{C}_{2} \mathrm{H}_{2}$, purple line; ion current at $m / z=53$, NCHCN, brown line). 


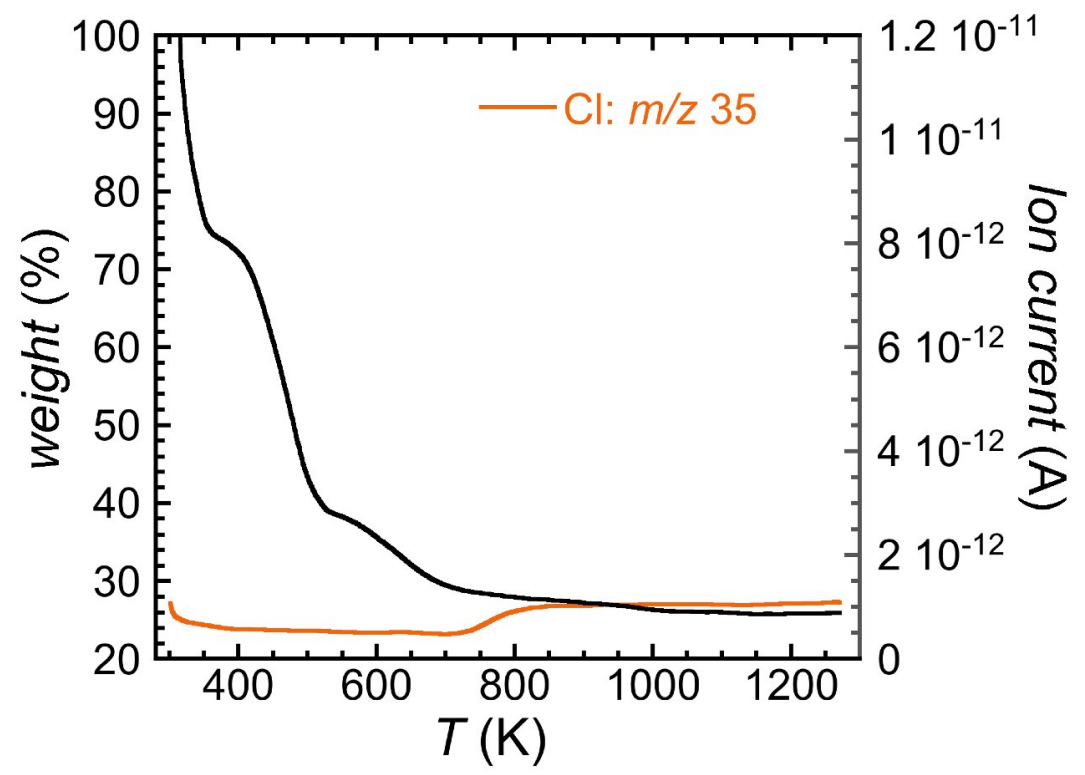

Fig. S21.

TGA-MS thermogram showing the weight loss in $\mathbf{2} \cdot$ (THF) (black line; at $5 \mathrm{~K} \mathrm{~min}^{-1}$ ) highlighting the chlorine loss and the corresponding ion current at $m / z=35$ (orange line). 


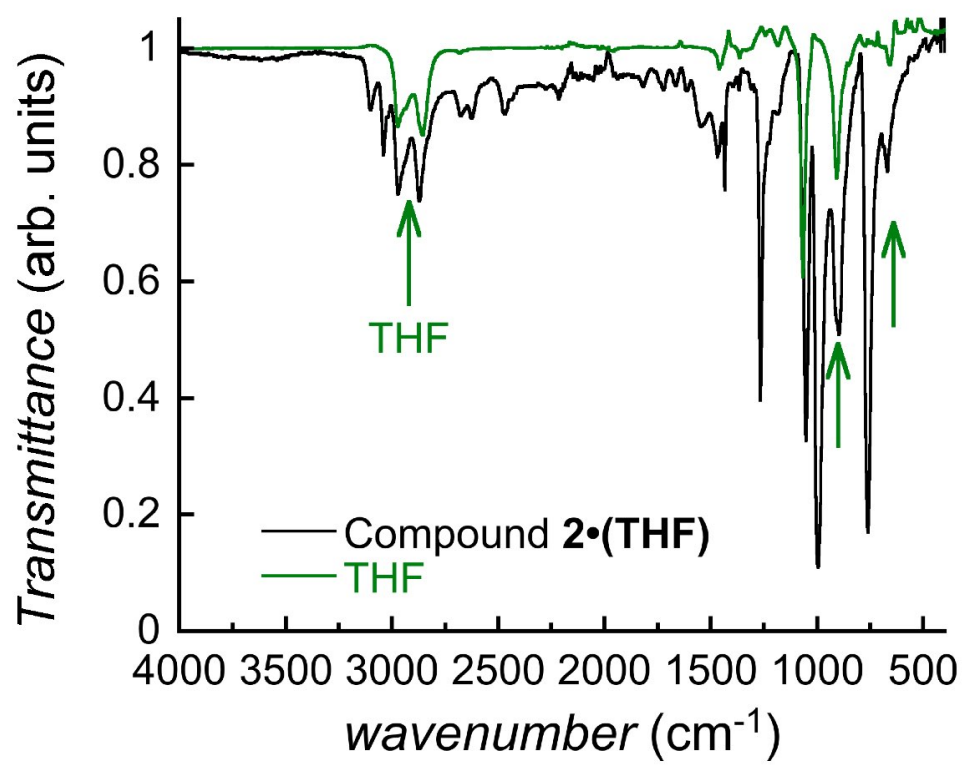

Fig. S22.

Fourier-transform infrared spectra collected at room temperature for $\mathbf{2 \cdot ( T H F ) ~ ( b l a c k ~ l i n e ) ~ a n d ~}$ THF (green line). Peak assignment for the most intense bands of THF $(61,62): 2972 \mathrm{~cm}^{-1}$, asymmetric $\mathrm{C}-\mathrm{H}$ stretching; $2856 \mathrm{~cm}^{-1}$, symmetric $\mathrm{C}-\mathrm{H}$ stretching; $1066 \mathrm{~cm}^{-1}$, ring stretching; $906 \mathrm{~cm}^{-1}$, ring breathing; $657 \mathrm{~cm}^{-1}, \mathrm{CH}_{2}$ wagging. The green arrows $(\uparrow)$ denote the areas in which the most relevant THF bands are observed in $\mathbf{2}$ (THF) (note that the band at $1066 \mathrm{~cm}^{-1}$ of THF overlaps with pyrazine bands). 


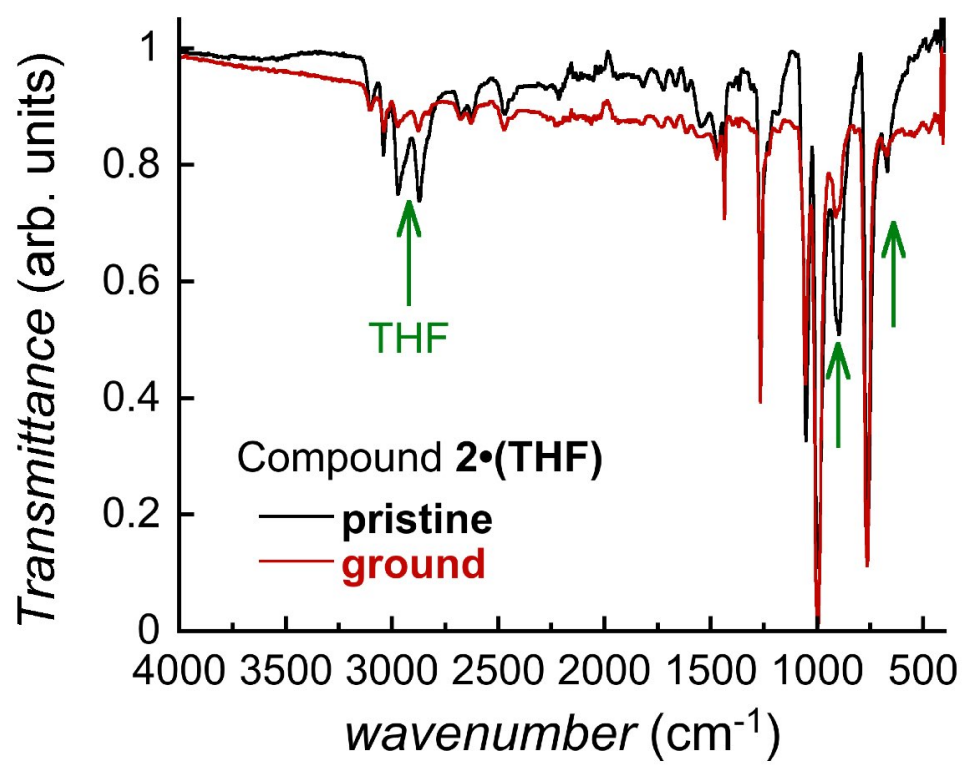

Fig. S23.

Fourier-transform infrared spectra collected at room temperature for $\mathbf{2 \cdot ( T H F ) ~ ( b l a c k ~ l i n e ) ~ a n d ~ a ~}$ ground sample (red line). The green arrows $(\uparrow)$ denote the areas in which the main differences between pristine and ground $\mathbf{2}$ (THF) are observed, which agree well with the areas in which the most intense bands of THF appear (note that the band at $1066 \mathrm{~cm}^{-1}$ of THF overlaps with pyrazine bands). 

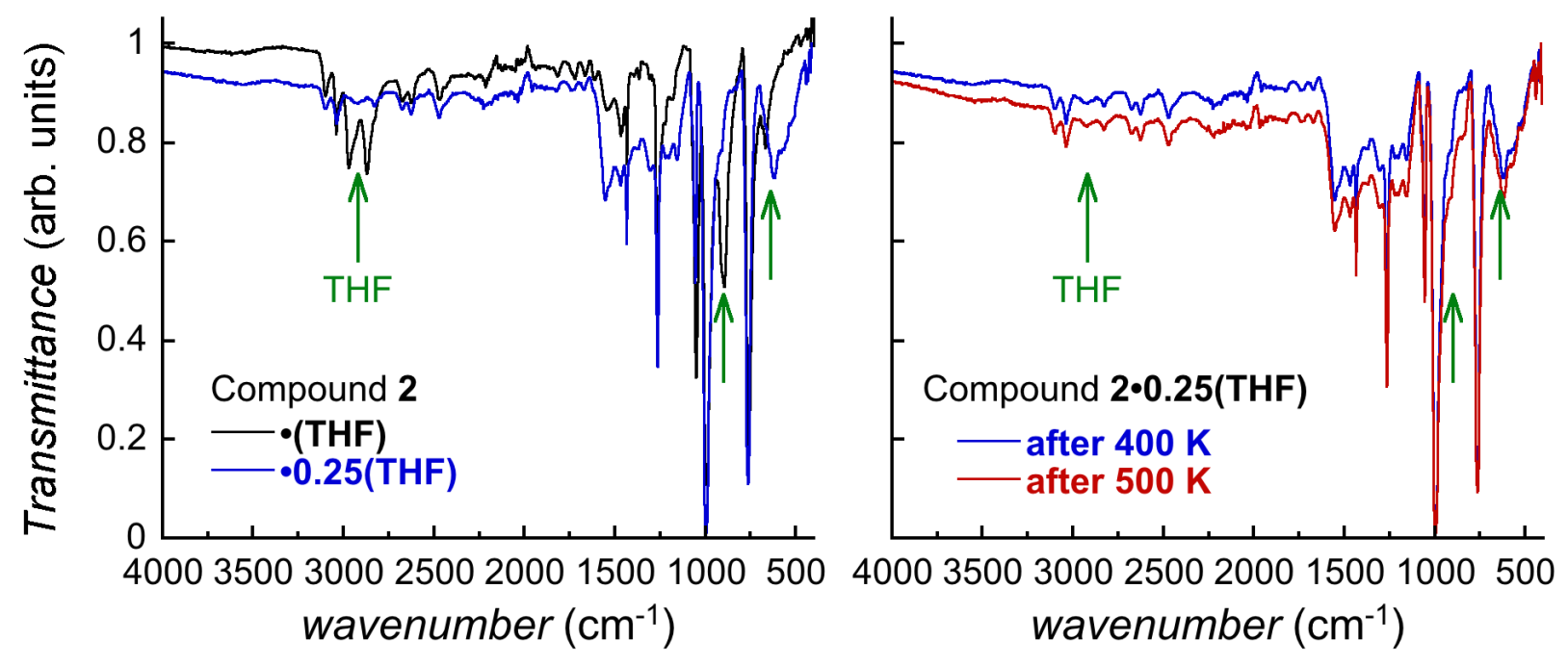

\section{Fig. S24.}

Fourier-transform infrared spectra collected at room temperature for $\mathbf{2} \cdot$ (THF) (black line) and 2·0.25(THF) after a $400-\mathrm{K}$ treatment (18 hours; blue lines) and after a $500-\mathrm{K}$ treatment (10 hours; red line). Left: green arrows $(\uparrow)$ denote the areas in which the main differences between $\mathbf{2} \cdot(\mathbf{T H F})$ and $2 \cdot \mathbf{0 . 2 5}$ (THF) are observed which agree well with the areas in which the most intense bands of THF appear (note that the band at $1066 \mathrm{~cm}^{-1}$ of THF overlaps with pyrazine bands). Right: green arrows $(\uparrow)$ denote the areas in which the most intense bands of THF should appear (note that the band at $1066 \mathrm{~cm}^{-1}$ of THF overlaps with pyrazine bands). 


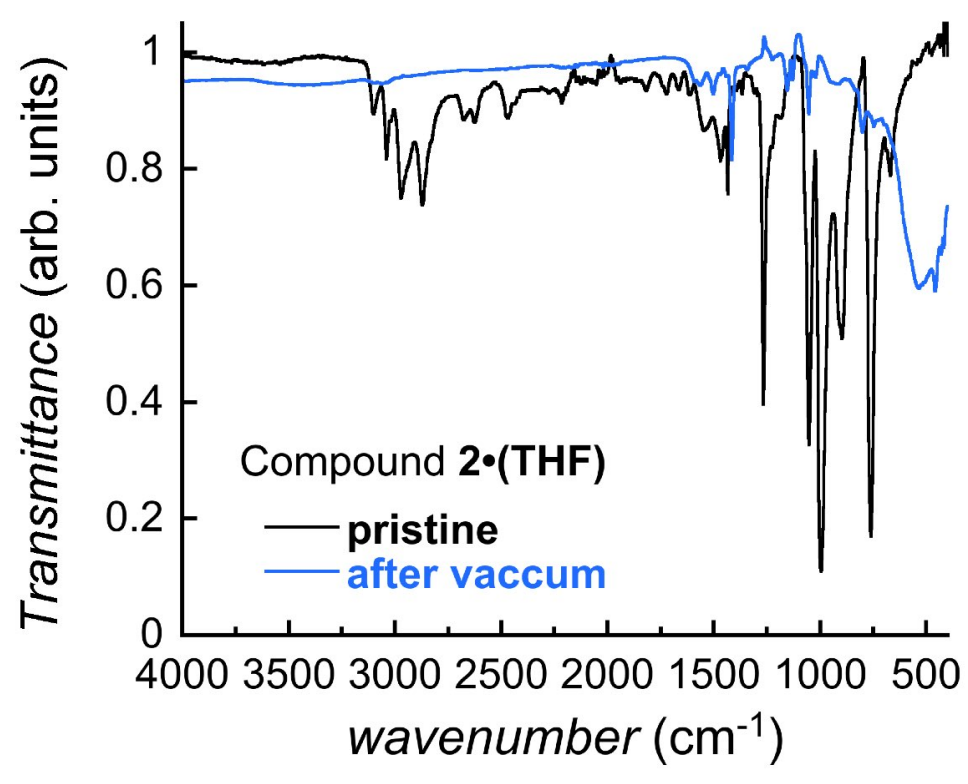

Fig. S25.

Fourier-transform infrared spectra collected at room temperature for $\mathbf{2} \cdot(\mathbf{T H F})$ (black line) and a sample exposed to dynamic vacuum $\left(10^{-3}\right.$ bar, blue line). The significant differences between both spectra indicate the decomposition of the material. 


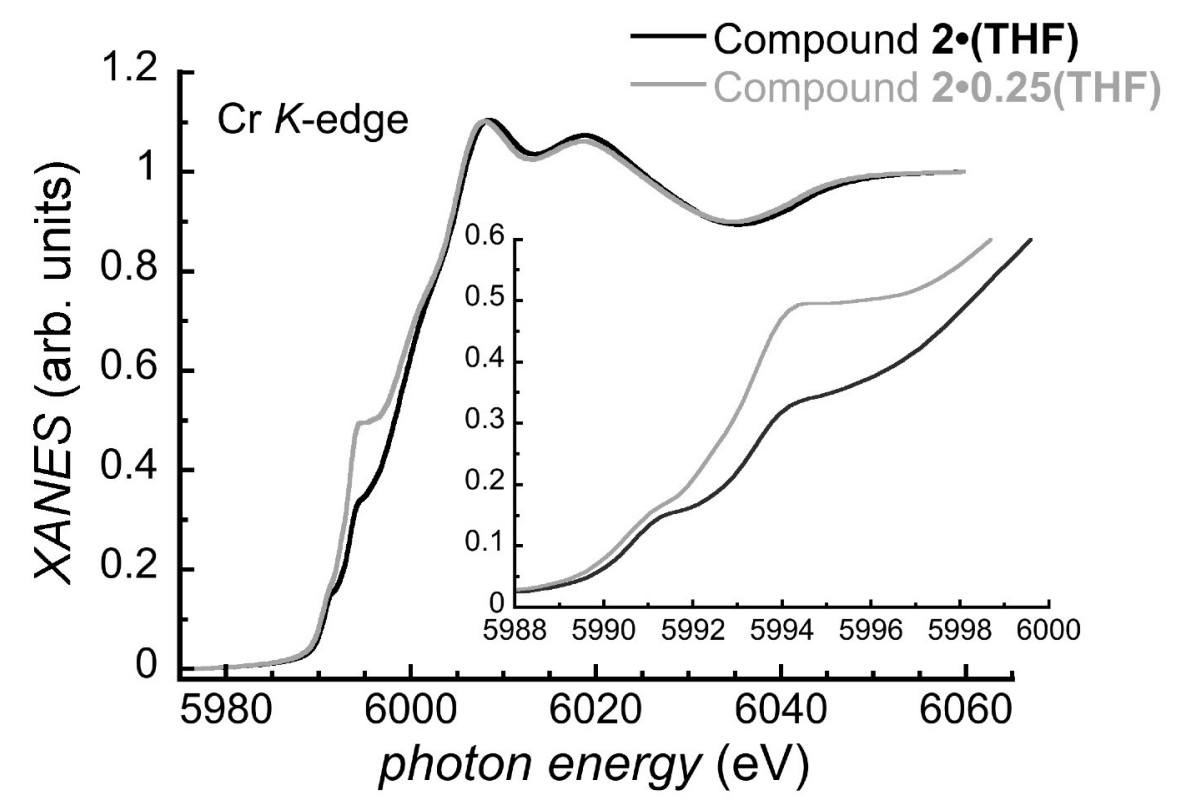

Fig. S26.

Normalized XANES spectra at the Cr $K$-edge of $\mathbf{2} \cdot($ THF) (black line) and $\mathbf{2} \cdot \mathbf{0 . 2 5}$ (THF) (grey line) recorded at $295 \mathrm{~K}$. Inset: zoom of the pre-edge region of the spectra. 


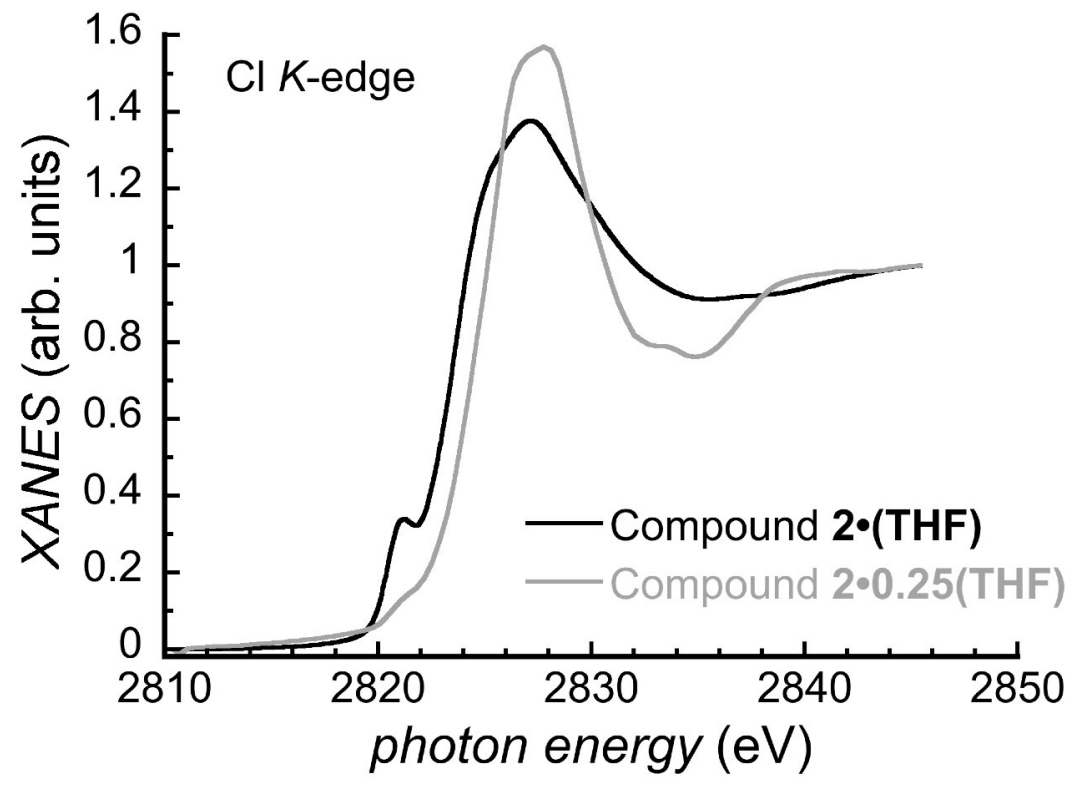

Fig. S27.

Normalized XANES spectra at the $\mathrm{Cl} K$-edge of $\mathbf{2} \cdot($ THF) (black line) and $\mathbf{2} \cdot \mathbf{0 . 2 5}$ (THF) (grey line) recorded at $295 \mathrm{~K}$. 


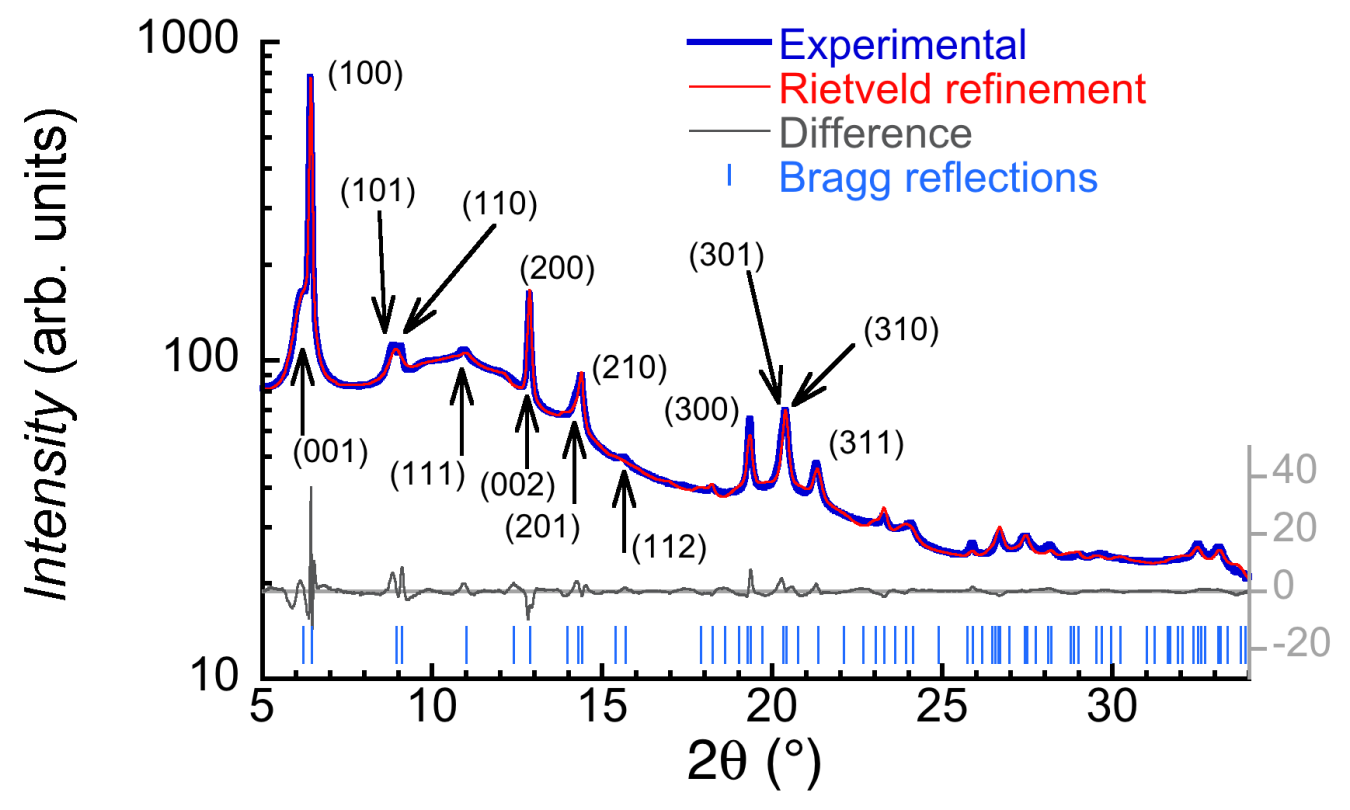

Fig. S28.

Synchrotron powder X-ray diffraction pattern of $\mathbf{2 \cdot 0 . 2 5}$ (THF) collected at $500 \mathrm{~K}$ with a wavelength of $0.7829 \AA$. The best Rietveld refinement (red line; change $R_{\mathrm{I}}=3.14 \%$ ) of the synchrotron PXRD pattern of $\mathbf{2 \cdot 0 . 2 5}$ (THF) at $500 \mathrm{~K}$ (blue line) is shown together with the experimental/model difference (grey line) and calculated line positions (blue bars). The resulting structural model is the same as the one shown in Fig. 3C-D. The indexation of the main diffraction peaks is shown. 


\section{Table S6.}

Crystallographic parameters of the structural model for $\mathbf{2 \cdot 0 . 2 5}$ (THF) obtained from the best Rietveld refinement of the powder X-ray diffraction pattern collected at $500 \mathrm{~K}$ (Fig. S28) and at $290 \mathrm{~K}$ after cooling from $500 \mathrm{~K}$ (Fig. 3).

\begin{tabular}{|l|c|c|}
\hline Temperature & $\mathbf{5 0 0} \mathbf{~ K}$ & $\mathbf{2 9 0} \mathbf{~ K}$ \\
\hline CCDC number & 2007863 & 1983877 \\
\hline Crystal system & tetragonal & tetragonal \\
\hline Space group & $P 4 / m m m$ & $P 4 / m m m$ \\
\hline $\boldsymbol{a} / \AA$ & $6.99618(13)$ & $6.98932(14)$ \\
\hline $\boldsymbol{b} / \AA$ & $6.99618(13)$ & $6.98932(14)$ \\
\hline $\boldsymbol{c} / \AA$ & $7.273(3)$ & $7.195(3)$ \\
\hline Volume / $\AA^{3}$ & $355.97(14)$ & $351.46(13)$ \\
\hline $\boldsymbol{Z}$ & 1 & 1 \\
\hline Observed reflections & 96 & 93 \\
\hline Parameters & 13 & 13 \\
\hline Restraints & 5 & 5 \\
\hline $\boldsymbol{G O F}$ & 4.11 & 4.54 \\
\hline $\boldsymbol{R}_{\mathbf{p}}$ & 1.559 & 1.632 \\
\hline $\boldsymbol{R}_{\mathrm{wp}}$ & 2.145 & 2.324 \\
\hline
\end{tabular}




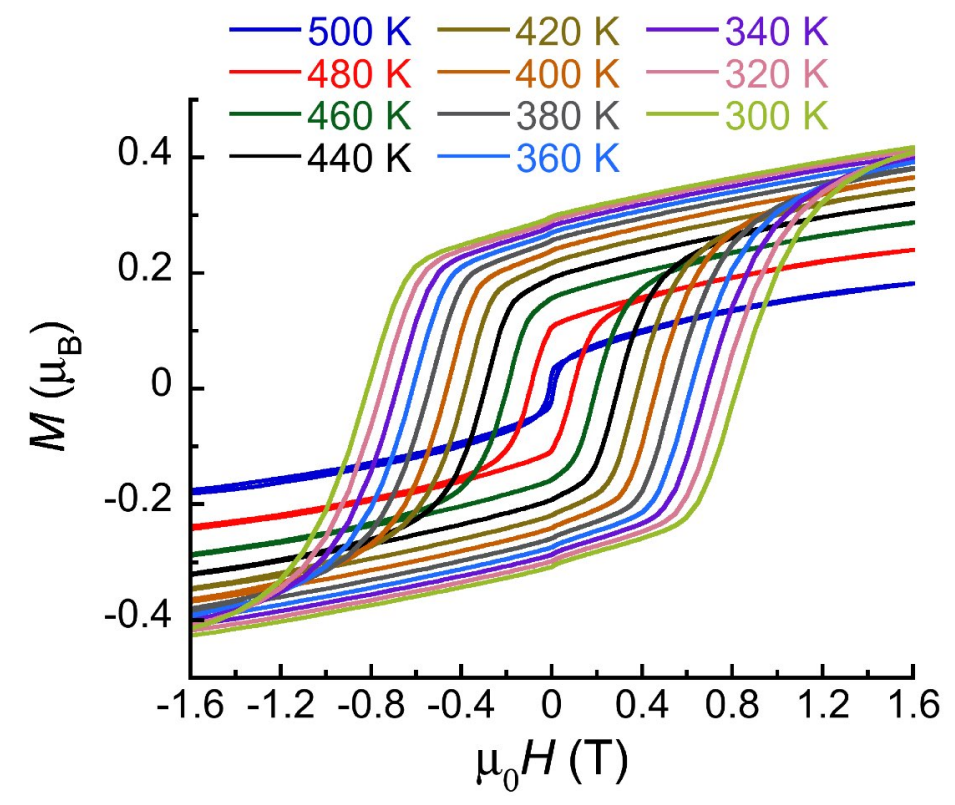

Fig. S29.

Magnetization versus applied $d c$ magnetic field data (at 8 to $12 \mathrm{Oe} / \mathrm{s}$ ) in the -1.8 to $1.8 \mathrm{~T}$ field range for $\mathbf{2} \cdot$ (THF) (and thus for $\mathbf{2 \cdot 0 . 2 5}$ (THF) after the loss of THF above $400 \mathrm{~K}$ ). These data were collected after the $M$ vs $H$ hysteresis plots shown in Figs. 4B-C, during the cooling process from $520 \mathrm{~K}$ to room temperature. 


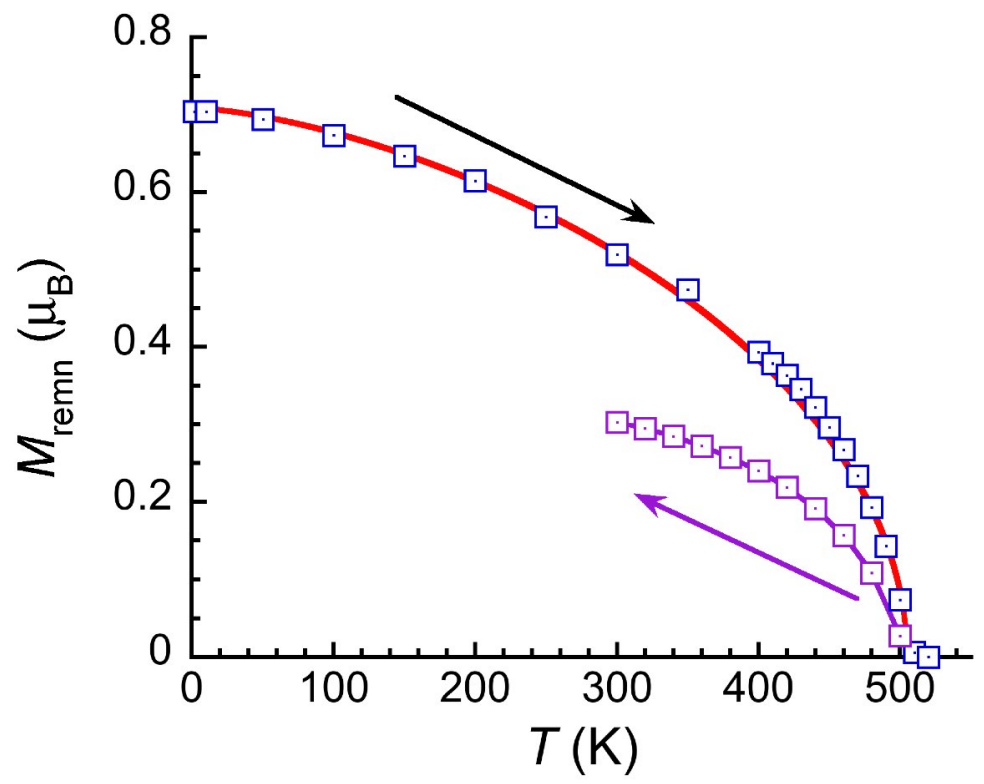

\section{Fig. S30.}

Temperature dependence of the remnant magnetization, $M_{\text {remn }}$, determined from the $M v s$. $H$ data (Figs. 4B-C and S29) at each temperature for 2-(THF) (and thus for 2.0.25(THF) after the loss of THF above $400 \mathrm{~K}$ ). The blue squares correspond to the first heating of the sample from 1.85 to $520 \mathrm{~K}$, while the purple squares are determined upon cooling from 500 to $300 \mathrm{~K}$. The solid red line is the best fit to the mean-field (MF) Bloch law: $M_{\text {remn }} \propto\left(1-\left(T / T T_{\mathrm{C}-\mathrm{MF}}\right)^{3 / 2}\right)^{1 / 2}$ with $T_{\mathrm{C}-\mathrm{MF}}=$ $506 \mathrm{~K},(38)$. The solid purple line is a guide for the eye. 


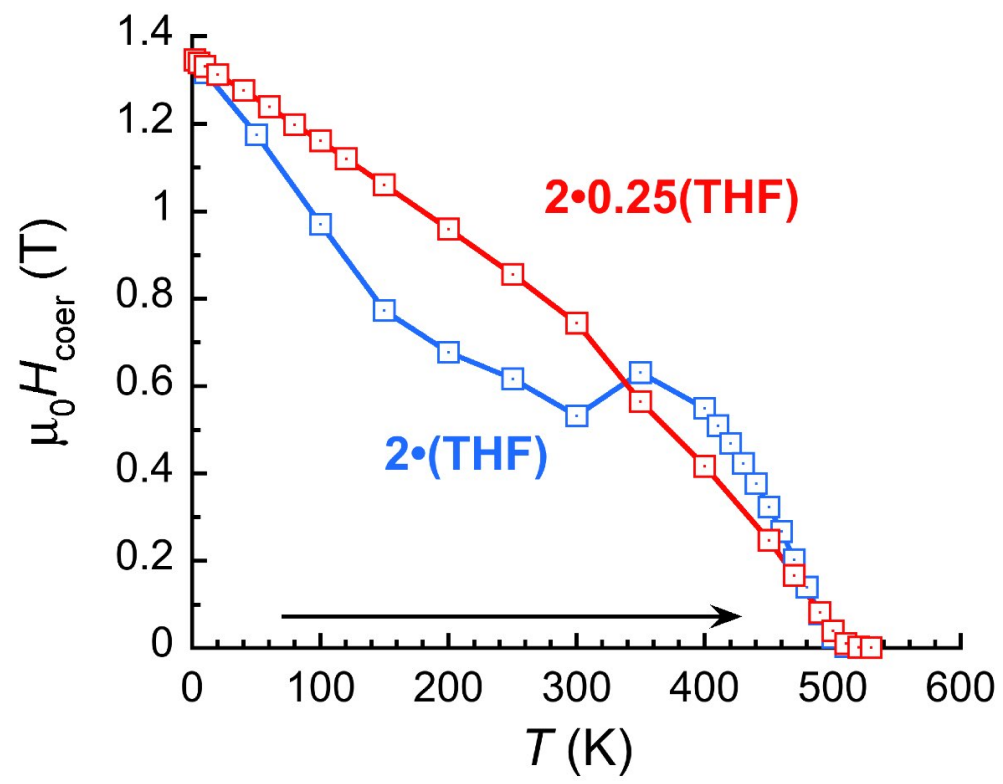

Fig. S31.

Temperature dependence of the coercive field, $H_{\text {coer, }}$, determined at each temperature from the $M$ vs. $H$ data for 2·(THF) (Fig. 4B-C; blue squares) and 2-0.25(THF) (Fig. S32; red squares) on the first heating from 1.85 to $530 \mathrm{~K}$. The solid lines are a guide for the eye. 


\section{Table S7.}

Critical temperatures $\left(T_{\mathrm{C}}\right)$ and coercive fields $\left(H_{\mathrm{Coer}}\right)$ for commercial inorganic magnets, $\mathbf{2} \bullet(\mathbf{T H F})$ and $2 \cdot 0.25($ THF $)$. RT $=$ room temperature.

\begin{tabular}{|c|c|c|c|}
\hline Compound & $T_{\mathbf{C}}(\mathbf{K})$ & $H_{\text {Coer }}(\mathrm{Oe})$ & Ref. \\
\hline Hard ferrites & 450 & 4000 (RT) & 63 \\
\hline $\mathrm{AlNiCo}_{5}$ & 850 & $800(\mathrm{RT})$ & 63 \\
\hline AlNiCo 8 & 850 & $2000(\mathrm{RT})$ & 63 \\
\hline $\mathrm{SmCo}_{5}$ & 720 & $44000(\mathrm{RT})$ & 63 \\
\hline $\mathrm{SmCo}_{5} / \mathrm{Sm}_{2} \mathrm{Co}_{17}$ & 820 & 38000 (RT) & 63 \\
\hline $\mathrm{Nd}_{2} \mathrm{Fe}_{14} \mathrm{~B}$ & 310 & 19000 (RT) & 63 \\
\hline $\mathrm{Li}_{0.7}\left[\mathrm{Cr}(\mathrm{pyz})_{2}\right] \mathrm{Cl}_{0.7} \cdot(\mathrm{THF})$ & $\sim 510$ & $\begin{array}{c}13500(1.85 \mathrm{~K}) \\
5300(\mathrm{RT}) \\
\end{array}$ & this work \\
\hline $\mathrm{Li}_{0.7}\left[\mathrm{Cr}(\mathrm{pyz})_{2}\right] \mathrm{Cl}_{0.7} \cdot \mathbf{0 . 2 5}$ (THF) & $\sim 515$ & $\begin{array}{c}13500(1.85 \mathrm{~K}) \\
7500(\mathrm{RT}) \\
\end{array}$ & this work \\
\hline
\end{tabular}




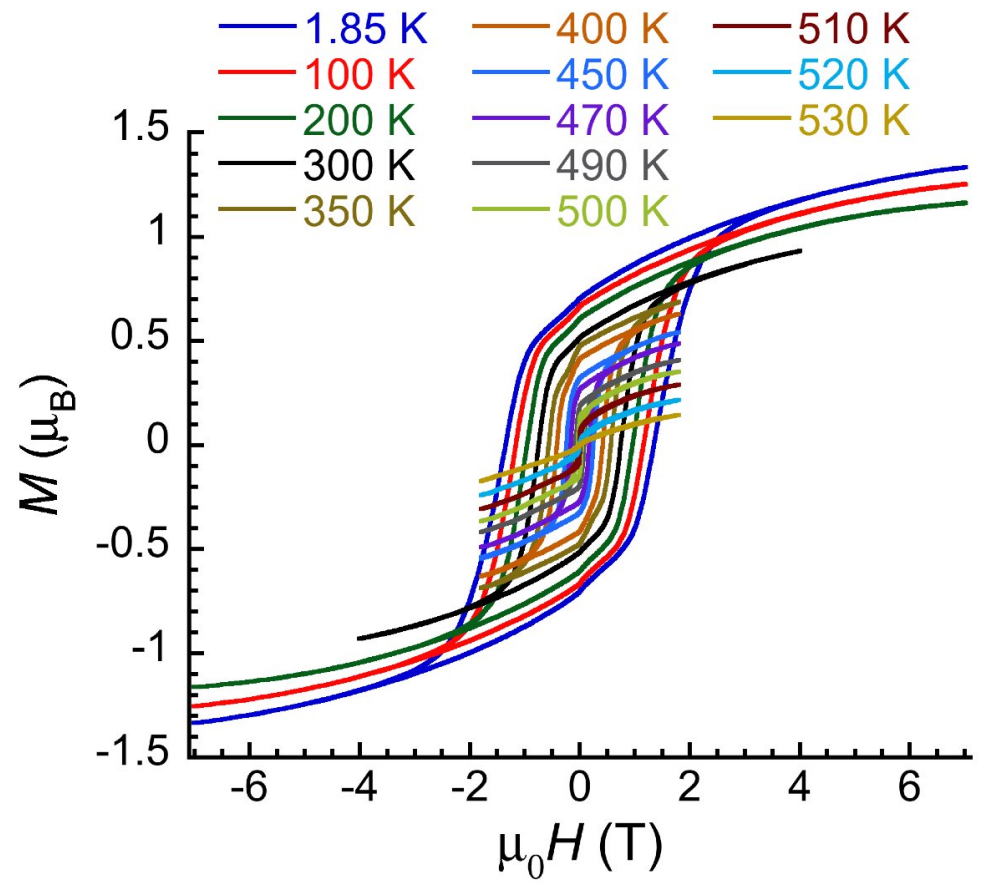

Fig. S32.

Magnetization versus applied $d c$ magnetic field data (at 5 to $12 \mathrm{Oe} / \mathrm{s}$ ) in the -7 to $7 \mathrm{~T}$ field range for $\mathbf{2 \cdot 0 . 2 5}$ (THF) from $1.85 \mathrm{~K}$ to $530 \mathrm{~K}$. 


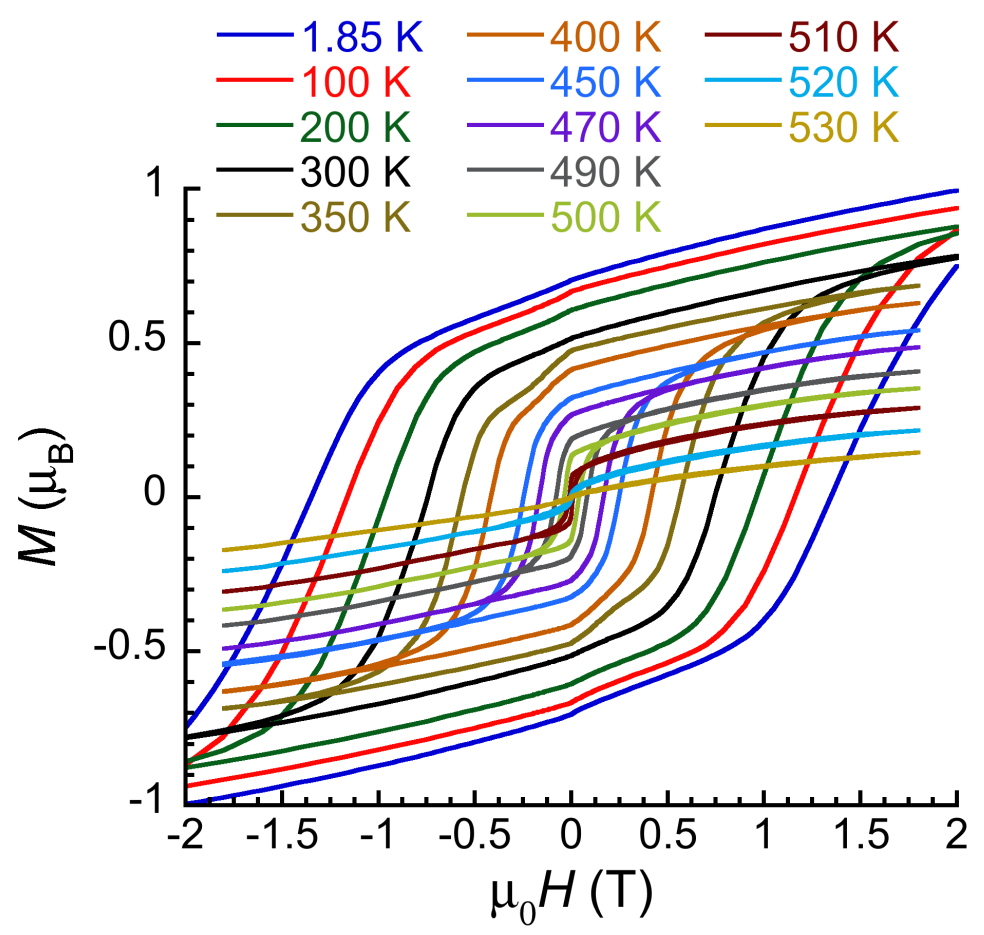

Fig. S33.

Zoom of the magnetization versus applied $d c$ magnetic field data (at 5 to $12 \mathrm{Oe} / \mathrm{s}$ ) in the -2 to $2 \mathrm{~T}$ field range for $\mathbf{2 \cdot 0 . 2 5}$ (THF) from $1.85 \mathrm{~K}$ to $530 \mathrm{~K}$. 


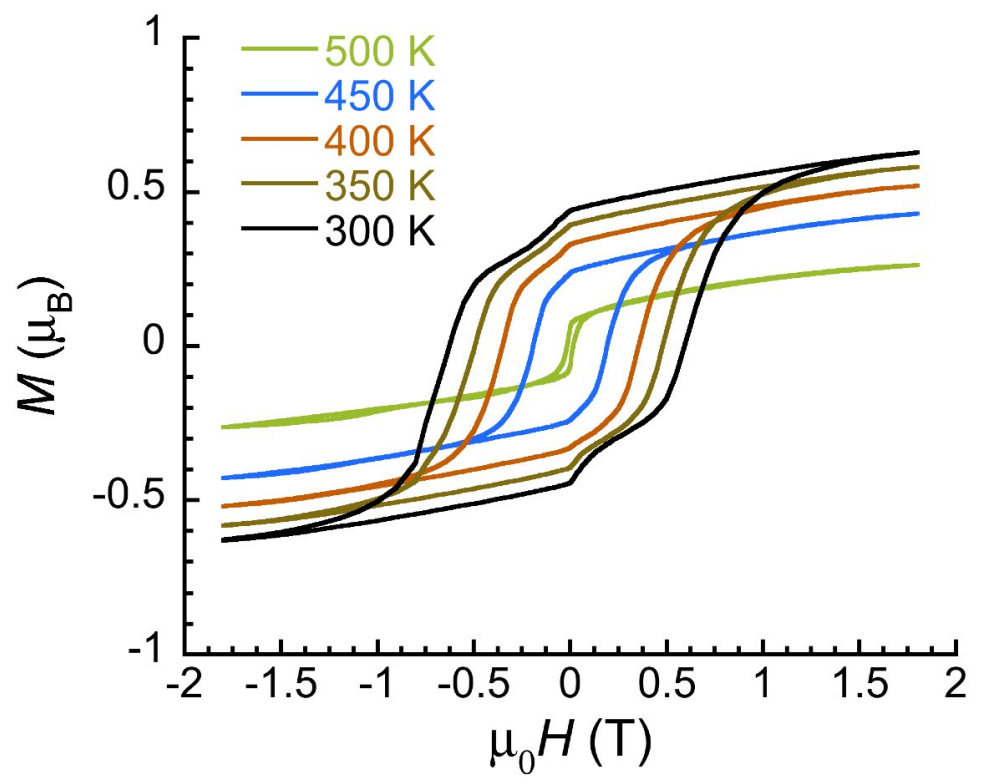

Fig. S34.

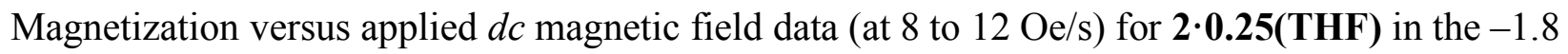
to $1.8 \mathrm{~T}$ field range after the data shown in Figs. S32-S33 and decreasing the temperature from 500 to $300 \mathrm{~K}$. 


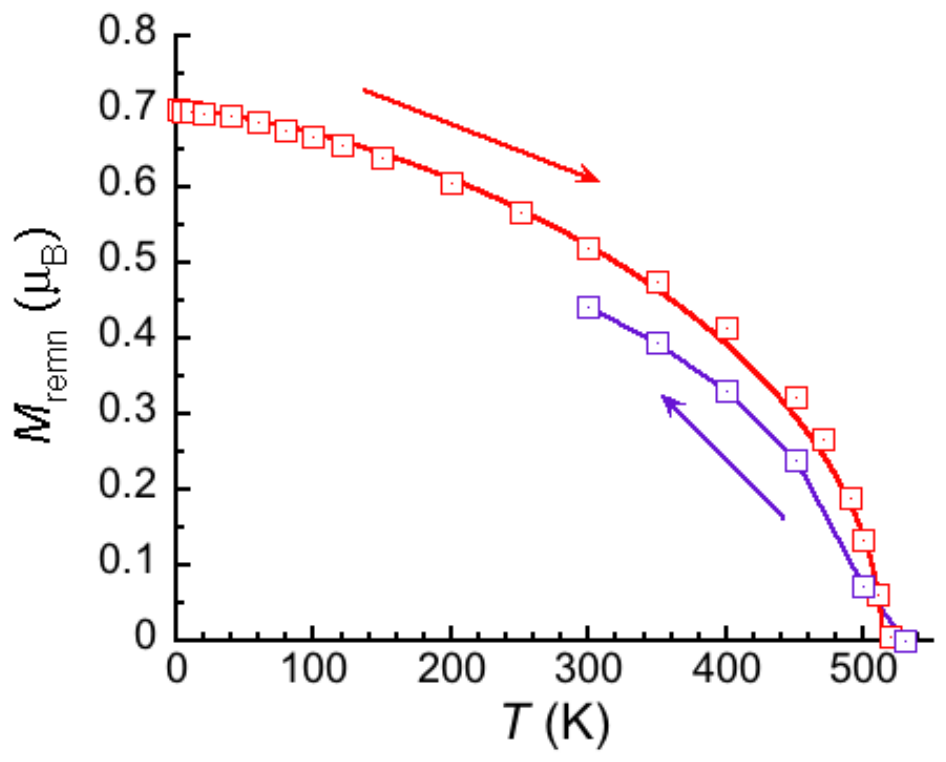

\section{Fig. S35.}

Temperature dependence of the remnant magnetization, $M_{\mathrm{remn}}$, determined from the $M v s . H$ data

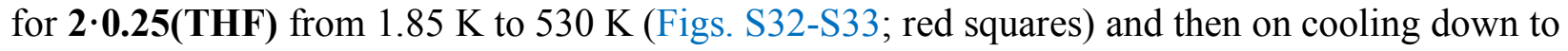
$300 \mathrm{~K}$ (Fig. S34; purple squares). The solid red line is the best fit to the mean-field (MF) Bloch law: $M_{\text {remn }} \propto\left(1-\left(T / T_{\mathrm{C}-\mathrm{MF}}\right)^{3 / 2}\right)^{1 / 2}$ with $T_{\mathrm{C}-\mathrm{MF}}=514 \mathrm{~K},(38)$. The solid purple line is a guide for the eye. 


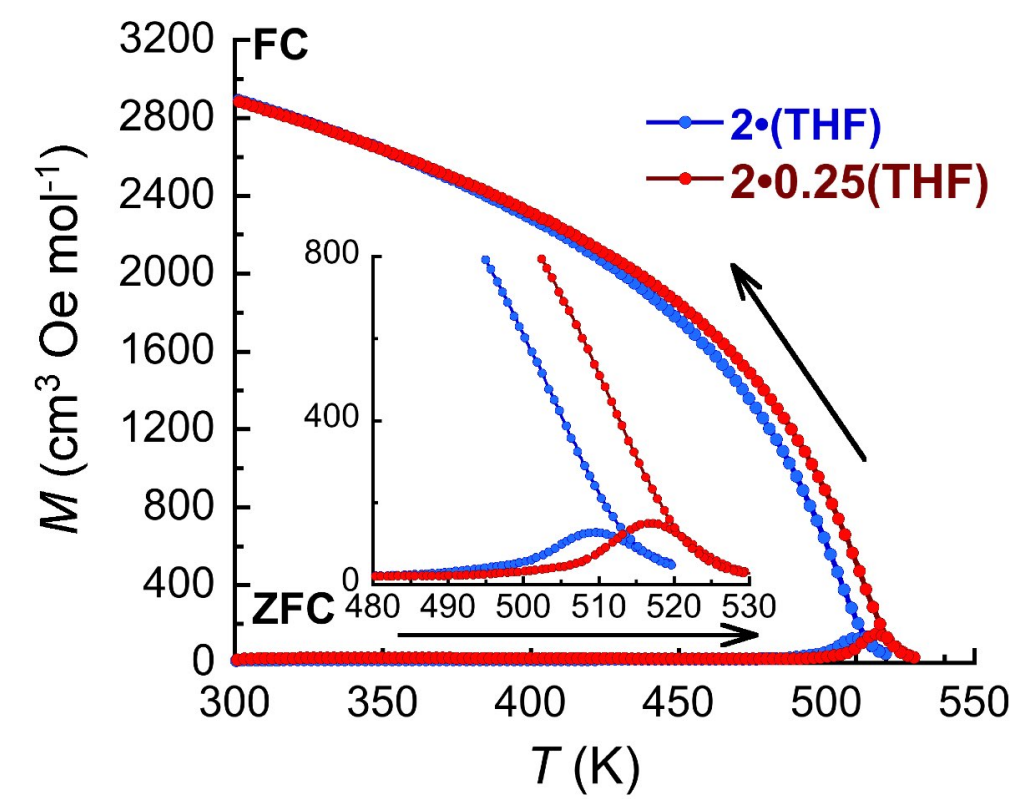

Fig. S36.

Zero-field cooled (ZFC)/field-cooled (FC) magnetization data for $\mathbf{2 \cdot ( T H F ) ~ ( b l u e ) ~ a n d ~}$ 2.0.25(THF) (red) obtained under an applied $d c$ magnetic field of 50 Oe at $5 \mathrm{~K} / \mathrm{min}$. Inset: zoom of the main plot in the temperature range $480-530 \mathrm{~K}$. The samples were introduced first in the magnetometer at $300 \mathrm{~K}$ under zero field. Magnetization data were obtained while warming in 50 Oe (ZFC) and subsequently cooling (FC) to room-temperature under the same magnetic field. The solid lines are a guide for the eye. 


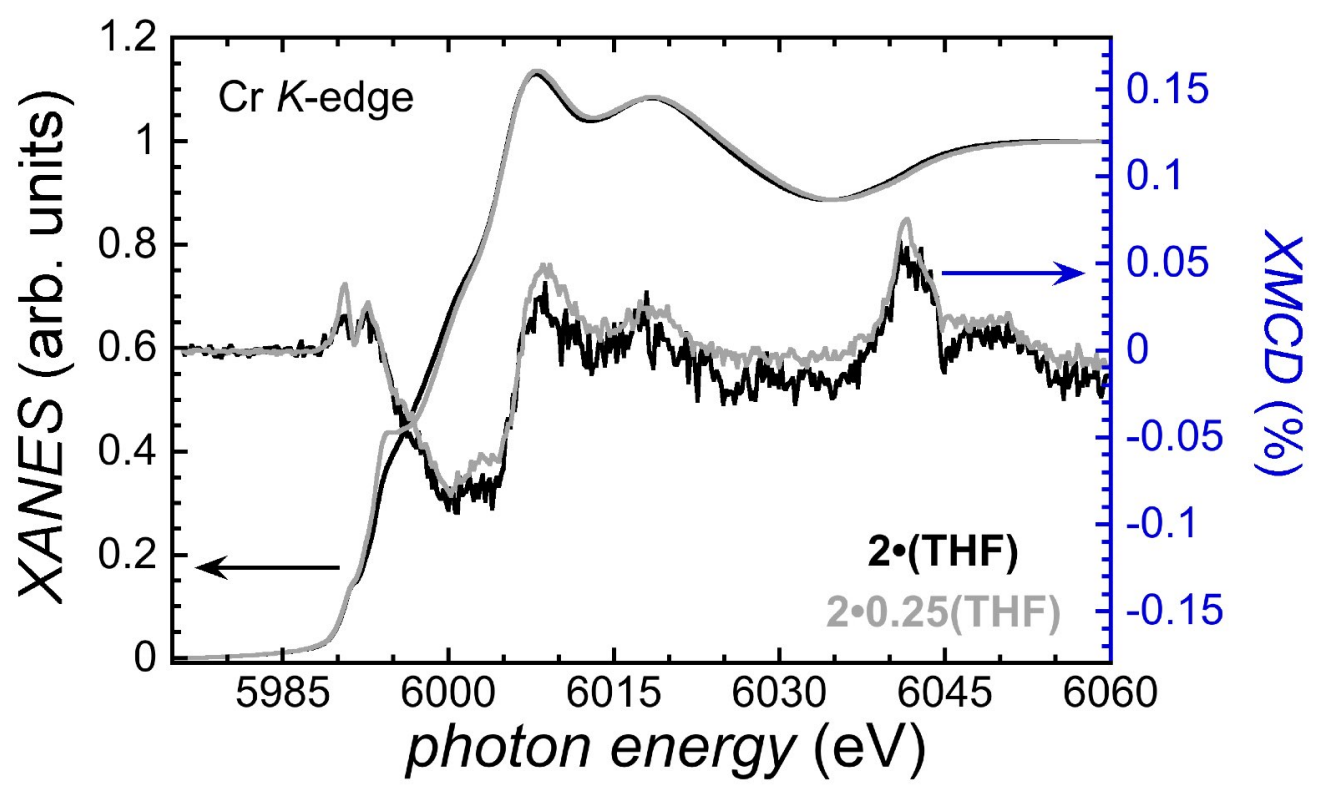

Fig. S37.

Normalized XANES and XMCD spectra at the $\mathrm{Cr} K$-edge of $\mathbf{2}$ (THF) (black line) and 2.0.25(THF) (grey line) recorded at $295 \mathrm{~K}$ under 7-T applied magnetic field. XMCD spectra are given as the percentage of the XANES edge jump. 


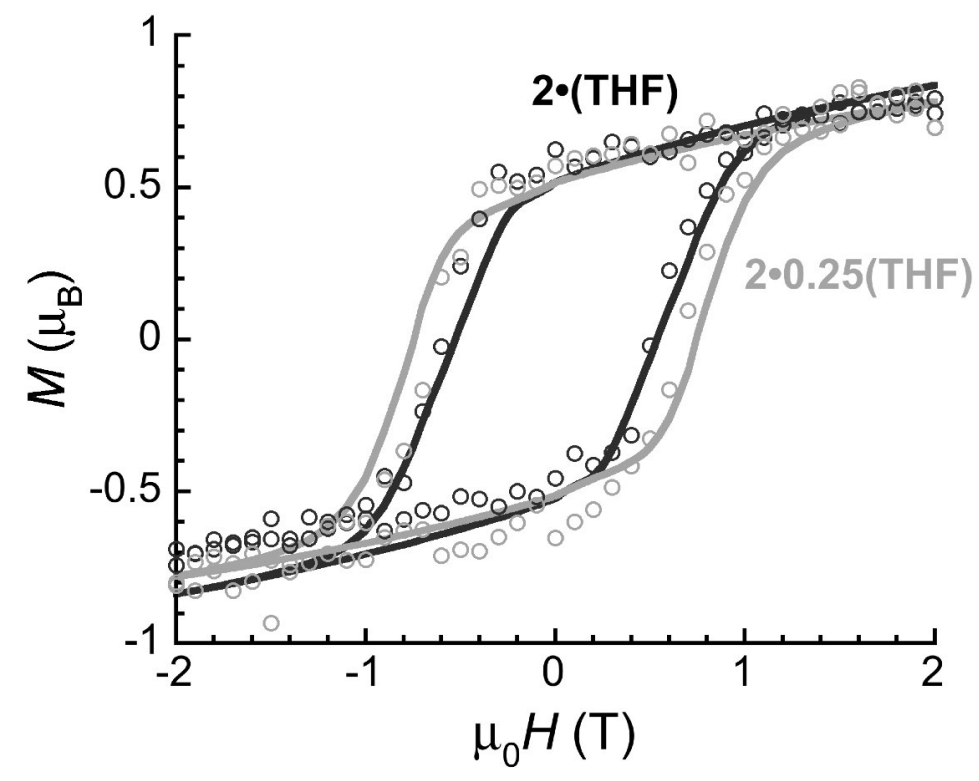

Figure S38.

Field dependence of the XMCD signal (at $\approx 71 \mathrm{Oe} / \mathrm{s})$ at $295 \mathrm{~K}$ at the maximum dichroism for $\mathbf{2} \cdot$ (THF) (black circles) and $\mathbf{2 \cdot 0 . 2 5}$ (THF) (grey circles) scaled and superimposed to the $M$ vs. $H$ data (at $\approx 5 \mathrm{Oe} / \mathrm{s}$ ) at $300 \mathrm{~K}$ (black and grey solid lines, for $\mathbf{2} \cdot(\mathbf{T H F})$ and $\mathbf{2 \cdot 0 . 2 5}(\mathbf{T H F})$, respectively). 


\section{Table S8.}

Calculated (B3LYP/def2-TZVP) energies of the high-spin state and three broken-symmetry states for the $\left[\mathrm{Cr}(\mathrm{pyz})_{4}\right]^{2-}$ fragment extracted from the structural model of $\mathbf{2 \cdot 0 . 2 5}$ (THF) used to calculate three exchange coupling constants using the Ising spin-Hamiltonian (Fig. S39). The spin density contour plots ( 0.01 isovalue) show which spins are flipped in a corresponding broken-symmetry state (purple color).

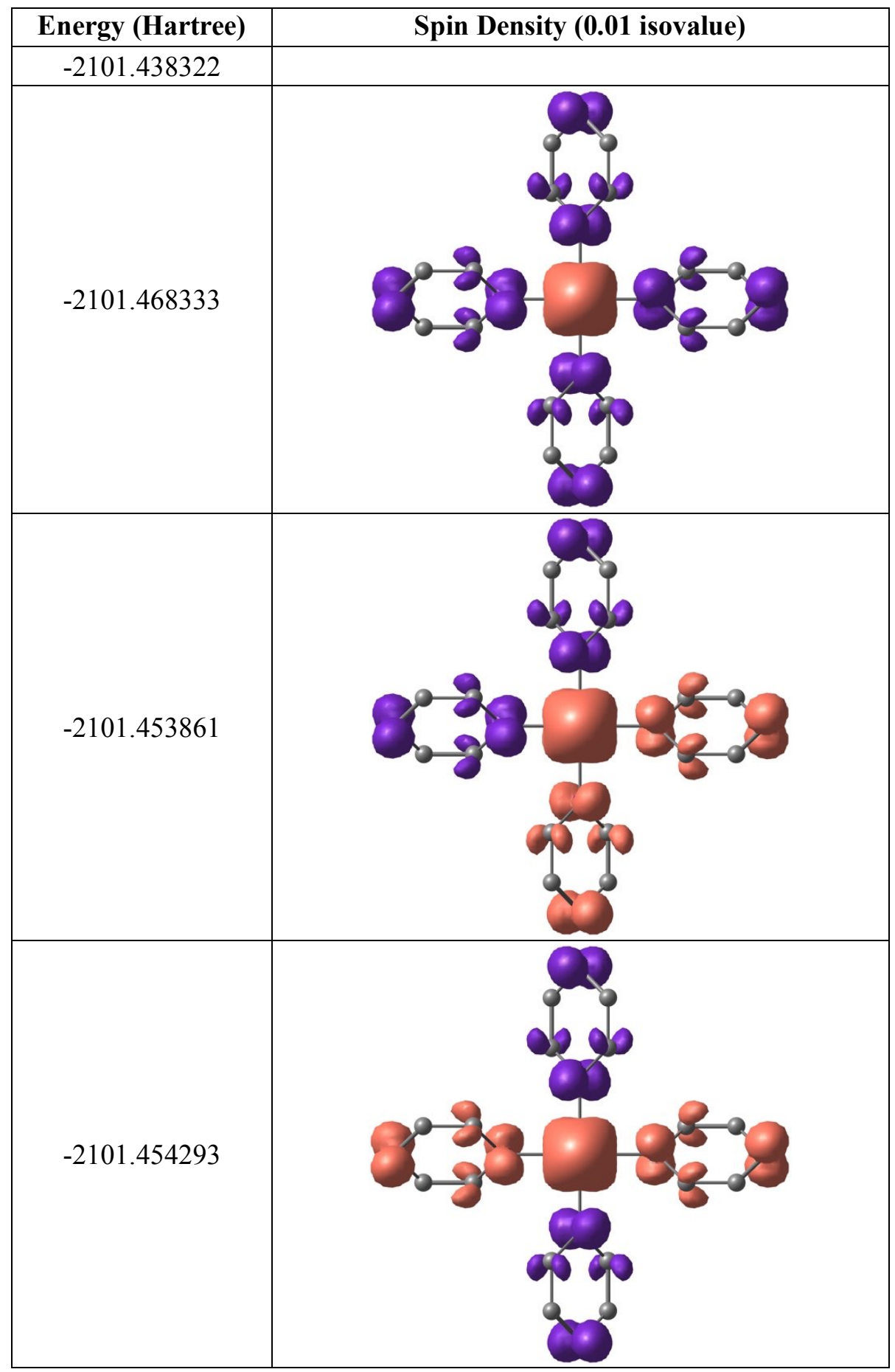



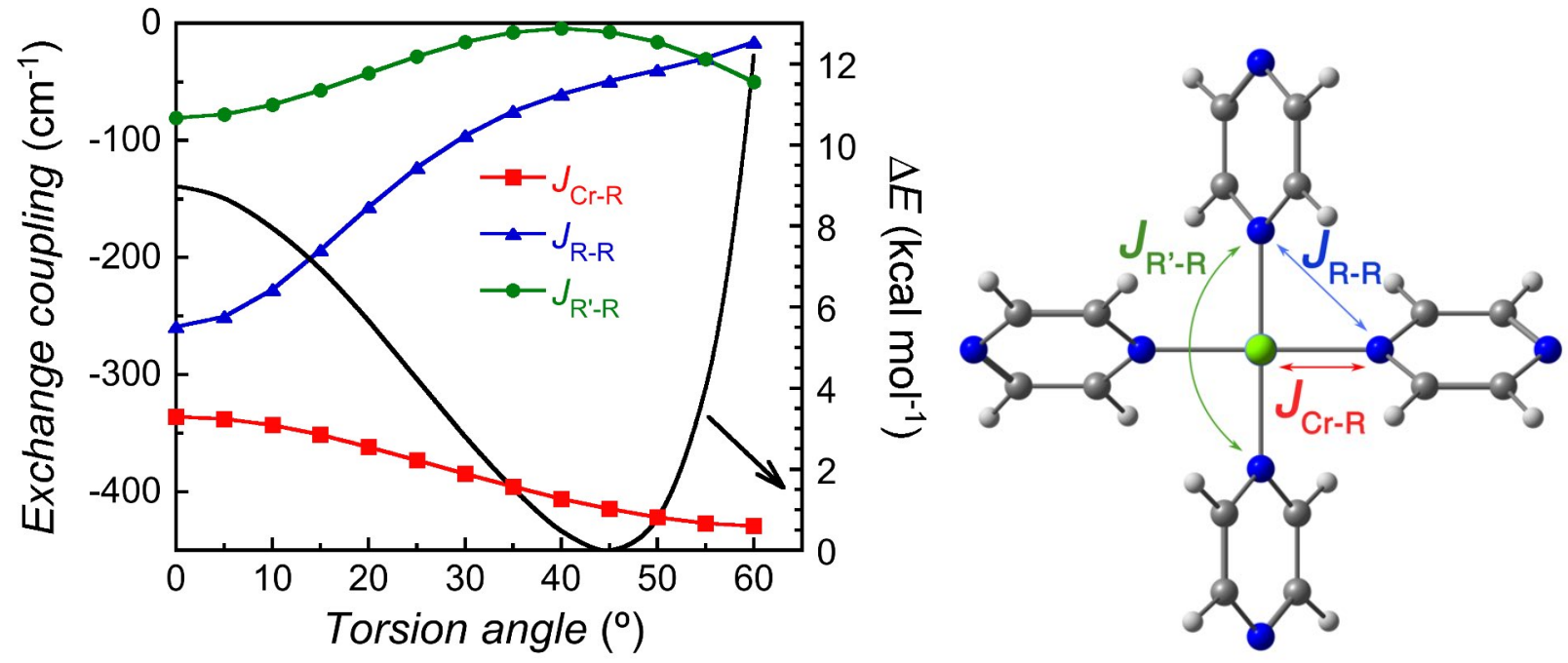

Fig. S39.

Left: Variation of the calculated (B3LYP/def2-TZVP) exchange coupling constants (in $\mathrm{cm}^{-1}$; defined in the scheme on the right) for the $\left[\mathrm{Cr}(\mathrm{pyz})_{4}\right]^{2-}$ fragment extracted from the structural model of $\mathbf{2 \cdot 0 . 2 5}$ (THF) (Fig. 3) with a modified pyrazine torsion angle (the zero torsion angle corresponds to a perpendicular arrangement of all pyrazines with respect to the layer; experimentally the torsion angle is estimated at $\left.43.2^{\circ}\right)$. Difference in energy of the high-spin state at a given torsion angle relative to that at $45^{\circ}(\Delta E$; in $\mathrm{kcal} / \mathrm{mol}$; see Table $\mathrm{S} 9)$ is plotted as the black trace. The antiferromagnetic metal-ligand exchange interaction, $\left|J_{\mathrm{Cr}-\mathrm{R}}\right|$, increases by $\sim 20 \%$ when the torsion angle changes from $0^{\circ}$ and $60^{\circ}$. This effect is more pronounced for weaker exchange interactions between organic spins. Right: Scheme of the magnetic exchange pathways in the $\left[\mathrm{Cr}(\mathrm{pyz})_{4}\right]^{2-}$ model fragment. 


\section{Table S9.}

Variation of the exchange coupling constants $\left(\mathrm{cm}^{-1}\right.$; defined in the right part of Fig. S39), the associated high-spin state energy (absolute value, $E$ in Hartree) and the difference in energy of the high-spin state at a given torsion angle relative to that at $45^{\circ}(\Delta E$; in $\mathrm{kcal} / \mathrm{mol})$ with a modified pyrazine torsion angle (the zero angle corresponds to a perpendicular arrangement of all pyrazines with respect to the layer; the experimentally found torsion angle is $\left.43.2^{\circ}\right)$. These parameters were calculated for the $\left[\mathrm{Cr}(\mathrm{pyz})_{4}\right]^{2-}$ fragment extracted from the structural model of $\mathbf{2 \cdot 0 . 2 5}$ (THF) (Fig. $3)$.

\begin{tabular}{|c|c|c|c|c|c|}
\hline $\begin{array}{c}\text { Torsion } \\
\text { angle }\left(\boldsymbol{(}^{\circ}\right.\end{array}$ & $\begin{array}{c}\text { Energy } \\
(\text { Hartree) }\end{array}$ & $\begin{array}{c}\boldsymbol{J}_{\mathbf{C r}-\mathbf{R}} / \boldsymbol{h} \boldsymbol{c} \\
\left(\mathbf{c m}^{-\mathbf{1}}\right)\end{array}$ & $\begin{array}{c}\boldsymbol{J}_{\mathbf{R}-\mathbf{R}} / \boldsymbol{h} \boldsymbol{c} \\
\left(\mathbf{c m}^{-\mathbf{1}}\right)\end{array}$ & $\begin{array}{c}\boldsymbol{J}_{\mathbf{R}^{\prime}-\mathbf{R}} / \boldsymbol{h} \boldsymbol{c} \\
\left(\mathbf{c m}^{-\mathbf{1}}\right)\end{array}$ & $\Delta \boldsymbol{E}(\mathbf{k c a l} / \mathbf{m o l})$ \\
\hline 0 & -2101.424124 & -336 & -259 & -81 & 8.98 \\
\hline 5 & -2101.424599 & -338 & -251 & -78 & 8.68 \\
\hline 10 & -2101.425758 & -343 & -227 & -70 & 7.95 \\
\hline 15 & -2101.427372 & -351 & -194 & -57 & 6.94 \\
\hline 20 & -2101.429411 & -362 & -157 & -43 & 5.66 \\
\hline 25 & -2101.431694 & -373 & -123 & -28 & 4.23 \\
\hline 30 & -2101.433952 & -385 & -96 & -16 & 2.81 \\
\hline 35 & -2101.435989 & -396 & -75 & -8 & 1.53 \\
\hline 40 & -2101.437674 & -406 & -60 & -5 & 0.48 \\
\hline 43.2 & -2101.438322 & -412 & -53 & -6 & $\mathbf{0 . 0 7}$ \\
\hline 45 & -2101.438434 & -415 & -49 & -7 & 0.00 \\
\hline 50 & -2101.437174 & -422 & -40 & -16 & 0.79 \\
\hline 55 & -2101.432058 & -427 & -30 & -31 & 4.00 \\
\hline
\end{tabular}




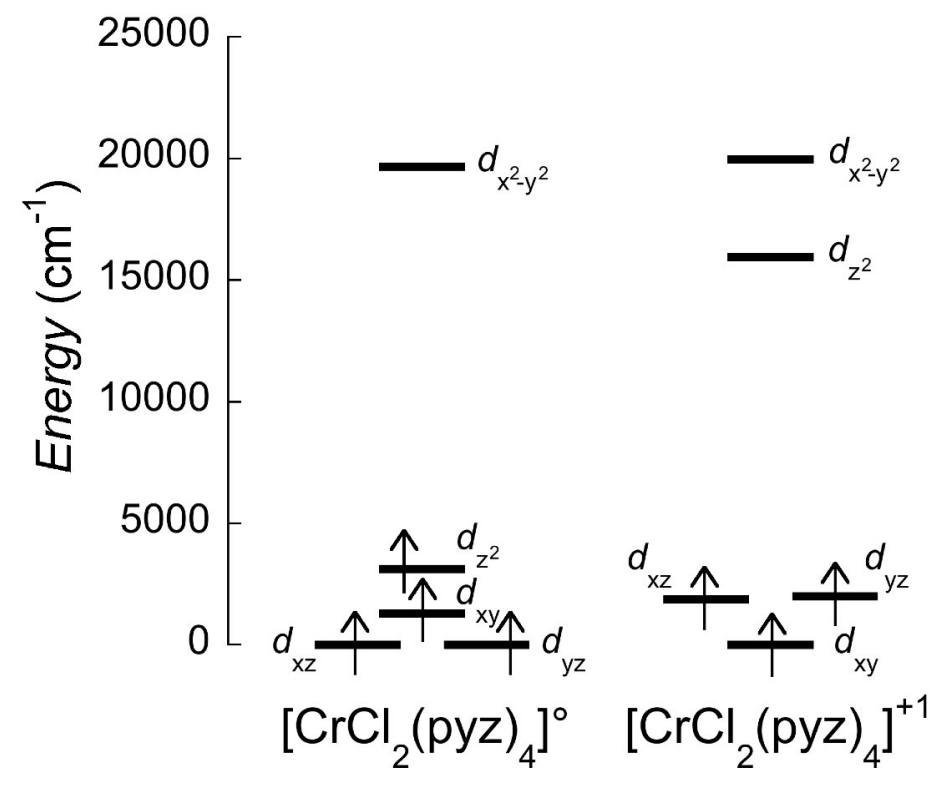

\section{Fig. S40.}

Ligand-field splitting of $\mathrm{Cr} 3 d$ orbitals computed using $a b$ initio ligand field theory based on CASSCF $(4,5) / N E V P T 2$ calculations of a neutral $\left[\mathrm{Cr}^{\mathrm{II}} \mathrm{Cl}_{2}(\mathrm{pyz})_{4}\right]^{\circ}$ fragment from structural model of 2.0.25(THF) (left) and a $\left[\mathrm{Cr}^{\mathrm{III}} \mathrm{Cl}_{2}\left(\mathrm{pyz}^{\circ}\right)_{4}\right]^{+}$fragment based on the X-ray structure of the $\mathrm{CrCl}_{2}$ (pyz) 2 precursor (right) (22). According to the calculations, the metal-ligand exchange interaction is strong and antiferromagnetic $J_{\mathrm{Cr}-\mathrm{R}} / h c=-412 \mathrm{~cm}^{-1}(-593 \mathrm{~K})$ in the $\left[\mathrm{Cr}^{\mathrm{II}} \mathrm{Cl}_{2}(\mathrm{pyz})_{4}\right]^{4-}$ fragment for $\mathbf{2 \cdot 0 . 2 5}$ (THF), but this value is considerably smaller than in the $\left[\mathrm{Cr}^{\mathrm{III}} \mathrm{Cl}_{2}(\mathrm{pyz})_{4}\right]^{\circ}$ fragment for $\mathrm{CrCl}_{2}$ (pyz) $)_{2}$ where the exchange interaction between $\mathrm{Cr}^{\mathrm{III}}$ and the radical spin was estimated to be $\sim-2000 \mathrm{~cm}^{-1}$ (22). The reason for that could be the additional contribution from singly occupied orbital ( $\mathrm{SOMO}) d_{z 2}$ of $\mathrm{Cr}^{\mathrm{II}}$ in $\mathbf{2}$, which is expected to be ferromagnetic due to its orthogonality with the SOMO of pyrazine radical. 


\section{References and notes}

1. O. Gutfleisch, M. A. Willard, E. Brück, C. H. Chen, S. G. Sankar, J. P. Liu, Magnetic materials and devices for the 21 st century: stronger, lighter, and more energy efficient. Adv. Mater. 23, 821-842 (2011).

2. J. S. Miller, Organic- and molecule-based magnets. Mater. Today 17, 224-235 (2014).

3. J. S. Miller, Magnetically ordered molecule-based materials. Chem. Soc. Rev., 40, 3266-3296 (2011).

4. O. Kahn, Molecular Magnetism, VCH, Weinheim (1993).

5. D. Gatteschi, R. Sessoli, J. Villain, Molecular Nanomagnets, Oxford University Press. (2006).

6. S. Demir, I.-R. Jeon, J. R. Long, T. D. Harris, Radical ligand-containing single-molecule magnets. Coord. Chem. Rev. 289-290, 149-176 (2015).

7. C. Coulon, V. Pianet, M. Urdampilleta, R. Clérac, Single-Chain Magnets and Related Systems. Molecular Nanomagnets and Related Phenomena. Structure and Bonding, vol 164, S. Gao Eds. (Springer, Berlin, Heidelberg, 2014), pp. 143-184.

8. A. E. Thorarinsdottir, T. David Harris, Metal-organic framework magnets. Chem. Rev., (2020) DOI: 10.1021/acs.chemrev.9b00666

9. J. M. D. Coey, Magnetism and Magnetic Materials, Cambridge University Press, Cambridge (2010).

10. N. Motokawa, H. Miyasaka, M. Yamashita, K. R. Dunbar, An electron-transfer ferromagnet with $T_{\mathrm{C}}=107 \mathrm{~K}$ based on a three-dimensional [ $\left.\mathrm{Ru}_{2}\right]_{2} / \mathrm{TCNQ}$ system. Angew. Chem. Int. Ed. 47, 7760-7763 (2008).

11. X. Ma, E. A. Suturina, S. De, P. Négrier, M. Rouzières, R. Clérac, P. Dechambenoit, A redoxactive bridging ligand to promote spin delocalization, high-spin complexes, and magnetic multi-switchability. Angew. Chem. Int. Ed. 57, 7841-7845 (2018).

12. J. S. Miller, S.-I. Ohkoshi, High- $T_{\mathrm{C}}$ Ordered Molecular Magnets. Molecular Magnetic Materials: Concepts and Applications, B. Sieklucka, D. Pinkowicz, Eds. (Wiley-VCH, 2017), chap. 7.

13. J. M. Manriquez, G. T. Yee, R. S. Mclean, A. J. Epstein, J. S. Miller, A room-temperature molecular/organic-based magnet. Science 252, 1415-1417 (1991).

14. S. Ferlay, T. Mallah, R. Ouahès, P. Veillet, M. Verdaguer, A room-temperature organometallic magnet based on Prussian blue, Nature 378, $701-703$ (1995).

15. J. Mahmood, J. Park, D. Shin, H.-J. Choi, J.-M. Seo, J.-W. Yoo, J.-B. Baek, Organic ferromagnetism: trapping spins in the glassy state of an organic network structure. Chem 4, 2357-2369 (2018).

16. H. Phan, T. S. Herng, D. Wang, X. Li, W. Zeng, J. Ding, K. P. Loh, A. T. S. Wee, J. Wu, Room-temperature magnets based on 1,3,5-triazine-linked porous organic radical frameworks. Chem 5, 1223-1234 (2019).

17. J. S. Miller, Oliver Kahn lecture: composition and structure of the V[TCNE $]_{x}$ $(\mathrm{TCNE}=$ tetracyanoethylene $)$ room-temperature, organic-based magnet - a personal perspective. Polyhedron 28, 1596-1605 (2009).

18. K. Taniguchi, J. Chen, Y. Sekine, H. Miyasaka, Magnetic phase switching in a tetraoxolenebridged honeycomb ferrimagnet using a lithium ion battery system. Chem. Mater. 29, 1005310059 (2017).

19. L. Liu, J. A. DeGayner, L. Sun, D. Z. Zee, T. D. Harris, Reversible redox switching of magnetic order and electrical conductivity in a 2D manganese benzoquinoid framework. Chem. Sci. 10, 4652-4661 (2019). 
20. J. A. DeGayner, I.-R. Jeon, L. Sun, M. Dincă, T. D. Harris, 2D conductive iron-quinoid magnets ordering up to $T=105 \mathrm{~K}$ via heterogenous redox chemistry. J. Am. Chem. Soc. 139, 4175-4184 (2017).

21. L. E. Darago, M. L. Aubrey, C. J. Yu, M. I. Gonzalez, J. R. Long, Electronic conductivity, ferrimagnetic ordering, and reductive insertion mediated by organic mixed-valence in a ferric semiquinoid metal-organic framework. J. Am. Chem. Soc. 137, 15703-15711 (2015).

22. K. S. Pedersen, P. Perlepe, M. L. Aubrey, D. N. Woodruff, S. E. Reyes-Lillo, A. Reinholdt, L. Voigt, Z. Li, K. Borup, M. Rouzières, D. Samohvalov, F. Wilhelm, A. Rogalev, J. B. Neaton, J. R. Long, R. Clérac, Formation of the layered conductive magnet $\mathrm{CrCl}_{2}$ (pyrazine) 2 through redox-active coordination chemistry. Nat. Chem. 10, 1056-1061 (2018).

23. P. Perlepe, I. Oyarzabal, K. S. Pedersen, P. Negrier, D. Mondieig, M. Rouzières, E. A. Hillard, F. Wilhelm, A. Rogalev, E. A. Suturina, C. Mathonière, R. Clérac, $\mathrm{Cr}(\text { pyrazine })_{2}\left(\mathrm{OSO}_{2} \mathrm{CH}_{3}\right)_{2}$ : a two-dimensional coordination polymer with an antiferromagnetic ground state. Polyhedron 153, 248-253 (2018).

24. See supplementary materials.

25. T. Trella, W. Frank, poster presented at the 17. Conference of the GDCh Division of Solid State Chemistry and Materials Research, Dresden, DE, 15-17 September 2014.

26. E. Fawcett, Spin-density-wave antiferromagnetism in chromium. Rev. Mod. Phys. 60, 209-283 (1988).

27. C. G. Shuli, M. K. Wilkinson, Neutron diffraction studies of various transition elements. Rev. Mod. Phys. 25, 100-107 (1953).

28. G. E. Bacon, N. Cowlam, Magnetic studies of annealed and alloyed chromium by neutron diffraction. J. Phys. C: Solid State Phys. 2, 238-251 (1969).

29. T. Furubayashi, I. Nakatani, Curie paramagnetism of chromium ultrafine particles. J. Appl. Phys. 73, 6412-6413 (1993).

30. W. Abdul-Razzaq, M. S. Seehra, Observation of oxidation and mechanical strain in $\mathrm{Cr}$ nanoparticles produced by ball-milling. Phys. Stat. Sol. 193, 94-102 (2002).

31. S. Foner, High-field antiferromagnetic resonance in $\mathrm{Cr}_{2} \mathrm{O}_{3}$. Phys. Rev. 130, 183-197 (1963).

32. J. M. D. Coey, M. Venkatesan, Half-metallic ferromagnetism: example of $\mathrm{CrO}_{2}$. J. Appl. Phys. 91, 8345-8350 (2002).

33. Y.-F. Deng, T. Han, Z. Wang, Z. Ouyang, B. Yin, Z. Zheng, J. Krzystek, Y.-Z-Zheng, Uniaxial magnetic anisotropy of square-planar chromium(II) complexes revealed by magnetic and HFEPR studies. Chem. Commun. 51, 17688-17691 (2015).

34. S. Cuello, J. Entwisle, J. Benning, C. Liu, S. Coburn, K. G. McAdam, J. Braybrook, H. Goenaga-Infante, Complementary HPLC-ICP-MS and synchrotron X-ray absorption spectroscopy for speciation analysis of chromium in tobacco samples. J. Anal. At. Spectrom. 31, 1818-1829 (2016).

35. S. DeBeer George, P. Brant, E. I. Solomon, Metal and ligand K-edge XAS of organotitanium complexes: metal $4 \mathrm{p}$ and $3 \mathrm{~d}$ contributions to pre-edge intensity and their contributions to bonding. J. Am. Chem. Soc. 127, 667-674 (2005).

36. A. B. Cairns, A. L. Goodwin, Structural disorder in molecular framework materials. Chem. Soc. Rev. 42, 4881-4893 (2013).

37. T. N. Ramesh, R. S. Jayashree, P. V. Kamath, Disorder in layered hydroxides: DIFFaX simulation of the X-ray powder diffraction patterns of nickel hydroxide. Clays Clay Miner. 51, 570-576 (2003). 
38. A. Zhukov, Novel Functional Magnetic Materials in Springer Series in Materials Science 231 Eds. (Springer, 2016), chap. 9.

39. F. Neese, Software update: the ORCA program system, version 4.0. WIREs Comp. Mol. Sci. 8, e1327 (2018).

40. F. Neese, The ORCA program system. WIREs Comp. Mol. Sci. 2, 73-78 (2012).

41. A. D. Becke, A new mixing of Hartree-Fock and local density-functional theories. $J$. Chem.Phys. 98, 1372-1377 (1993).

42. C. Lee, W. Yang, R. G. Parr, Development of the Colle-Salvetti correlation-energy formula into a functional of the electron density. Phys. Rev. B 37, 785-789 (1988).

43. S. H. Vosko, L. Wilk, M. Nusair, Accurate spin-dependent electron liquid correlation energies for local spin density calculations: a critical analysis. Can. J. Phys. 58, 1200-1211 (1980).

44. P. J. Stephens, F. J. Devlin, C. F. Chabalowski, M. J. Frisch, Ab Initio calculation of vibrational absorption and circular dichroism spectra using density functional force fields. J. Phys. Chem. 98, 11623-11627 (1994).

45. F. Weigend, R. Ahlrichs, Balanced basis sets of split valence, triple zeta valence and quadruple zeta valence quality for $\mathrm{H}$ to Rn: Design and assessment of accuracy. Phys. Chem. Chem. Phys. 7, 3297-3305 (2005).

46. M. J. Frisch, G. W. Trucks, H. B. Schlegel, G. E. Scuseria, M. A. Robb, J. R. Cheeseman, G. Scalmani, V. Barone, G. A. Petersson, H. Nakatsuji, M. C. X. Li, A. Marenich, J. Bloino, B. G. Janesko, R. Gomperts, B. Mennucci, H. P. Hratchian, J. V. Ortiz, A. F. Izmaylov, J. L. Sonnenberg, D. Williams-Young, F. Ding, F. Lipparini, F. Egidi, J. Goings, B. Peng, A. Petrone, T. Henderson, D. Ranasinghe, V. G. Zakrzewski, N. R. J. Gao, G. Zheng, W. Liang, M. Hada, M. Ehara, K. Toyota, R. Fukuda, J. Hasegawa, M. Ishida, T. Nakajima, Y. Honda, O. Kitao, H. Nakai, T. Vreven, K. Throssell, J. A. M. Jr., J. E. Peralta, F. Ogliaro, M. Bearpark, J. J. Heyd, E. Brothers, K. N. Kudin, V. N. Staroverov, T. Keith, R. Kobayashi, J. Normand, K. Raghavachari, A. Rendell, J. C. Burant, S. S. Iyengar, J. Tomasi, M. Cossi, J. M. Millam, M. Klene, C. Adamo, R. Cammi, J. W. Ochterski, R. L. Martin, K. Morokuma, O. Farkas, J. B. Foresman, D. J. Fox, Revision D.01 ed., Gaussian, Inc., Wallingford CT, 2016.

47. N. Lee, T. Petrenko, U. Bergmann, F. Neese, S. DeBeer, Probing valence orbital composition with iron $\mathrm{k}_{\beta} \mathrm{X}$-ray emission spectroscopy. J. Am. Chem. Soc. 132, 9715-9727 (2010).

48. A. D. Becke, Density-functional exchange-energy approximation with correct asymptotic behavior. Phys. Rev. A 38, 3098-3100 (1988).

49. J. P. Perdew, Density-functional approximation for the correlation energy of the inhomogeneous electron gas. Phys. Rev. B 33, 8822-8824 (1986).

50. D. A. Pantazis, X.-Y. Chen, C. R. Landis, F. Neese, All-electron scalar relativistic basis sets for third-row transition metal atoms. J. Chem. Theory Comput. 4, 908-919 (2008).

51. F. Neese, Efficient and accurate approximations to the molecular spin-orbit coupling operator and their use in molecular g-tensor calculations. J. Chem. Phy. 122, 034107 (2005).

52. B. de Souza, G. Farias, F. Neese, R. Izsák, Predicting phosphorescence rates of light organic molecules using time-dependent density functional theory and the path integral approach to dynamics. J. Chem. Theory Comput. 15, 1896-1904 (2019).

53. J. Rodríguez-Carvajal, Recent advances in magnetic structure determination by neutron powder diffraction. Phys. B: Condens. Matter 192, 55-69 (1993).

54. M.S. Modeling, Materials Studio, version 5.5, http://accelrys.com/products/collaborativescience/biovia-materials-studio. 
55. A. Rogalev, F. Wilhelm, Magnetic circular dichroism in the hard X-ray range. Phys. Met. Metallogr. 116, 1285-1336 (2015).

56. A. Rogalev, V. Gotte, J. Goulon, C. Gauthier, J. Chavanne, P. Elleaume, XAFS and X-MCD spectroscopies with undulator gap scan. J. Synchrotron Rad. 5, 989-991 (1998)

57. K. V. Klementiev, VIPER for Windows. Freeware: http:॥www.desy.de/ klmn/viper.html.

58. E. B. Wilson, The normal modes and frequencies of vibration of the regular plane hexagon model of the benzene molecule. Phys Rev. 45, 706-714 (1934).

59. K. V. Berezin, V. V. Nechaev, P. M. Él'kin, Anharmonic resonances in the vibrational spectra of pyrazine. J. Appl. Spectros. 72, 9-19 (2005).

60. J. F. Arenas, M. S. Woolley, I. L. Tocón, J. C. Otero, J. I. Marcos, Complete analysis of the surface-enhanced Raman scattering of pyrazine on the silver electrode on the basis of a resonant charge transfer mechanism involving three states. J. Chem. Phys. 112, 7669-7683 (2000).

61. B. Cadioli, E. Gallinella, C. Coulombeau, H. Jobic, G. Berthier, Geometric structure and vibrational spectrum of tetrahydrofuran. J. Phys. Chem. 97, 7844-7856 (1993).

62. H. F. Shurvell, M. C. Southby, Vib. Spectrosc. 15, 137-146 (1997).

63. J. Fidler, T. Schrefl, S. Hoefinger, M. Hajduga, Recent developments in hard magnetic bulk materials. J. Phys.: Condens. Matter 16, S455-S470 (2004). 